University of Louisville

ThinkIR: The University of Louisville's Institutional Repository

Electronic Theses and Dissertations

8-2018

\title{
Alpha-amino methylation and acetylation are novel regulators of MYL9 function.
}

Christopher David Nevitt

University of Louisville

Follow this and additional works at: https://ir.library.louisville.edu/etd

Part of the Amino Acids, Peptides, and Proteins Commons, Biochemical Phenomena, Metabolism, and Nutrition Commons, Biological Factors Commons, and the Medical Biochemistry Commons

\section{Recommended Citation}

Nevitt, Christopher David, "Alpha-amino methylation and acetylation are novel regulators of MYL9 function." (2018). Electronic Theses and Dissertations. Paper 3032.

https://doi.org/10.18297/etd/3032

This Doctoral Dissertation is brought to you for free and open access by ThinkIR: The University of Louisville's Institutional Repository. It has been accepted for inclusion in Electronic Theses and Dissertations by an authorized administrator of ThinkIR: The University of Louisville's Institutional Repository. This title appears here courtesy of the author, who has retained all other copyrights. For more information, please contact thinkir@louisville.edu. 


\title{
ALPHA-AMINO METHYLATION AND ACETYLATION ARE NOVEL REGULATORS OF MYL9 FUNCTION
}

\author{
By \\ Christopher David Nevitt \\ B.S., University of Louisville, 2013 \\ M.S., University of Louisville, 2016

\begin{abstract}
A Dissertation
Submitted to the Faculty of the

School of Medicine of the University of Louisville

in Partial Fulfillment of the Requirements

for the Degree of

Doctor of Philosophy

in Biochemistry and Molecular Genetics

Department of Biochemistry and Molecular Genetics

University of Louisville

Louisville, Kentucky
\end{abstract}

August 2018 


\section{Copyright 2018 by Christopher David Nevitt}

All rights reserved 



\title{
ALPHA-AMINO METHYLATION AND ACETYLATION ARE NOVEL REGULATORS OF MYL9 FUNCTION
}

\author{
By \\ Christopher David Nevitt \\ B.S., University of Louisville, 2013 \\ M.S., University of Louisville, 2016
}

A Dissertation Approved on

June 27, 2018

by the following Dissertation Committee:

Dissertation Director
Christine Schaner Tooley

Carolyn Klinge

Barbara Clark

Alan Cheng

Brian Ceresa 


\title{
DEDICATION
}

This dissertation is dedicated to my parents

\author{
Mr. David Nevitt \\ and \\ Mrs. Sharon Deibel
}

who always encourage me to follow my passion. 


\section{ACKNOWLEDGMENTS}

Profound thanks are owed to my mentor, Dr. Christine Schaner Tooley, who never turned down a discussion, academic or otherwise. Her insight and guidance have been invaluable throughout my graduate career, and I will continue to rely on it in the future. Thanks are also owed to Dr. Amanda LeBlanc, who carried out the unenviable task of showing me the ropes of biomedical research with aplomb. Finally, a special thank you to my friends, mentors, and peers over the years that have inspired me with their curiosity, creativity, and hard work. 


\section{ABSTRACT \\ ALPHA-AMINO METHYLATION AND ACETYLATION ARE NOVEL REGULATORS OF MYL9 FUNCTION

\author{
Christopher David Nevitt
}

June 27, 2018

Dysregulation of alpha-amino post-translational modifications (N $\alpha-\mathrm{PTMs})$ is found in multiple cancers and developmental disorders. However, the exact roles $\mathrm{N} \alpha-$ PTMs play in regulating protein function remain poorly understood. I sought to clarify the role of $\mathrm{N} \alpha$-methylation and $\mathrm{N} \alpha$-acetylation in the regulation of Myosin Regulatory Light Chain 9 (MYL9). MYL9 is a key cytoskeletal regulator and transcription factor and is the first protein confirmed to undergo both $\mathrm{N} \alpha$-methylation and $\mathrm{N} \alpha$-acetylation. Through this work I revealed novel regulatory features of MYL9, while also presenting a framework by which to understand the coordinated regulation of proteins by $\mathrm{N} \alpha$ methylation and $\mathrm{N} \alpha$-acetylation.

N $\alpha$-PTM selective mutants of MYL9 were generated by modifying the consensus sequence targeted by $\mathrm{N} \alpha$-methyltransferases and $\mathrm{N} \alpha$-acetyltransferases. These mutants were assayed alongside wildtype (WT) protein for effects on MYL9 stability and function in mammalian cell lines. Offering a counterpoint to the dogmatic perspective of $\mathrm{N} \alpha$ PTMs as modifiers of protein stability, loss of either $\mathrm{N} \alpha$-methylation or $\mathrm{N} \alpha$-acetylation did not 
alter MYL9 half-life. Instead, distinct functionality of $\mathrm{N} \alpha$-methylated and $\mathrm{N} \alpha$-acetylated MYL9 was observed.

MYL9 is known primarily as a regulator of cytoskeletal dynamics through its regulation of non-muscle myosin II (NMII) activity. A specialized nuclear role for MYL9 has been described in which it binds at select gene promoters and activates transcription. My results show that $\mathrm{N} \alpha$-methylation promotes this nuclear function of MYL9. The N $\alpha-$ methylation selective mutant of MYL9 increased TNF $\alpha$ stimulated transcription of intercellular adhesion molecule 1 (ICAM1) as compared to all other variants of MYL9. In addition, this MYL9 mutant showed increased binding at the ICAM1 promoter. N $\alpha$ methylation has been shown to increase protein-DNA interactions, implicating this mechanism in the regulation of MYL9 nuclear function. Phosphorylation of MYL9 at serine 19 (pS19) is required for NMII activity. Expression of a N $\alpha$-methylation deficient mutant of MYL9 increased the occurrence of pS19 after stimulation as compared to all other variants of MYL9. This mutant of MYL9 also displayed increased cell migration and cell spreading on fibronectin, measures of NMII activity. As such, I propose a model in which N $\alpha$-methylation of MYL9 favors nuclear activity while blocking cytoplasmic activity. 
TABLE OF CONTENTS

DEDICATION

PAGE

ACKNOWLEDGEMENTS

iii

iv

ABSTRACT

$\mathrm{v}$

LIST OF FIGURES

viii

LIST OF TABLES

ix

CHAPTER 1 - INTRODUCTON 1

Protein Acetylation and Methylation: The Histone Code as a Framework 2

Protein Acetylation and Methylation: Regulation of Non-Histone Proteins 7

Alpha-Amino Protein Acetylation and Methylation

PTMs of MYL9 Regulate Diverse and Essential Cellular Processes

CHAPTER 2 - ALPHA-AMINO POST-TRANSLATIONAL MODIFICATIONS

ARE NOVEL REGULATORS OF MYL9 FUNCTION

$\begin{array}{ll}\text { Introduction } & 40\end{array}$

Results 44

Discussion $\quad 52$

Experimental Procedures $\quad 59$

CHAPTER 3 - WORKING MODEL, SUPPLEMENTARY EXPERIMENTS, AND FUTURE DIRECTIONS

Working Model

83

Supplementary Experiments

Future Directions

REFERENCES 


\section{LIST OF FIGURES}

FIGURE

PAGE

1. NMII activity is regulated by phosphorylation of MYL9

2. Proposed model of MYL9 regulation by Na-PTMs 38

3. MYL9 mutants alter Na-PTM state

4. The half-life of MYL9 is not altered by Na-PTMs

5. Loss of MYL9 Na-methylation increases cell spreading on fibronectin

6. The SSQ mutant of MYL9 does not show increased N $\alpha$-acetylation

7. N $\alpha$-methylation limits the cytoskeletal activity of MYL9

8. N $\alpha$-methylation promotes the transcriptional activity of MYL9

9. Working model of MYL9 regulation by N $\alpha$-PTMs

10. Known methyl and acetyl reader domains do not bind Na-PTMs

99

11. SILAC screen of N $\alpha$-PTM effect on MYL9 protein-protein interactions

103 


\section{LIST OF TABLES}

TABLE

1. Impacts of acetylation and methylation on non-histone protein function

2. Substrate recognition by NatA and NRMTs

3. Impacts of $\mathrm{N} \alpha$-acetylation and $\mathrm{N} \alpha$-methylation on protein function
PAGE

30

32

34 


\section{CHAPTER I}

\section{INTRODUCTION}

The protein machinery of a cell is regulated by numerous mechanisms to generate a system capable of carrying out the many cellular activities required for life. One such mechanism is the alteration of protein biochemistry and function through posttranslational modifications (PTMs). Our knowledge of the types of PTMs that occur and the manners in which they regulate protein function continues to grow, reflecting a remarkably diverse and complex system. In this dissertation, I seek to expand our understanding of protein regulation by a novel class of PTMs that occur on the free protein alpha-amino group (Na-PTMs) rather than on amino acid sidechains.

Specifically, I report the first study of how $\mathrm{N} \alpha$-methylation and $\mathrm{N} \alpha$-acetylation regulate a shared substrate.

Myosin regulatory light chain 9 (MYL9) was recently identified to occur in both $\mathrm{N} \alpha$-methylated and $\mathrm{N} \alpha$-acetylated states (Petkowski, Schaner Tooley et al. 2012). More than 100 substrates are predicted to be modified in such a manner, with MYL9 being the first among them to be confirmed in vivo (Petkowski, Schaner Tooley et al. 2012). As the regulatory subunit of the non-muscle myosin II holoenzyme (NMII), MYL9 is involved in basic cellular processes that are essential across the spectrum of human cell types (Betapudi 2014). My research investigates the impact of $\mathrm{N} \alpha$-methylation and $\mathrm{N} \alpha-$ acetylation on MYL9 both in order to contribute to a more complete understanding of the regulation of this key protein, as well as to provide a model of how these N $\alpha$-PTMs can 
act to coordinately regulate protein function. In this chapter, I will discuss the current state of knowledge regarding protein methylation, acetylation, and $\mathrm{N} \alpha$-PTMs, before moving on to discuss the cellular functions and regulation of MYL9.

\section{$\underline{\text { Protein Acetylation and Methylation: The Histone Code as a Framework }}$}

Over the last two decades, knowledge regarding the regulatory roles played by protein acetylation and methylation have increased dramatically. Perhaps the most striking example of this is the deciphering of the histone code. The histone code hypothesis was first proposed in 2000 and posited that the pattern of PTMs on histone proteins serves as a code that regulates chromatin structure and influences DNAdependent processes (Strahl and Allis 2000).

The basic repeating unit of chromatin is the nucleosome, which consists of $147 \mathrm{bp}$ of DNA wrapped around a histone octamer (two H2A-H2B dimers and a tetramer formed by two H3 and two H4 proteins) (Kornberg and Lorch 1999). Nucleosomes are then packed into high order structures, eventually giving rise to chromosomes. This tight packing of DNA necessitates a mechanism to open the structure of chromatin, making it accessible to the machinery associated with DNA-templated processes, such as transcription and replication (Kornberg and Lorch 1999). Numerous studies have established that chromatin structure is intimately tied to the regulation of gene expression, with dense regions of heterochromatin being associated with gene silencing and open euchromatin regions being associated with active transcription (Lorch and Kornberg 2017). Post-translational modification of histones, particularly their N-terminal 
tails, which extend from the nucleosome core, represent a dynamic mechanism by which chromatin structure is regulated (Gardner, Allis et al. 2011).

Acetylation and methylation are major modifications of the histone code, which also includes phosphorylation, ubiquitination, and propionylation, among other PTMs (Rothbart and Strahl 2014). Enzymes that deposit these modifications have been termed writers, while those that remove histone PTMs have been termed erasers (Gardner, Allis et al. 2011). The effects of histone PTMs can be directly mediated by the biophysical properties of the modification itself or by proteins termed readers that contain domains that recognize and bind histone PTMs (Rothbart and Strahl 2014). The complexity of the histone code is greatly increased by extensive interplay between modifications (Zhang, Cooper et al. 2015). Based on biological context and the specific residues modified, histone acetylation and methylation can function in opposition or in concert with one another. The biophysical properties of these PTMs, as well as the properties of their writers, readers, and erasers contribute to this complex interplay.

Acetylation occurs on lysine residues and results in a neutral charge on the residue sidechain replacing the native positive charge. This charge alteration has been proposed to disturb electrostatic histone-histone and histone-DNA interactions, promoting the transcriptionally active euchromatin state (Wolffe and Hayes 1999). High levels of lysine acetylation on the tails of histones H3 and H4 (Myers, Evans et al. 2001), as well as lysine acetylation on the globular domain residues of histone H3 lysine 56 (H3acK56) (Yuan, Pu et al. 2009) and lysine 64 (H3acK64) (Di Cerbo, Mohn et al. 2014), favor decreased DNA association with the nucleosome and are observed in actively transcribed regions of chromatin. Additionally, histone $\mathrm{H} 3$ lysine 122 acetylation 
(H3acK122) favors transcriptional activity, likely through the promotion of histone eviction (Tropberger, Pott et al. 2013).

A direct biophysical impact of histone methylation on chromatin structure has not been described. Methylation occurs on both lysine and arginine residues but does not alter the positive charge of these residue's sidechains. Lysine residues can be mono, di, or tri methylated, while arginine residues can be mono or di methylated. In certain contexts, these states appear to be functionally distinct. In lower order eukaryotes, writers of methylation can catalyze each of these states (Wagner and Carpenter 2012). However, in mammals catalysis of histone trimethylation has evolved as a specialized function of the methyltransferase SETD2 (Kizer, Phatnani et al. 2005). Other mammalian histone methyltransferases, including the NDS 1/2/3 family and SMYD2, catalyze only mono/di methylation in vivo (Wagner and Carpenter 2012). Further evidence of distinct roles for mono/di/tri methylation is provided by examining the chromatin regions in which these modifications predominantly occur. Trimethylation of histone H3 lysine 9 (H3me3K9) is strongly associated with heterochromatin (Wang, An et al. 2003, Bilodeau, Kagey et al. 2009), while monomethylation (H3me1K9) can be found in euchromatin regions (Tachibana, Ueda et al. 2005, Collins, Northrop et al. 2008). Similarly, histone H3 lysine 36 trimethylation (H3me3K36) is found at actively transcribed genes (Carrozza, Li et al. 2005, Joshi and Struhl 2005), while the mono/di methylated form is more widely distributed (Kim, Kiefer et al. 2007, Schneider, Arteaga-Salas et al. 2011).

Much of what is known about the functional impact of histone methylation focuses on the roles of reader proteins. A large number of domains recognize and bind methylated lysine and arginine, including, chromo, PHD, Tudor, and PWWP domains 
(Taverna, Li et al. 2007, Vezzoli, Bonadies et al. 2010). In contrast, only bromo, and more recently Yeats, domains have been identified as readers of lysine acetylation (Vezzoli, Bonadies et al. 2010, Li, Wen et al. 2014). Additionally, some reader domains recognize and bind unmodified lysine and arginine residues (Lan, Collins et al. 2007), creating a system in which each state of a residue carries with it information that can be propagated toward a functional outcome by reader proteins. Writers and erasers of histone PTMs commonly contain reader domains, and this contributes to the establishment of positive and negative crosstalk between modifications (Zhang, Cooper et al. 2015). Other proteins that contain reader domains include ATP-dependent chromatin remodeling enzymes and members of the core transcriptional machinery (Vermeulen, Mulder et al. 2007, Swygert and Peterson 2014).

Often, multiple modifications work coordinately to recruit reader proteins. Due to its double bromodomains, the TFIID subunit TAF1 is preferentially recruited to diacetylated histones (Jacobson, Ladurner et al. 2000). TRIM24 contains both a PHD finger and a bromodomain, contributing to its binding the combination of unmodified H3K4 and H3acK23 (Tsai, Wang et al. 2010). Recruitment of TEFb and efficient transcriptional elongation are favored at nucleosomes that contain both histone $\mathrm{H} 3$ phosphorylated at serine $10(\mathrm{H} 3 \mathrm{phS} 10)$ and histone $\mathrm{H} 4$ acetylated at lysine 16 (H4acK16), through a process that involves multiple reader proteins (Zippo, Serafini et al. 2009). Neighboring modifications can also negatively regulate reader protein binding. For example, binding of heterochromatin protein 1 to mono/di methylated $\mathrm{H} 3 \mathrm{~K} 9$ is blocked by phosphorylation of H3K10 (Fischle, Tseng et al. 2005). 
Interplay between histone PTMs is abundant and appears to be an essential feature of chromatin regulation. Modification of H3K27 provides an interesting study of the interplay between protein acetylation and methylation. H3K27 is found mono, di, or tri methylated, as well as acetylated (Pauler, Sloane et al. 2009, Creyghton, Cheng et al. 2010, Ferrari, Scelfo et al. 2014). The trimethylated form is linked to transcriptional repression, and is thought to exert its functional effect by blocking binding of the HATs p300 and CBP, preventing an accumulation of acetylation at enhancers that is required for gene activation (Pauler, Sloane et al. 2009, Pasini, Malatesta et al. 2010). H3acK27 has an opposing effect, favoring the activation of enhancers and gene transcription (Creyghton, Cheng et al. 2010). The switching of chromatin from a repressed to an active state requires the removal of trimethylation and deposition of acetylation at H3K27. This transition is facilitated in part by phosphorylation of the neighboring residue H3S28 (Gehani, Agrawal-Singh et al. 2010). This phosphorylation blocks methylation of H3K27 by the Polycomb complex PRC2, allowing for acetylation to predominate (Gehani, Agrawal-Singh et al. 2010, Lau and Cheung 2011). The reverse switch, from an active to a repressed state, requires removal of the acetylation mark by the NURD complex and subsequent methylation by PRC2 (Reynolds, Salmon-Divon et al. 2012). During differentiation, the accumulation of $\mathrm{H} 3 \mathrm{me} 3 \mathrm{~K} 27$ and gene silencing is facilitated by CTBP2 functioning with NURD to remove H3K27 acetylation (Kim, Kang et al. 2015). Interestingly, monomethylaton of $\mathrm{H} 3 \mathrm{~K} 27$ is found at actively transcribed genes, suggesting an opposing effect for this modification as compared to H3me3K27 (Barski, Cuddapah et al. 2007, Creyghton, Cheng et al. 2010). Dimethylation of H3K27 is widely occurring, but its functional role remains unknown (Jung, Pasini et al. 2010). Further 
research will be required to create a more complete picture of how $\mathrm{H} 3 \mathrm{~K} 27$ methylation and acetylation combine to regulate chromatin structure and gene expression.

\section{$\underline{\text { Protein Acetylation and Methylation: Regulation of Non-Histone Proteins }}$}

Recent advances in proteomic technologies have led to the discovery that methylation and acetylation are also widely occurring on non-histone proteins. Similar to histones, methylation and acetylation on non-histone proteins is regulatory and dynamic (Choudhary, Weinert et al. 2014, Biggar and Li 2015). Often, the same writers and erasers of acetylation and methylation identified as part of the histone code machinery catalyze the modification of non-histone proteins. Proteomic analysis has revealed that the majority of identified methylation sites are actually found on non-histone substrates (Guo, Gu et al. 2014), and the majority of acetylated proteins are non-nuclear (Choudhary, Kumar et al. 2009). Additionally, proteomics has identified non-histone protein methylation and acetylation in species ranging from bacteria through mammals, highlighting the importance of these modifications in cellular biology (Krause, Yang et al. 2007, Zhang, Sprung et al. 2009). While mass spectrometry has been vital in determining the wide occurrence of protein acetylation and methylation, biochemical studies have begun to provide insights into the functions and mechanisms associated with these modifications. Methylation and acetylation have been observed to regulate protein function by altering stability, protein-protein and protein-DNA interactions, and through crosstalk with other PTMs (Choudhary, Weinert et al. 2014, Biggar and Li 2015).

Acetylation is frequently seen to block ubiquitination and thus increase the stability of proteins. Nearly one-third of acetylation sites are also targets of 
ubiquitination, highlighting the potential for competition between these modifications (Wagner, Beli et al. 2011). Following this model, the TGF $\beta$ regulator SMAD7 is stabilized by p300-dependent acetylation at K64 and K70, which blocks ubiquitination of these residues by SMURF1 and subsequent degradation (Gronroos, Hellman et al. 2002, Simonsson, Heldin et al. 2005). Similarly, MDM2 mediated degradation of $\mathrm{p} 53$ has been shown to require recruitment of the deacetylayse HDAC1 in order to remove multiple lysine acetylations that are directly blocking ubiquitination sites (Ito, Kawaguchi et al. 2002). Adding to the complex interplay of PTMs in p53 regulation, methylation of p53 at K372 was shown to promote acetylation and thus stabilization (Ivanov, Ivanova et al. 2007). An opposing interaction between methylation and acetylation in the regulation of stability is described for the transcription factor E2F1. Methylation of E2F1 at K185 inhibits protein acetylation, increases ubiquitination, and ultimately increases protein degradation (Kontaki and Talianidis 2010). Several additional instances of methylation decreasing protein stability have been published, including for DNMT1 and the NF- $\mathrm{kB}$ subunit p65 (Esteve, Chin et al. 2009, Yang, Huang et al. 2009). Based on these examples it appears that acetylation may be a conserved mechanism for promoting protein stability, while the impact of methylation is more likely to be protein and site specific.

Additionally, interplay between methylation and acetylation in the regulation of protein stability has been observed in multiple cases and may occur frequently.

Non-histone protein acetylation and methylation have been seen to differentially regulate molecular interactions. As is seen with histone proteins, acetylation appears to facilitate protein-protein interactions while disrupting protein-nucleic acid interactions. This effects has been described for the HIV protein Tat. In its non-acetylated state, Tat 
binds an HIV RNA stem-loop structure known as TAR (Reeder, Kwak et al. 2015). Acetylation of Tat at K50 reduces RNA binding and increases interaction with the protein PCAF (Dorr, Kiermer et al. 2002). PCAF contains a bromodomain that interacts with acetylated Tat (Mujtaba, He et al. 2002). While the interaction of readers containing bromodomains with acetylated residues has been described extensively for histone proteins, few examples exist for a bromodomain interaction with acetylated non-histone proteins. This corresponds with the finding that the majority of bromodomain containing proteins are nuclear (Filippakopoulos and Knapp 2012), while the majority of nonhistone protein acetylation occurs in the cytoplasm and in mitochondria (Choudhary, Kumar et al. 2009).

In opposition to acetylation, protein methylation appears to facilitate protein-DNA interactions. Arginine methylation of p53-binding protein 1 (53BP1) by PRMT1 is required for its binding to DNA and function in DNA damage repair (Boisvert, Rhie et al. 2005). The DNA damage checkpoint protein MRE11 is also methylated by PRMT1 and loss of this methylation impairs MRE11 function, leading to check point defects (Boisvert, Dery et al. 2005). While the direct mechanism by which methylation facilitates MRE11 function has yet to be shown, protein-DNA interaction is strongly implicated, as checkpoint protein complex formation was shown to not be altered by loss of methylation (Boisvert, Dery et al. 2005). DNA-binding of p65 and downstream gene transcription is favored by methylation at R30, extending the role of methylation in protein-DNA interactions to transcription factors (Wei, Wang et al. 2013).

Methylation is also involved in protein-protein interactions. Protein reader domains that were originally described in the context of histones are emerging as readers 
of non-histone protein methylation. 53BP1 contains dual Tudor domains that bind dimethylated K382 of p53 (Kachirskaia, Shi et al. 2008). The negative regulator of p53 L3MBTL1 can also recognize and bind p53 at methylated K382, but this interaction occurs through MBT domains rather than Tudor domains (West, Roy et al. 2010). Interestingly, K382 of p53 can also be acetylated, a modification that activates transcription through the recruitment of co-activators (Barlev, Liu et al. 2001). As such, methylation and acetylation are in direct competition for modification of this lysine of p53, with each promoting opposing functional outcomes through alteration of proteinprotein interactions.

Crosstalk between methylation and other PTMs, especially phosphorylation, is also common. The blocking of phosphorylation by methylation of a neighboring residue has been termed the 'methylation-phosphorylation switch' (Sabbattini, Sjoberg et al. 2014, Biggar and Li 2015). Such a switch occurs in the regulation of Rb, where methylation at K810 blocks phosphorylation of the neighboring residues S809 and S811 (Carr, Munro et al. 2011). By blocking phosphorylation, methylation functions to promote cell cycle arrest (Munro, Khaire et al. 2010). In addition to Rb, DNMT1 also undergoes a methylation-phosphorylation switch. Methylation of DNMT at K142 prevents phosphorylation at S143 (Esteve, Chang et al. 2011). Methylation has also been described to increase phosphorylation of target proteins in certain contexts. For example, autophosphorylation of the receptor tyrosine kinase (RTK) VEGFR2 at Y1052 requires methylation at the nearby residue K1041 (Hartsough, Meyer et al. 2013). Another RTK, EGF, shows a similar requirement for methylation to allow for autophosphorylation of a nearby residue (Hsu, Chen et al. 2011). Interactions between methylation and 
phosphorylation have been further described in the MAPK, Hippo, and JAK-STAT pathways (Biggar and Li 2015). These studies suggest that methylation may serve as a mechanism to fine tune protein regulation by phosphorylation in many settings. It will be important to evaluate the interaction between methylation and phosphorylation as additional proteins are biochemically evaluated, particularly when methylation and phosphorylation sites occur in close proximity.

FOXO1 provides a case in which acetylation and methylation regulate protein function in opposing manners through several of the mechanisms described above. FOXO1 is a transcription factor that regulates metabolism-related gene expression in response to insulin signaling (Accili and Arden 2004). Phosphorylation of FOXO1 at S253 by AKT leads to its retention in the cytoplasm, where it is preferentially ubiquitinated and degraded (Aoki, Jiang et al. 2004, Yamagata, Daitoku et al. 2008). Acetylation of FOXO1 increases S253 phosphorylation, favoring increased cytoplasmic retention and decreased stability (Matsuzaki, Daitoku et al. 2005). Further, FOXO1 acetylation at residues K242, K245, and K262 decrease FOXO1 binding to DNA and subsequent transcriptional activity (Matsuzaki, Daitoku et al. 2005, Jing, Gesta et al. 2007). Conversely, methylation of FOXO1 by PRMT1 at R248 and R250 block S253 phosphorylation, leading to increased FOXO1 stability and transcriptional activity (Yamagata, Daitoku et al. 2008).

Both acetylation and methylation are emerging as key regulators of protein function (Table 1). Abundant crosstalk has been described between acetylation, methylation, and other PTMs, highlighting the complex nature of protein regulation by these modifications. Acetylation and methylation appear to have predominantly opposing 
effects on protein stability and molecular interactions. However, there are instances in which acetylation and methylation show positive interplay. As such, future studies should carefully address how, in a substrate-specific manner, acetylation and methylation are coordinately regulated to drive protein function.

\section{$\underline{\text { Alpha-Amino Protein Acetylation and Methylation }}$}

Acetylation and methylation of both histone and non-histone proteins are abundant and play important regulatory roles. However, the discussion thus far has focused exclusively on methylation and acetylation of lysine and arginine side chains. It has long been known that proteins are also modified on the free alpha-amino group at their N-terminus (Brown and Roberts 1976, Pettigrew and Smith 1977, Stock, Clarke et al. 1987, Mullen, Kayne et al. 1989). Proteins are known to be acetylated, methylated, ubiquitinated, sumoylated, and modified in numerous other ways at this location (Tooley and Schaner Tooley 2014). Biochemical and functional studies of Na-PTMs have lagged considerably behind the study of traditional PTMs on residue sidechains. This is likely due to a combination of technical difficulties in studying Na-PTMs, as well as, a pervasive bias in the field that $\mathrm{N} \alpha$-PTMs are constitutive rather than regulatory in nature. Recent studies of $\mathrm{N} \alpha$-acetylation and $\mathrm{N} \alpha$-methylation, the most abundant $\mathrm{N} \alpha$-PTMs, have done a great deal to counteract this perception, and many important regulatory roles for these modifications are emerging. An overlap in the substrate pools for $\mathrm{N} \alpha$-acetylation and $\mathrm{N} \alpha$-methylation has also recently been discovered, raising the possibility that these modifications can confer distinct functional readouts to the same target proteins (Petkowski, Schaner Tooley et al. 2012). 
$\mathrm{N} \alpha$-acetylation is catalyzed by the $\mathrm{N}$-terminal acetyltransferase (NAT) family of enzymes, consisting of NatA through NatF in higher order eukaryotes (Starheim, Gevaert et al. 2012). The NATs catalyze the transfer of an acetyl moiety from acetyl-CoA to the amino terminus of substrate proteins. These enzymes are responsible for the modification of more than $80 \%$ of the human proteome, making $\mathrm{N} \alpha$-acetylation one of the most widely occurring human PTMs (Arnesen, Van Damme et al. 2009, Aksnes, Drazic et al. 2016). Most NAT family members predominantly localize to the cytoplasm, with only NatF associating with the Golgi apparatus (Aksnes, Van Damme et al. 2015, Aksnes, Drazic et al. 2016). Among the NAT family, NatA targets the largest number of substrates, acting on more than $30 \%$ of the human proteome (Aksnes, Drazic et al. 2016). NatA catalyzes the modification of proteins in which the initiator methionine has been cleaved, revealing an N-terminal serine, threonine, alanine, glycine, cysteine, or valine (Table 2) (Polevoda, Norbeck et al. 1999, Polevoda and Sherman 2003). A proline in the second position after the N-terminus blocks NatA activity (Polevoda, Norbeck et al. 1999). Two subunits compose NatA, NAA10 and NAA15 (Starheim, Gevaert et al. 2012). NAA10 is the catalytic subunit and shows activity when not associated to NAA15 (Van Damme, Evjenth et al. 2011). NAA15 associates with the ribosome and helps establish cotranslational modification of substrate proteins (Gautschi, Just et al. 2003). Posttranslational activity of NatA has also been reported (Helbig, Gauci et al. 2010, Helsens, Van Damme et al. 2011).

Underlying the importance of $\mathrm{N} \alpha$-acetylation by $\mathrm{NatA}$ to proper cell function, a mutation in NAA10 was recently shown to be causal in the lethal X-linked developmental disorder Ogden syndrome (Van Damme, Stove et al. 2014, Myklebust, 
Van Damme et al. 2015). Additionally, both over and under expression of NAA10 is seen in a variety of cancers, suggesting that precise regulation of $\mathrm{N} \alpha$-acetylation levels is important for regulated cell growth (Kalvik and Arnesen 2013).

N-terminal RCC1 methyltransferase 1 and 2 (NRMT1, NRMT2) are the only known eukaryotic N-terminal methyltransferases (Tooley, Petkowski et al. 2010, Petkowski, Bonsignore et al. 2013). These enzymes were identified in 2010 and 2013, respectively, allowing for the first real functional studies of $\mathrm{N}$-terminal methylation (Tooley, Petkowski et al. 2010, Petkowski, Bonsignore et al. 2013). Both NRMT1 and NRMT2 show nuclear localization, and to date, all characterized substrates of $\mathrm{N} \alpha-$ methylation have known nuclear roles (Tooley and Schaner Tooley 2014). Based on the experimental determination of the NRMT consensus sequence, greater than 300 substrates are predicted (Petkowski, Schaner Tooley et al. 2012). NRMT1 and NRMT2 predominantly methylate proteins in which the initiator methionine has been cleaved to reveal an N-terminal alanine, proline, serine, or glycine, but substrate specificity is also determined by the residues in the second and third positions from the N-terminus (Table 2) (Petkowski, Schaner Tooley et al. 2012).

NRMT1 is a distributive trimethylase, catalyzing the successive transfer of methyl groups from S-adenosyl methionine (SAM) to a substrate protein's amino terminus (Richardson, Mao et al. 2015). As such, NRMT1 can catalyze mono, di, or trimethylation of substrates but trimethylation predominates both in vitro and in vivo (Chen, Muratore et al. 2007, Tooley, Petkowski et al. 2010, Richardson, Mao et al. 2015). In contrast, NRMT2 catalyzes only monomethylation (Petkowski, Bonsignore et al. 2013). NRMT1 shows more widespread tissue distribution and higher expression than NRMT2, but 
NRMT2 expression activates NRMT1 activity (Petkowski, Bonsignore et al. 2013). It was originally proposed that NRMT2 primarily serves to relieve substrate burden and prime substrates for trimethylation by NRMT1, but it has recently been shown that NRMT2 catalytic activity is not necessary for NRMT1 activation, and it actually works by binding and stabilizing NRMT1 (unpublished data from Jon Faughn and Christine Schaner Tooley).

The biological importance of $\mathrm{N} \alpha$-methylation is highlighted by several lines of evidence. First, mice lacking NRMT1 are small in size, show signs of prematuring aging (including graying and kyphosis), exhibit female-specific infertility, and have a high rate of morbidity by 6 months of age (Bonsignore, Tooley et al. 2015). NRMT1 misregulation and mutation are observed in a variety of cancers (Sabates-Bellver, Van der Flier et al. 2007, Brune, Tiacci et al. 2008, Finak, Bertos et al. 2008), and NRMT1 knockdown (KD) increases the rate of tumor growth in a breast cancer xenograft model (Bonsignore, Butler et al. 2015).

While the importance of both $\mathrm{N} \alpha$-acetylation and $\mathrm{N} \alpha$-methylation is clear, studies of the biochemical and functional impact of these modification at the substrate level have only just begun. Early studies of Na-PTMs focused mainly on their impact on protein stability (Stock, Clarke et al. 1987). Na-methylation was described as a blocking group preventing access by aminopeptidases and leading to increased protein stability (Pettigrew and Smith 1977, Smith and Pettigrew 1980). This effect was demonstrated for cytochrome $\mathrm{c}$ and was hypothesized to extend to additional $\mathrm{N} \alpha$-methylated substrates (Smith and Pettigrew 1980, Stock, Clarke et al. 1987). Several instances of N $\alpha-$ acetylation decreasing protein stability have been observed, leading to the proposal of an 
Ac/N-end rule pathway. The Ac/N-end rule refers to the recognition of specific $\mathrm{N} \alpha-$ acetylated $\mathrm{N}$-terminal sequences, known as degrons, by E3 ubiquitin ligases and subsequent targeting of proteins for proteosomal degradation (Hwang, Shemorry et al. 2010). The rule was originally described in yeast, where $\mathrm{N} \alpha$-acetylated methionine, serine, threonine, alanine, valine, or cysteine residues are recognized by the E3 ubiquitin ligases Doa10 or Not4 (Hwang, Shemorry et al. 2010, Shemorry, Hwang et al. 2013). The Ac/ $\mathrm{N}$-end rule has been proposed to extend to mammals as $\mathrm{N} \alpha$-acetylation has been shown to lead to ubiquitination and degradation of human RGS2 (Park, Kim et al. 2015). The effect of N $\alpha$-PTMs on stability may very well be substrate specific, however. The stability of human protein THOC7 (Myklebust, Van Damme et al. 2015) and Drosophila protein Hyx (Goetze, Qeli et al. 2009) are increased by Na-acetylation. Given the current state of knowledge, substrate specific studies should be carried out to determine how $\mathrm{N} \alpha$ methylation and $\mathrm{N} \alpha$-acetylation impact stability. In particular, it will be interesting to see if regulation of stability proves to be a conserved role for $\mathrm{N} \alpha$-methylation as was initially proposed.

Emerging evidence shows a role for both $\mathrm{N} \alpha$-acetylation and $\mathrm{N} \alpha$-methylation in the regulation of molecular interactions. Indeed, the predominate function identified to date for $\mathrm{N} \alpha$-methylation has been the promotion of protein-DNA interactions. Trimethylation of regulator of chromosome condensation 1 (RCC1) was shown to be required for its proper localization to chromosomes during mitosis, and loss of trimethylation resulted in multipolar spindle formation and aneuploidy (Chen, Muratore et al. 2007, Tooley, Petkowski et al. 2010). Loss of RCC1 localization with DNA was observed in NRMT1 KD cells (Tooley, Petkowski et al. 2010), as well as with a non- 
methylatable K4Q mutant of RCC1 (Chen, Muratore et al. 2007). DNA damage binding protein 2 (DDB2) was also shown to require $\mathrm{N} \alpha$-trimethylation for its localization to sites of DNA damage (Cai, Fu et al. 2014). Loss of DDB2 Na-methylation resulted in increased sensitivity to UV light exposure and decreased repair of cyclobutane pyrimidine dimers (Cai, Fu et al. 2014). An effect of $\mathrm{N} \alpha$-acetylation on protein-DNA interactions has yet to be described, but based on the lysine and arginine acetylation data, we predict it will inhibit protein-nucleic acid interactions.

There is some evidence that $\mathrm{N} \alpha$-methylation may also be involved in proteinprotein interactions. Recently, proper recruitment of the constitutive centromere associated network was found to require Na-methylation of CENP-A (Sathyan, Fachinetti et al. 2017). Centromere nucleosomes containing non-methylated CENP-A showed reduced recruitment of CENP-T and CENP-I, leading to defects in chromosome segregation (Sathyan, Fachinetti et al. 2017). Although this work did not prove a direct role for $\mathrm{N} \alpha$-methylation in protein-protein interaction, it did show a requirement for $\mathrm{N} \alpha$ methylation for proper protein complex formation. Previously, $\mathrm{N} \alpha$-methylation was modeled to occur at sites of hydrophilic binding in protein complexes, but this has yet to be experimentally verified (Stock, Clarke et al. 1987). The involvement of $\mathrm{N} \alpha-$ methylation in protein-protein interactions will be an interesting area of continued research.

The involvement of $\mathrm{N} \alpha$-acetylation in protein-protein interactions has been established. Na-acetylation of the APC/C complex protein Hcn1 facilitates its binding to Cut9 (Zhang, Kulkarni et al. 2010). When the Na-acetyl group of Hen1 is not bound by Cut9 it instead acts as a docking site for the E3 ubiquitin ligase Doa10, promoting Hcn1 
degradation (Shemorry, Hwang et al. 2013). In a separate line of research, it was shown that the $\mathrm{N} \alpha$-acetyl methionine of the E2 enzyme Ubc12 is buried in a hydrophobic pocket of the E3 enzyme Dcn1 (Scott, Monda et al. 2011). This Na-acetyl dependent interaction was shown to facilitate ubiquitin complex activity, increasing the modification of Cul1 (Scott, Monda et al. 2011).

$\mathrm{N} \alpha$-methylation and $\mathrm{N} \alpha$-acetylation also impact the sub-cellular localization of certain substrates. As discussed previously, $\mathrm{N \alpha}$-methylation facilitates the proper localization of a number of proteins to DNA. Loss of N $\alpha$-methylation causes these proteins to show diffuse nuclear localization, rather than accumulation at sites of functionality (Chen, Muratore et al. 2007, Cai, Fu et al. 2014, Sathyan, Fachinetti et al. 2017). Na-acetylation has been shown to play a role in the sorting and targeting of proteins to organelles. Specifically, cytosolic proteins were found to be enriched in $\mathrm{Na}$ acetylation while ER-targeted proteins were found to be predominantly unmodified (Forte, Pool et al. 2011). In this study, the engineering of secretory proteins bound for the ER resulted in their mislocalization to the cytosol (Forte, Pool et al. 2011). N $\alpha$ acetylation has also been reported to increase the localization of $\alpha$-Synuclein to the plasma membrane (Dikiy and Eliezer 2014). This was shown to occur through the N $\alpha$ acetylation dependent stabilization of an $\mathrm{N}$-terminal $\alpha$-helix that facilitates the proteinmembrane interaction of $\alpha$-Synuclein (Dikiy and Eliezer 2014).

As discussed previously, lysine and arginine methylation and acetylation have been shown to participate extensively in PTM crosstalk. It seems likely that the same will hold true for $\mathrm{N \alpha}$-PTMs, but there are still only a small number of observations in this regard. One example of crosstalk between an Na-PTM and an internal PTM has been 
described for histone $\mathrm{H} 4$. In yeast, loss of histone $\mathrm{H} 4 \mathrm{~N} \alpha$-acetylation leads to an increase in dimethylation of H4R3 and an associated increase in ribosomal DNA silencing (Schiza, Molina-Serrano et al. 2013). Follow-up in vitro studies showed that $\mathrm{N} \alpha-$ acetylation of histone $\mathrm{H} 4$ led to decreased H4R3 methylation by PRMT3, but did not affect methylation by PRMT1, PRMT5, or PRMT8 (Fulton, Zhang et al. 2017). This suggests that in some settings, Na-PTMs may influence the occurrence of internal PTMs by modulating the activity of specific modifying enzymes. As additional substrates of $\mathrm{N} \alpha$-acetylation and $\mathrm{N} \alpha$-methylation are studied at the biochemical level, it is likely that additional instances of PTM crosstalk will be observed.

Early studies showed that $\mathrm{N} \alpha$-acetylation and $\mathrm{N} \alpha$-methylation both occur on proteins with an $\mathrm{N}$-terminal alanine or serine, but until recently no common substrates had been identified and these modifications were considered mutually exclusive. This misconception arose from the observation that all identified $\mathrm{N} \alpha$-methylated proteins shared the N-terminal sequence X-P-K, where $\mathrm{X}$ was alanine, serine, or proline (Stock, Clarke et al. 1987). Based on this observation, the still unidentified methyltransferase was considered to require a proline in the $2^{\text {nd }}$ position and a lysine in the $3^{\text {rd }}$ position. Indeed, this hypothetical methyltransferase was even referred to as the PK methyltransferase. A proline in the second position of substrates is known to block NAT catalytic activity, leading to the belief that $\mathrm{N} \alpha$-acetylation and $\mathrm{N} \alpha$-methylation were mutually exclusive (Polevoda, Norbeck et al. 1999, Polevoda and Sherman 2003).

The identification of NRMT1 and NRMT2 as the eukaryotic methyltransferases allowed for comprehensive studies of $\mathrm{N}$-terminal sequence recognition to be performed. In vitro methylation assays and in vivo immunoprecipitation experiments demonstrated 
that NRMT could bind and modify an expanded consensus sequence in which the second amino acid was not restricted to proline, but instead could accommodate most nonpolar or uncharged polar amino acids (Petkowski, Schaner Tooley et al. 2012). Among the newly identified NRMT consensus sequences was SSK, a sequence also permissive for Na-acetylation by NatA (Polevoda and Sherman 2003, Petkowski, Schaner Tooley et al. 2012). The SSK N-terminal sequence containing protein myosin regulatory light chain 9 (MYL9) was then immunoprecitated and identified by mass spectrometry in both $\mathrm{N} \alpha-$ methylated and $\mathrm{N} \alpha$-acetylated forms, making it the first known protein subject to both of these modifications (Petkowski, Schaner Tooley et al. 2012). Additional consensus sequences that allow for overlap of NRMT and NatA substrates include SNK and SQK (Polevoda and Sherman 2003, Petkowski, Schaner Tooley et al. 2012). NRMT can act on some substrates that retain the initiator methionine, resulting in potential overlap with NatB substrates that have the consensus sequences MNK and MNR (Polevoda and Sherman 2003, Petkowski, Schaner Tooley et al. 2012). This results in a set of greater than 100 proteins that are potential targets of both $\mathrm{N} \alpha$-methylation and $\mathrm{N} \alpha$-acetylation. The ability of MYL9 to be both N $\alpha$-methylated and N $\alpha$-acetylated has been verified but the functional relevance of these modifications remains to be determined.

In summary, methylation and acetylation are important regulators of protein function. These modifications regulate diverse functions, whether they occur on lysine and arginine sidechains, or on the alpha-amino terminus of proteins (Table 3). While the number of identified methylated and acetylated proteins has quickly increased due to advances in proteomic technologies, biochemical and functional characterization lags behind. Evidence from both histone and non-histone proteins points toward acetylation of 
residue sidechains decreasing protein-nucleic acid interactions by disrupting electrostatic interactions, while serving as a potential site for protein-protein interactions. $\mathrm{N} \alpha-$ acetylation has been shown to be directly involved in protein-protein interactions, but its effect on protein-nucleic interactions has yet to be described. In opposition to this, $\mathrm{N} \alpha$ methylation has been shown to increase protein-nucleic acid interactions, but as of yet is only implicated in influencing protein-protein interactions. Methylated residue sidechains of both histone and non-histone proteins participate in protein-protein interactions, suggesting a similar role for $\mathrm{N} \alpha$-methylation may still emerge as biochemical studies continue.

Interplay between PTMs is emerging as a conserved mechanism of protein regulation. The idea that complex, combinatorial deposition of PTMs determines end protein function was first described in the histone code hypothesis (Strahl and Allis 2000). This combinatorial deposition includes PTMs on neighboring residues, as well as, different PTMs on the same residue. The authors of this hypothesis also suggested that multifactorial regulation of proteins by PTMs may extend beyond histones. Mounting evidence favors this perspective and shows that internal PTMs on non-histone proteins also act in concert to coordinately regulate protein function. We now aim to show that $\mathrm{N} \alpha$-PTMs can also serve as part of a protein regulatory code, with differing N $\alpha$-PTMs promoting distinct functional readouts for shared substrates. As MYL9 is the first proven substrate for both $\mathrm{N} \alpha$-methylation and $\mathrm{N} \alpha$-acetylation, we will begin our studies there.

\section{$\underline{\text { PTMs of MYL9 Regulate Diverse and Essential Cellular Processes }}$}


Myosin regulatory light chain 9 (MYL9) is a ubiquitously expressed protein whose function is absolutely crucial to nearly every cell type in the human body (Betapudi 2014, Heissler and Sellers 2014). As a regulatory light chain of the non-muscle myosin II (NMII) holoenzyme, MYL9 function is a determinant of cytoskeletal dynamics and signal mechanotransduction (Vicente-Manzanares, Ma et al. 2009, Humphrey, Dufresne et al. 2014). In addition, a nuclear role for MYL9 as a transcriptional activator of select genes, including intercellular adhesion molecule 1 (ICAM1) and xanthine oxidase (XDH), has recently emerged (Li and Sarna 2009, Zhang, Liu et al. 2015). As will be discussed further below, MYL9 impacts diverse cellular processes ranging from migration to stem cell differentiation. Numerous disease states are associated with dysregulation of MYL9, including developmental disorders and cancers (Newell-Litwa, Horwitz et al. 2015). In this section, I will discuss the cellular function of MYL9 as a regulator of NMII, before moving on to examine its emerging role in the nucleus. Finally, I will discuss open questions regarding MYL9 function and how N $\alpha$-PTMs may be involved in the regulation of this key protein.

The best described role of MYL9 is as the regulatory subunit of NMII. NMII is found in nearly every cell in the human body, where it functions as a force-generating ATPase that contributes to actin cytoskeleton dynamics (Vicente-Manzanares, Hodges et al. 2009, Betapudi 2014). Precise regulation of NMII activity contributes to essential cellular processes that are shared by many cell types. NMII activity must be coordinated to achieve directional cellular migration, requiring both extension of laemellopodia at the leading edge and retraction of the plasma membrane at the trailing edge (VicenteManzanares, Zareno et al. 2007, Vicente-Manzanares, Koach et al. 2008). Establishment 
of planar cell polarity (PCP) involves regulation of NMII downstream of the noncanonical WNT PCP pathway (Phillips, Murdoch et al. 2005, Lee, Andreeva et al. 2012). NMII provides the force necessary for cytokinesis and requires proper regulation in order to achieve correct division and maintain genome integrity (Wu, Sahasrabudhe et al. 2010, Yang, Wei et al. 2012). Cell-cell adhesions also involve NMII as adherens junctions require actin rearrangement for the formation of interdigitating filipodia at these junctions (Hoelzle and Svitkina 2012). Additionally, NMII is a key player in mechanotransduction, the conversion of mechanical forces to biochemical signals. Mechanical strain on the cytoskeleton leads to nuclear translocation of YAP, a transcription factor that coordinates stem cell differentiation, and as such is regulated by NMII activity (Dupont, Morsut et al. 2011). MYL9 is the target of regulatory pathways determining NMII function in each of these processes. As such, MYL9 and NMII are intimately involved in diverse cellular events such as embryogenesis, body patterning, auditory sensing, retinal function, angiogenesis, synapse formation, tumorigenesis, and cancer metastasis (Betapudi 2014, Newell-Litwa, Horwitz et al. 2015).

The NMII holoenzyme includes six subunits: two heavy chains (MHCs), two regulatory light chains (RLCs), and two essential light chains (ELCs) (Figure 1). Lower eukaryotes have a single NMII isoform, while three isoforms (NMIIA, NMIIB, and NMIIC) are found in mammals (Richards and Cavalier-Smith 2005). Isoforms of NMII are defined by their myosin heavy chain incorporation and show tissue specific expression (Kawamoto and Adelstein 1991). Three MHC paralogs, MYH9, MYH10, and MYH14, are incorporated into NMIIA, NMIIB, and NMIIC, respectively (Simons, Wang et al. 1991, Golomb, Ma et al. 2004). Isoforms of NMII show overlapping ELC and RLC 
expression, and MYL9 can be incorporated into each form of NMII found in humans (Park, Han et al. 2011).

The central structure of NMII is a homodimer of two $230 \mathrm{kDa}$ MHCs. The heavy chains contain three functional domains: a globular head, a flexible neck region, and a coiled-coil $\alpha$-helical tail region. The head domain binds both actin and ATP, and undergoes a conformational change upon hydrolysis of ATP that is responsible for the conversion of chemical energy to mechanical work. The flexible neck region contains two amphiphilic, $\alpha$-helical IQ domains. The first IQ domain is bound by a $17 \mathrm{kDa}$ myosin ELC, which plays a structural role in supporting NMII function. The second IQ domain is bound by the $20 \mathrm{kDa}$ RLC, MYL9, which regulates NMII activity. The flexible neck region is also responsible for amplification of the mechanical change induced by ATP hydrolysis within the head group (Uyeda, Abramson et al. 1996). The coiled-coil tail region is responsible for $\mathrm{MHC}$ homodimerization, resulting in a double headed myosin enzyme. Higher-order oligomerization of NMII enzymes also occurs within their coiledcoil tail domains, leading to myosin filament formation. Anti-parallel association of NMII enzymes in filaments allows for the transmission of contractile forces to the actin cytoskeleton. The $\alpha$-helical coiled coil tail terminates in a short, non-helical C-terminal region that is the primary site of divergence among the MHC paralogs. Some evidence suggests that this non-helical portion of the tail helps determine localization within the cell.

Regulation of NMII activity primarily occurs through post-translational modification of the N-terminal tail of MYL9. Phosphorylation of MYL9 at serine 19 (S19) alone or in combination with threonine 18 (T18) results in activation of NMII 
(Heissler and Sellers 2014). These activating PTMs of MYL9 result in increased myosin filament formation, increased ATPase activity of the head group, and subsequent increases in actin filament binding (Ikebe, Koretz et al. 1988, Trybus 1989). The activation of NMII by phosphorylation of MYL9 is characterized by a transition from an inactive 10S state to an active 6S state (Cross, Jackson et al. 1988). In the 10S state, the non-helical C-terminal region of the MHC tail associates with the neck region, preventing myosin filament formation (Trybus, Huiatt et al. 1982). Phosphorylation at S19 or S19/T18 of MYL9 facilitates transition to the 6S state by causing dissociation of the MHC tail from the neck region, allowing the coiled-coil tail region to form a rod like structure and oligomerize with other NMII proteins to form myosin filaments (Cross, Jackson et al. 1988, Trybus 1991).

The activation of NMII is tightly regulated by multiple upstream kinases that target MYL9. These include kinases downstream of small Rho GTPases (RhoA, Rac, and $\mathrm{Cdc} 42$ ) as well as $\mathrm{Ca}^{2+} /$ calmodulin responsive kinases (MLCK and ZIPK) (Somlyo and Somlyo 2003). Rho associated kinase (ROCK) functions downstream of RhoA and is considered a master regulator of NMII (Newell-Litwa, Horwitz et al. 2015). In addition to phosphorylating MYL9 at S19/T18 (Amano, Ito et al. 1996, Chrzanowska-Wodnicka and Burridge 1996), ROCK also phosphorylates and inactivates the primary negative regulator of NMII activity, myosin light chain phosphatse (MLCP) (Kimura, Ito et al. 1996, Katoh, Kano et al. 2001). While all of the above named kinases target S19/T18 of MYL9, their tissue specific expression and subcellular distribution can lead to distinct phenotypes upon activation. ROCK activation in fibroblasts leads to abundant formation of actomyosin filament bundles known as stress fibers throughout the cytoplasm 
(Totsukawa, Yamakita et al. 2000). In contrast, $\mathrm{Ca}^{2+} /$ calmodulin activation of myosin light chain kinase (MLCK) in fibroblasts leads to actomyosin bundle formation at the periphery of the plasma membrane (Totsukawa, Yamakita et al. 2000). MYL9 can also be phosphorylated on the N-terminal tail at serines 1 and 2 (S1 and S2), and threonine 9 (T9) by protein kinase C (PKC) (Nishikawa, Sellers et al. 1984, Varlamova, Spektor et al. 2001). In vitro studies show that phosphorylation at these residues decrease MLCK affinity for NMII and thus oppose activation (Nishikawa, Sellers et al. 1984). However, studies in cells found no substantial effect on the regulation of NMII activity for these phosphorylation sites (Beach, Licate et al. 2011). As such, the relevance of S1, S2, and T9 phosphorylation remains an open question regarding MYL9 and NMII function.

NMII is predominantly localized to the cytoplasm, but MYL9 and NMII have both been found in the nucleus of multiple cell types (Li and Sarna 2009, de Lanerolle 2012, Zhang, Liu et al. 2015). A unique role for nuclear MYL9 in transcriptional activation is beginning to emerge that involves direct binding to DNA within the core promoter region of target genes. In colonic smooth muscle cells, nuclear MYL9 was found to mediate inflammation through transcription of ICAMI (Li and Sarna 2009). Increased transcription of ICAMI required binding of MYL9 to an AGCTCC sequence 39 base pairs upstream of the transcription start site. MYL9 was immunoprecipitated with MHC as well as transcription factor IIB (TFIIB) and RNA polymerase II (RNAPII), suggesting that interaction of the NMII complex with preinitiation complex (PIC) machinery may be involved in transcriptional activation. Similarly, in cardiomyocytes, nuclear MYL9 was found to contribute to ischemia/reperfusion injury through the activation of $X D H$ transcription (Zhang, Liu et al. 2015). In this case MYL9 bound the 
promoter sequence GTCGCC, a similar sequence as was bound at the ICAMI gene. Additionally, MYL9 interacted with MHC and PIC members in the cardiomyocytes nucleus. In a related finding, the cardiac-specific RLC MYL2 activated NADPH oxidase $2(N O X 2)$ gene transcription through binding to an AGCTCC sequence and associating with the PIC machinery (Zhang, Liu et al. 2015).

The above examples describe a novel nuclear role for MYL9, but many questions remain regarding the mechanism by which transcriptional activation is achieved. It has been suggested that NMII may provide mechanical force to generate the sliding motion of RNAPII with respect to the DNA ( $\mathrm{Li}$ and Sarna 2009). This hypothesis requires the interaction of NMII with filamentous actin in order to generate mechanical force, which has yet to be seen (de Lanerolle 2012). In fact, the majority of actin in the nucleus is monomeric and not filamentous (de Lanerolle and Serebryannyy 2011). Non-muscle myosin I (NMI) has also been described in the nucleus where it interacts with both RNA polymerase I (RNAPI) and RNAPII. NMI has been shown to require interaction with polymeric actin for transcriptional activation of ribosomal DNA when associated with RNAPI, suggesting a requirement for motor activity (Ye, Zhao et al. 2008). Interestingly, NMI does not appear to require actin in order to activate transcription in complex with RNAPII (Hofmann, Vargas et al. 2006). The ability of NMI to promote RNAPIIdependent transcription without interacting with actin led to the suggestion that NMI functions through protein complex stabilization and that ATPase activity is not required for this function (de Lanerolle 2012). Further complicating the issue, dephosphorylation of MYL9 was found to favor transcription of ICAM1 while phosphorylation of MYL9 favored transcription of XDH (Li and Sarna 2009, Zhang, Liu et al. 2015). Clearly, 
further research is required to delineate the mechanism by which MYL9 and NMII exert transcriptional regulation.

Several pressing questions remain regarding MYL9 function. Chief among these is how the cytoplasmic versus nuclear role of MYL9 is regulated. No mechanism has been described governing the cytoplasmic versus nuclear localization or activity of MYL9 and NMII. NMII function is predominantly regulated by PTMs of the N-terminal tail of MYL9, making this an important region to be further evaluated when addressing these questions. MYL9 is known to exist in distinct $\mathrm{N} \alpha$-methylated and $\mathrm{N} \alpha$-acetylated forms, but the regulatory role of these modifications remains unknown. Given the cytoplasmic localization of NATs and the nuclear localization of NRMTs, these modifications may be important to delineate the cytoplasmic versus nuclear roles of MYL9 and NMII. Additionally, studies of histone acetylation show that this modification plays a role in blocking protein-DNA interactions. Conversely, $\mathrm{N} \alpha$-methylation of multiple proteins has been shown to facilitate protein-DNA interactions.

Chapter II describes my original research to address the open question of how $\mathrm{N} \alpha$ PTMs regulate MYL9. I hypothesized that Na-acetylation of MYL9 promotes its cytoplasmic roles and/or blocks its nuclear roles, while $\mathrm{N} \alpha$-methylation promotes its nuclear roles (Figure 2). Based on observations of protein acetylation and methylation highlighted in this chapter, I further hypothesized that Na-PTMs regulate these functions by altering MYL9 stability, molecular interactions, and internal PTMs. I addressed these hypotheses through three aims. In Aim 1, I investigated the impact of Na-PTMs on MYL9 stability. Aim 2 investigated the impact of Na-PTMs on MYL9 cytoskeletal 
function in the cytoplasm, and Aim 3 investigated their impact on the nuclear function of MYL9 as a transcription factor.

This research reveals novel regulatory features of MYL9, a protein whose function is intimately tied to the maintenance of health and progression of disease in numerous cell and tissue types. Simultaneously, this work provides a model for understanding how $\mathrm{N} \alpha$-methylation and $\mathrm{N} \alpha$-acetylation act coordinately to regulate protein function. 


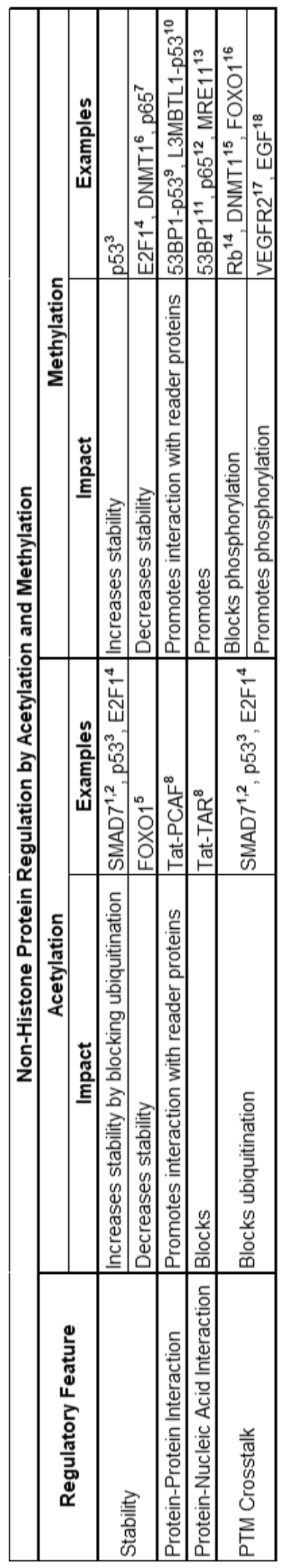


Table 1 Summary of known impacts of acetylation and methylation on non-histone protein function. Acetylation of lysine sidechains and methylation of lysine or arginine sidechains is a conserved, prevalent, and dynamic protein regulatory event. Biochemical studies have begun to discern the functional impacts of these PTMs on non-histone proteins. Here, the impacts of these modifications on non-histone protein stability, molecular interactions, and other PTMs are summarized. Acetylation frequently occurs at sites that are also targets of ubiquitination and has been observed to increase protein stability by blocking ubiquitin-mediated proteasomal degradation. In the case of the HIV Tat protein, acetylation blocks a protein-nucleic acid interaction and favors a proteinprotein interaction, reflecting mechanisms seen with histone acetylation. Methylation predominantly promotes protein stability, facilitates both protein-protein and proteinnucleic acid interactions, and shows complex regulatory crosstalk with sites of phosphorylation. 1=(Gronroos, Hellman et al. 2002), 2=(Simonsson, Heldin et al. 2005), 3=(Ito, Kawaguchi et al. 2002), 4=(Kontaki and Talianidis 2010), 5=(Matsuzaki, Daitoku et al. 2005), 6=(Esteve, Chin et al. 2009), $7=($ Yang, Huang et al. 2009), 8=(Dorr, Kiermer et al. 2002), $9=($ Kachirskaia, Shi et al. 2008), 10=(West, Roy et al. 2010), $11=($ Boisvert, Rhie et al. 2005), 12=(Wei, Wang et al. 2013), 13=(Boisvert, Dery et al. 2005), $14=($ Carr, Munro et al. 2011), 15=(Esteve, Chang et al. 2011), 16=(Yamagata, Daitoku et al. 2008), 17=(Hartsough, Meyer et al. 2013), 18=(Hsu, Chen et al. 2011). 
Substrate Consensus Sequence Restrictions by Amino Acid Position

\begin{tabular}{|l|c|c|c|c|}
\hline \multicolumn{5}{|c|}{ Substrate Consensus Sequence Restrictions by Amino Acid Position } \\
\hline \multicolumn{1}{|c|}{ Enzyme } & iMet & $\mathbf{1}$ & $\mathbf{2}$ & $\mathbf{3}$ \\
\hline NatA & Cleaved & Ser, Thr, Ala, Gly, Cys, Val & Blocked by Pro & Unrestricted \\
\hline NRMT1 and NRMT2 & Cleaved or Un-Cleaved & Ser, Ala, Pro, Gly, Met & Pro, Ala, Ser, Gly, Met, Glu, Asn, Gln & Lys, Arg \\
\hline
\end{tabular}


Table 2 Substrate recognition by NatA and NRMTs is determined by the N-terminal amino acid sequence of target proteins. NatA catalyzes $\mathrm{N} \alpha$-acetylation of over $30 \%$ of the human proteome. It broadly recognizes and modifies proteins with a cleaved initiator methionine (iMet), but its activity is blocked by a Proline in the second position. NRMT1 and NRMT2 share substrate recognition characteristics. The NRMTs act predominantly on proteins in which the iMet has been cleaved, but can also target some proteins in which the iMet is retained. Historically, the NRMTs were thought to require a Proline in the second position of substrate proteins. Further studies revealed that most non-polar or polar uncharged amino acids in the second position are permissive for NRMT activity. Evaluation of consensus sequence requirements revealed a subset of more than 100 proteins that can undergo modification by both NatA and the NRMTs. 


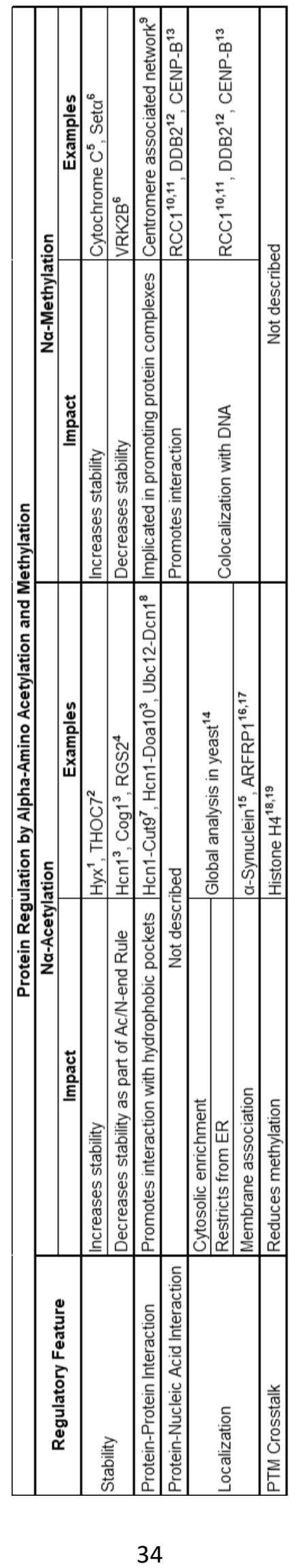




\section{$\underline{\text { Table } 3}$ Summary of known impacts of $\mathrm{N} \alpha$-acetylation and $\mathrm{N} \alpha$-methylation on}

protein function. Over the past decade, biochemical studies have begun to reveal the regulatory impacts of $\mathrm{N} \alpha$-PTMs on protein function. While the role of $\mathrm{N} \alpha$-PTMs appears to be largely substrate specific, some trends are beginning to appear. Na-acetylation can promote protein degradation through the Ac/N-end rule pathway, facilitate proteinprotein interactions, and promote cytosolic localization or association with membranes. In contrast, $\mathrm{N} \alpha$-methylation favors protein stabilization and facilitates protein-nucleic acid interactions. 1=(Goetze, Qeli et al. 2009), 2=(Myklebust, Stove et al. 2015), $3=($ Shemorry, Hwang et al. 2013), 4=(Park, Kim et al. 2015), $5=($ Smith and Pettigrew 1980), 6=(unpublished data, Schaner Tooley lab), 7=(Zhang, Kulkarni et al. 2010), $8=($ Scott, Monda et al. 2011), $9=($ Sathyan, Fachinetti et al. 2017), $10=($ Chen, Muratore et al. 2007), 11=(Tooley, Petkowski et al. 2010), 12=(Cai, Fu et al. 2014), 13=(Dai, Otake et al. 2013), 14=(Forte, Pool et al. 2011), 15=(Dikiy and Eliezer 2014), 16=(Behnia, Panic et al. 2004), 17=(Setty, Strochlic et al. 2004), 18=(Schiza, Molina-Serrano et al. 2013), 19=(Fulton, Zhang et al. 2017). 


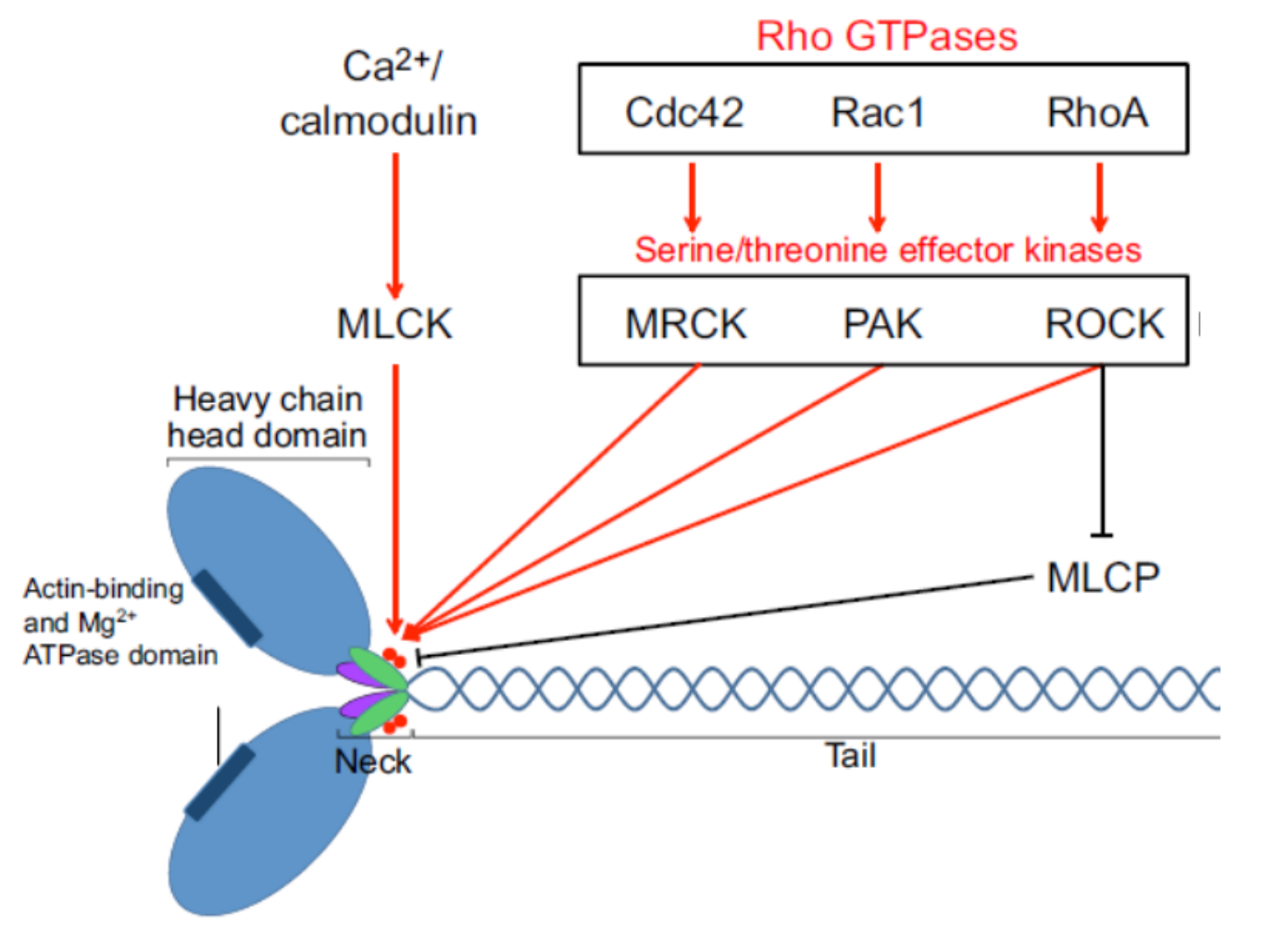

\begin{tabular}{|l} 
Key ELC \\
RLC
\end{tabular}


Figure 1 NMII activity is regulated by phosphorylation of MYL9. The non-muscle myosin II (NMII) holoenzyme is composed of two myosin heavy chains (MHCs), two essential light chains (ELCs), and two regulatory light chains (RLCs). The MHCs are composed of a head group with actin-binding and ATPase domains, a flexible neck region which is bound by the light chains, and a coiled-coil tail domain that is the site of homodimerization between MHCs. The head group undergoes a conformational change upon ATP hydrolysis, converting chemical energy into mechanical work. In addition to facilitating homodimerization, the tail domain also supports anti-parallel filament formation between NMII enzymes, allowing for the transfer of contractile forces to the actin cytoskeleton. The ELCs help maintain the structure of the NMII holoenzyme. MYL9 is a RLC and is the primary regulatory region for NMII. Phosphorylation of MYL9 at S19 or S19/T18 increases the activity of NMII by increasing the ATPase activity of the MHC head group and by promoting myosin filament formation. A number of upstream kinases act on these residues, including serine/threonine kinases downstream of Rho GTPases, as well as the $\mathrm{Ca}^{2+}$-responsive kinase myosin light chain kinase (MLCK). NMII activation is attenuated by the action of myosin light chain phosphatase (MLCP), which removes phosphorylation at S19 and T18. This figure is reproduced from (Newell-Litwa, Horwitz et al. 2015) under a creative commons license. 


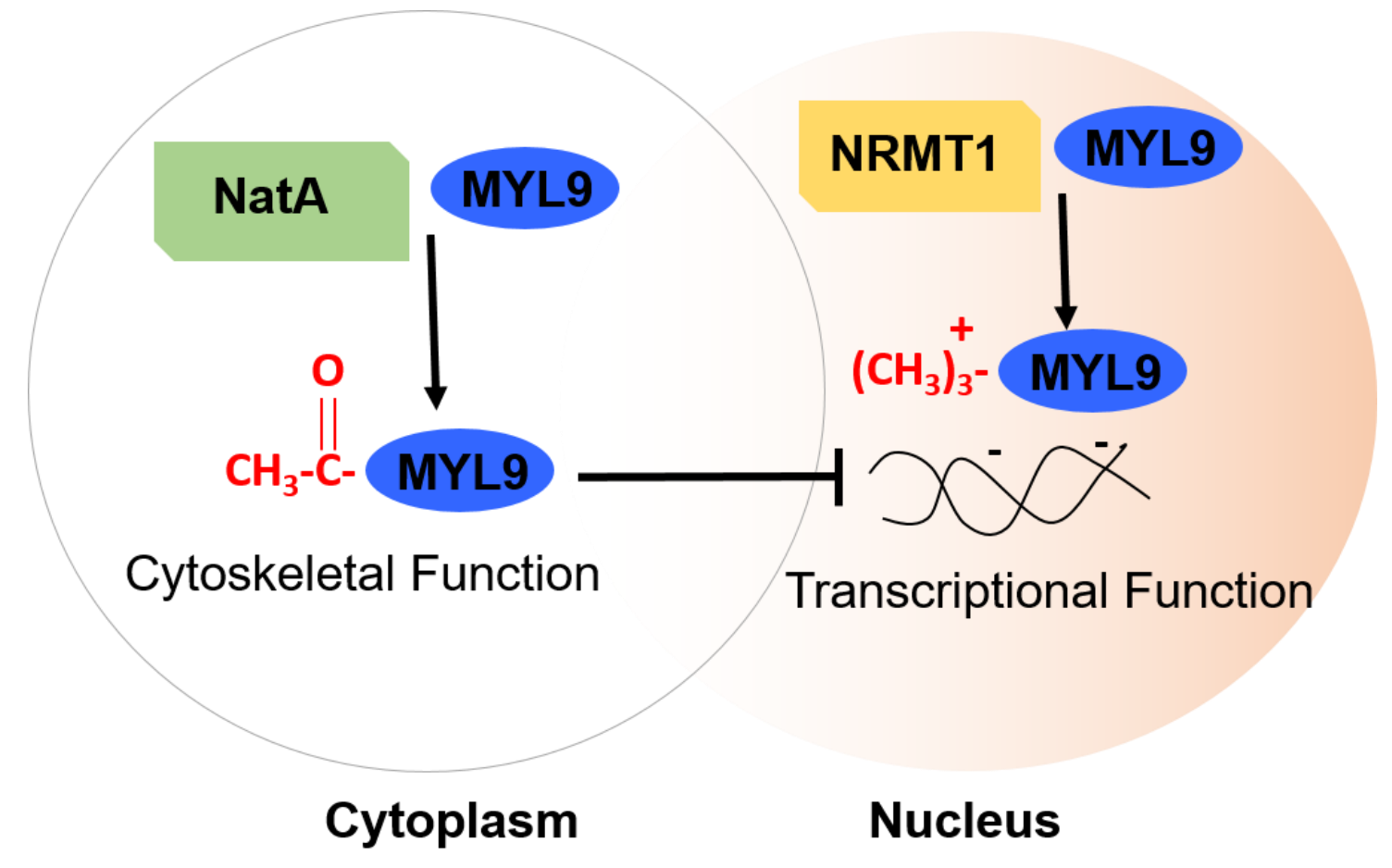




\section{Figure 2 Proposed model of the impact of $\mathrm{N \alpha}$-acetylation and $\mathrm{N \alpha}$-methylation on}

MYL9. MYL9 has been found in both $\mathrm{N} \alpha$-acetylated and $\mathrm{N} \alpha$-methylated states, but the role of these modifications in MYL9 regulation is unknown. Given the cytoplasmic and nuclear localization of NATs and NRMTs, respectively, I propose a role for these PTMs in establishing pools of MYL9 specialized for compartmental specific functions. N $\alpha-$ acetylated MYL9 participates in cytoskeletal regulation in the cytoplasm and N $\alpha$ methylated MYL9 acts as a transcriptional activator through direct DNA binding in the

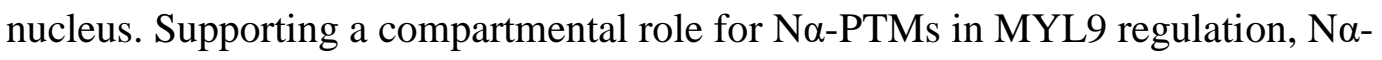
methylation has been shown to facilitate protein-DNA interactions, while acetylation has been shown to disrupt protein-DNA interactions. 


\section{CHAPTER II}

\section{ALPHA-AMINO POST-TRANSLATIONAL MODIFICATIONS ARE NOVEL REGULATORS OF MYL9 FUNCTION}

\section{Introduction}

Post-translational modifications (PTMs) are a primary means by which cells regulate the biochemistry and function of their protein machinery. PTMs play roles in virtually every known cellular process, and our knowledge of them is essential to understanding development, homeostasis, and disease (Edwards, Schwammle et al. 2014, Santos and Lindner 2017, Simithy, Sidoli et al. 2018). Alpha-amino PTMs (Na-PTMs), occurring on the free protein alpha-amino group rather than on residue sidechains, are a widely occurring class of modification whose role in protein regulation remains poorly understood (Brown and Roberts 1976, Stock, Clarke et al. 1987, Tooley and Schaner Tooley 2014). The most prevalent N $\alpha$-PTMs, acetylation and methylation, were originally considered to occur on mutually exclusive substrates based on consensus sequence restrictions (Stock, Clarke et al. 1987, Polevoda and Sherman 2003, Chen, Muratore et al. 2007). Updated consensus sequences and the identification of both $\mathrm{N} \alpha-$ acetyl and Na-methyl proteoforms of myosin regulatory light chain 9 (MYL9) led to the recognition that more than 100 proteins are prospective substrates for such dual modification (Petkowski, Schaner Tooley et al. 2012). Here, we investigate for the first 
time $\mathrm{N} \alpha$-acetylation and $\mathrm{N} \alpha$-methylation as PTMs that provide distinct and opposing regulation on the function of a common substrate, MYL9, and provide a groundwork towards a general understanding of how these $\mathrm{N} \alpha-\mathrm{PTMs}$ work coordinately to govern protein function.

MYL9 is a regulatory subunit of the force-generating ATPase non-muscle myosin II (NMII) (Conti and Adelstein 2008). NMII is ubiquitously expressed across cell types, where it associates with actin filaments to govern cytoskeletal dynamics (Conti and Adelstein 2008, Vicente-Manzanares, Ma et al. 2009). As such, MYL9 and NMII are intimately involved in basic cellular processes such as the establishment of cell shape, cell polarity, adhesion, migration, and signal mechanotransduction (Vicente-Manzanares, Ma et al. 2009, Newell-Litwa, Horwitz et al. 2015). The activity of NMII is largely regulated by post-translational modifications of MYL9 (Adelstein and Conti 1975, Vicente-Manzanares, Ma et al. 2009, Newell-Litwa, Badoual et al. 2015). Multiple kinases associated with the Rho family of GTPases and the $\mathrm{Ca}^{2+}$ responsive myosin light chain kinase (MLCK) phosphorylate MYL9 at threonine 18 and serine 19 (Amano, Ito et al. 1996, Vicente-Manzanares, Ma et al. 2009, Yuen, Ogut et al. 2009, Newell-Litwa, Badoual et al. 2015). Phosphorylation at these residues increase the association of NMII with actin filaments as well as the ATPase activity of the myosin head group (Adelstein and Conti 1975, Amano, Ito et al. 1996, Conti and Adelstein 2008).

MYL9 has also been found to play a unique role in the nucleus, associating with the promoter of intercellular adhesion molecule 1 (ICAM1) and acting as a transcriptional activator (Li and Sarna 2009). Studies in human colonic smooth muscle cells identified the binding site for MYL9 at the ICAM1 promoter as AGCTCC (-39/-34) and further 
showed an interaction with RNAPII and TFIIB, members of the core transcriptional machinery (Li and Sarna 2009). MYL9 also activates transcription of xanthine oxidase in cardiomyocytes through promoter binding and association with preinitiation complex members (Zhang, Liu et al. 2015). How the distinct nuclear and cytoplasmic roles of MYL9 are regulated is not yet understood, and to date there have been no investigations into what role the Na-PTMs of MYL9 play.

$\mathrm{N} \alpha$-acetylation is catalyzed by the cytoplasmic $\mathrm{N}$-terminal acetyltransferase (NAT) family of enzymes and is thought to occur on up to $80 \%$ of the human proteome (Brown and Roberts 1976, Aksnes, Drazic et al. 2016). NatA is the family member with the widest substrate specificity, and its substrate recognition sequence makes MYL9 a prospective target (Polevoda and Sherman 2003). Diverse, substrate-specific impacts of $\mathrm{N} \alpha$-acetylation on protein biochemistry and function have been described. It has been shown to promote protein degradation by acting as a docking site for E3 ubiquitin ligases, to be directly involved in protein-protein interactions by facilitating binding in hydrophobic pockets, to assist with proper protein folding and prevention of aggregation, as well as, to increase protein localization to the plasma membrane (Arnesen, Starheim et al. 2010, Hwang, Shemorry et al. 2010, Monda, Scott et al. 2013, Dikiy and Eliezer 2014, Aksnes, Drazic et al. 2016).

$\mathrm{N \alpha}$-methylation is catalyzed by the $\mathrm{N}$-terminal RCC1 methyltransferases 1 and 2 (NRMT1 and NRMT2), the only known eukaryotic alpha-amino methyltransferases (Tooley, Petkowski et al. 2010, Petkowski, Bonsignore et al. 2013). These enzymes are found in the nucleus and have over 300 predicted substrate proteins (Tooley, Petkowski et al. 2010, Petkowski, Schaner Tooley et al. 2012, Petkowski, Bonsignore et al. 2013). 
While NRMT2 catalyzes monomethylation, NRMT1 is a distributive methyltransferase that catalyzes the addition of up to three methyl groups to a protein $\mathrm{N}$-terminus, resulting in trimethylation (Tooley, Petkowski et al. 2010, Petkowski, Bonsignore et al. 2013). NRMT1 shows more widespread and higher expression across cell types than NRMT2, and trimethylation is the predominant form of $\mathrm{N} \alpha$-methylation found in cells (Tooley, Petkowski et al. 2010, Petkowski, Bonsignore et al. 2013). Until recently, N $\alpha$ methylation was thought to be a general promoter of protein stability, as it was originally identified as a modification that protected cytochrome $\mathrm{c}$ from degradation (Pettigrew and Smith 1977, Smith and Pettigrew 1980). We and others have now shown that it also facilitates the protein-DNA interaction of substrates such as RCC1, CENP-A, CENP-B, and DDB2, and thus, plays an important role in the maintenance of genome integrity (Chen, Muratore et al. 2007, Dai, Otake et al. 2013, Cai, Fu et al. 2014, Bonsignore, Butler et al. 2015, Bonsignore, Tooley et al. 2015, Sathyan, Fachinetti et al. 2017). While several transcription factors are substrates of NRMT1, it has not yet been experimentally demonstrated that $\mathrm{N} \alpha$-methylation plays a role in transcriptional regulation (Tooley, Petkowski et al. 2010, Petkowski, Schaner Tooley et al. 2012).

While we have previously shown that MYL9 in cells can be found in both the N $\alpha$ acetylated and N $\alpha$-methylated forms (Petkowski, Schaner Tooley et al. 2012), we now confirm that MYL9 is a direct substrate of both NatA and NRMT1. We then utilize the consensus sequence requirements of these enzymes to generate mutants of MYL9 that select for either $\mathrm{N} \alpha$-methylation or $\mathrm{N} \alpha$-acetylation. This allows us to describe for the first time the impact of these modifications on MYL9 stability and function. We use a photoswitchable fluorescent tag to demonstrate that despite the prevailing dogma in the 
field, $\mathrm{N} \alpha$-acetylation and $\mathrm{N} \alpha$-methylation do not alter the half-life of MYL9. Rather, we find evidence that these Na-PTMs help to specialize MYL9 for its distinct roles in the cytoplasm and nucleus. Importantly, we reveal $\mathrm{N} \alpha$-methylation as a novel regulator of MYL9 that compromises its cytoskeletal function while enhancing its activity as a transcriptional activator.

\section{Results}

$\mathrm{N}$-terminal consensus sequence mutants of MYL9 select for $\mathrm{N \alpha -methylation} \mathrm{or} \mathrm{N \alpha}$ acetylation

MYL9 has previously been immmunoprecipitated from cells or tissue in both $\mathrm{N} \alpha$ methyl and $\mathrm{N} \alpha$-acetyl modification states (Petkowski, Schaner Tooley et al. 2012). The N-terminal methionine of MYL9 is cleaved, revealing an SSK amino acid sequence that fits within the consensus recognition sequence for both NRMT1 and NatA (Figure 3A) (Polevoda and Sherman 2003, Petkowski, Schaner Tooley et al. 2012). To confirm the Na-PTMs of MYL9 are catalyzed by these enzymes, in vitro enzymatic assays were performed with rhNRMT1 and rhNAA10, the catalytic subunit of NatA. A peptide substrate corresponding to amino acids 2-15 of MYL9 was used at varying concentrations to generate a Km determination for each enzyme. Both NRMT1 and NAA10 were found to catalyze the modification of MYL9. NRMT1 showed moderate activity with a Km of $28.8 \mu \mathrm{M}$ (Figure 3B), while NAA10 showed high activity with a Km of $0.7 \mu \mathrm{M}$ (Figure $3 C)$.

To test if we could select for either N $\alpha$-methylation or N $\alpha$-acetylation of MYL9, we designed N-terminal mutants of MYL9 based on the consensus sequence 
requirements for NRMT1 and NatA. The N-terminal amino acid sequence SPK is known to be a favorable substrate for NRMT1, while a proline in the second position of proteins is well described as blocking NatA activity (Polevoda and Sherman 2003, Tooley, Petkowski et al. 2010, Petkowski, Schaner Tooley et al. 2012). Similarly, NRMT1 activity is reported to be restricted by a glutamine in the third position, while this amino acid is permissive for NatA activity (Polevoda and Sherman 2003, Chen, Muratore et al. 2007, Petkowski, Schaner Tooley et al. 2012). Based on this information, we utilized 14 amino acid peptides of MYL9 containing an S3P (SPK MYL9) or K4Q (SSQ MYL9) mutation in the in vitro enzymatic assays to see if they could select for the activity of either NRMT1 or NatA (Figure 3A).

Matching the published consensus sequence requirements, NRMT1 showed increased affinity for SPK MYL9 with a Km of $0.7 \mu \mathrm{M}$ (Figure 3D), while NAA10 showed no activity with SPK MYL9 out to $40 \mu \mathrm{M}$ of substrate (Figure 3E). SSQ MYL9 showed opposing results, with NRMT1 having no activity on this substrate out to $160 \mu \mathrm{M}$ of substrate (Fig 3F), and NAA10 maintaining activity with a Km of $5.0 \mu \mathrm{M}$ (Figure 3G). Taken together, these results demonstrate that the $\mathrm{N}$-terminal consensus sequence of MYL9 is permissive for modification by both NRMT1 and NatA, and that SPK and SSQ mutants of MYL9 select for either N $\alpha$-methylation or N $\alpha$-acetylation, respectively.

\section{Na-PTMs do not alter the half-life of MYL9}

A major focus of the N $\alpha$-PTM field has been on how these modifications impact the stability of proteins. Early studies suggested that $\mathrm{N \alpha}$-methylation protects proteins from degradation, as this modification was shown to increase the stability of cytochrome 
c and block degradation by aminopeptidases (Pettigrew and Smith 1977, Smith and Pettigrew 1980). N $\alpha$-acetylation is known to decrease the stability of some proteins by acting as a docking site for $\mathrm{E} 3$ ubiquitin ligases, and thus promoting proteolytic degradation (Hwang, Shemorry et al. 2010, Shemorry, Hwang et al. 2013). However, accumulating evidence suggests that these effects on stability are substrate specific, rather than intrinsic properties of $\mathrm{N} \alpha$-acetylation and $\mathrm{N} \alpha$-methylation (Tooley and Schaner Tooley 2014, Aksnes, Drazic et al. 2016).

To see if N $\alpha$-PTMs regulate the stability of MYL9, the photoswitchable fluorescent protein Dendra2 was C-terminally tagged to full-length WT, SPK, and SSQ MYL9. Dendra2 in its basal state fluoresces in the GFP channel, but after photoconversion fluoresces in the RFP channel (Gurskaya, Verkhusha et al. 2006, Adam, Nienhaus et al. 2009). This allows for tracking of half-life by following the rate of red fluorescence decay after photoconversion, and alleviates the need to treat with cytotoxic agents such as cycloheximide (Zhang, Gurskaya et al. 2007). When Dendra2 was expressed alone and photoconverted, the sum red fluorescence intensity was found to be stable over a 48 hour period (Figure 4A,B). When WT and mutant MYL9 was tagged with Dendra2, decay in red fluorescence related to the degradation of MYL9 was observable within 24 hours of photoconversion for all variants (Figure 4C).

The half-life of WT MYL9 was determined to be 16.4 hours (95\% confidence interval, $15.49-17.52$ hours) by fitting fluorescence decay data gathered over 48 hours to a model of one-phase exponential decay. To determine if alterations in $\mathrm{N} \alpha$-modification state could be statistically linked to changes in the rate of MYL9 decay, SPK and SSQ MYL9 fluorescence data were each fit to an individual model of decay as well as a model 
shared with WT MYL9. These models were compared for best fit, and in each case it was found that a model of decay shared with WT MYL9 was adequate to describe the decay of SPK and SSQ MYL9 (Fig 4D,E). This demonstrates that regulation of MYL9 stability is not a role for $\mathrm{N} \alpha$-methylation or $\mathrm{N} \alpha$-acetylation, and helps overturn the perception that the primary role of these modifications is as modifiers of protein half-life.

\section{Na-methylation deficient MYL9 promotes cell spreading on fibronectin}

We next turned our attention to how Na-PTMs regulate the function of MYL9 in the cytoplasm and nucleus. The primary role of MYL9 in the cytoplasm is regulation of actin cytoskeletal dynamics through modulation of NMII activity (Conti and Adelstein 2008, Vicente-Manzanares, Ma et al. 2009). We analyzed cell spreading of NIH3T3 mouse fibroblasts on fibronectin, as fibroblast adhesion to fibronecton is a well-studied process requiring active cytoskeletal rearrangement (Potter, Tirnauer et al. 1998, Zhong, Chrzanowska-Wodnicka et al. 1998, Huveneers, Truong et al. 2008). We hypothesized that $\mathrm{N} \alpha$-acetylation would facilitate the cytoplasmic role of MYL9 as a cytoskeletal regulator. As such, we expected the Na-acetylation deficient SPK mutant of MYL9 to show impaired cell spreading.

Control NIH3T3 cells or cells transduced with WT, SPK, or SSQ MYL9-FLAG were plated on $3 \mu \mathrm{g} / \mathrm{ml}$ fibronectin-coated chamber slides and imaged every 15 minutes for 1 hour. Cells were placed on ice prior to plating to promote a uniform distribution of rounded, single cells (Figure 5A, first column). Surprisingly, SPK MYL9 transduced cells showed levels of cell spreading that were comparable to control or WT MYL9 transduced cells (Figure 5A,B). We unexpectedly found that cells expressing the Na- 
methylation deficient SSQ MYL9 mutant showed significantly greater cell spreading over 1 hour (Figure 5B). Only SSQ MYL9 expressing cells had readily observable lamellipodia and filopodia that stretched over the fibronectin-coated surface by 1 hour (Figure 5A, black arrows). In order to ensure that expression level differences were not driving our results, we confirmed equal expression of WT, SPK, and SSQ MYL9-FLAG by Western blotting (Figure 5C). The SSQ MYL9 mutant is not recognized by NRMT1, but is targeted by NatA at levels comparable to WT (Figure 3C,G), suggesting that a decrease in N $\alpha$-methylation of MYL9 is responsible for the increase in cell spreading. As such, it appears that N $\alpha$-methylation restricts the participation of MYL9 in cytoskeletal rearrangement.

To address the possibility that loss of $\mathrm{N} \alpha$-methylation leads to an increase in $\mathrm{N} \alpha$ acetylation in vivo, we compared levels of N $\alpha$-acetylation for WT and SSQ MYL9-FLAG in NIH3T3 cells. WT or SSQ MYL9-FLAG was immunoprecipitated from cell lysates using anti-FLAG beads. Western blotting for total and Na-acetyl MYL9 was then performed using a FLAG antibody and a newly generated N $\alpha$-acetyl MYL9 antibody (Ubf1), respectively. As expected, levels of Na-acetylation did not increase for SSQ as compared to WT MYL9 (Figure 6A). This confirms that the functional impacts associated with SSQ MYL9 are a result of loss of Na-methylation rather than alteration of $\mathrm{N} \alpha$-acetylation. The Ubf1 antibody was raised against a synthetic $\mathrm{N} \alpha$-acetylated MYL9 peptide. This antibody was tested against unmodified, $\mathrm{N} \alpha$-acetylated, $\mathrm{N} \alpha$ methylated, and Na-trimethylated MYL9 peptides. Ubf1 only showed binding to the Naacetylated MYL9 peptide, confirming the specificity of this antibody (Figure 6B). 


\section{Na-methylation reduces the cytoskeletal activity of MYL9}

We next sought to confirm the impact of $\mathrm{N} \alpha$-methylation on the cytoskeletal activity of MYL9 in HCT116 human colon carcinoma cells. These cells have a migratory phenotype, and the nuclear role of MYL9 in ICAM1 transcription has been reported in colon cells, making this cell line suited for the study of both cytoplasmic and nuclear functions of MYL9 (Li and Sarna 2009, Nigro, Schettino et al. 2018). To test the role of N $\alpha$-modifications of MYL9 in regulating cytoskeletal activity, we measured the migratory potential of non-transduced control cells and cells transduced with WT, SPK, or SSQ MYL9-FLAG. A Boyden chamber design was employed, in which cells were serum-starved, plated on an extracellular matrix extract, and migration towards serum containing media was quantified after 24 hours. MYL9 variants were transduced into cells at equal levels so that protein abundance differences would not affect results (Figure 7A). Only HCT116 cells expressing the Na-methylation deficient SSQ MYL9 mutant showed a significant increase in migration as compared to non-transduced cells (Figure 7B). This suggests that loss of N $\alpha$-methylation of MYL9 leads to increased cytoskeletal dynamics, as required for migration. This result is consistent with our findings in NIH3T3 cells, and supports a model in which Na-methylated MYL9 does not participate in activation of NMII.

Multiple signaling pathways converge on phosphorylation of MYL9 at serine 19 (pS19) in order to increase NMII activity (Conti and Adelstein 2008, VicenteManzanares, Ma et al. 2009). Because of the requirement for pS19 MYL9 in NMII related activities, including migration and cell spreading, we next tested if the activated cytoskeletal function of SSQ MYL9 is associated with increased levels of pS19. To 
accomplish this, we treated HCT116 control and MYL9-FLAG (WT and mutant)

expressing cell lines with calcimycin, an MLCK activator, and evaluated pS19 levels. We found that after treatment, the non-methylatable SSQ MYL9 mutant has increased pS19 as compared to WT and SPK MYL9 (Fig 7C,D). The ratio of pS19 to total MYL9-FLAG was quantified, and it confirmed that SSQ MYL9 shows enrichment of this activating PTM (Figure 7D). This result provides a biochemical basis for the cytoskeletal phenotypes shown by SSQ MYL9 expressing cells.

To confirm the role of $\mathrm{N} \alpha$-methylation in these findings and ensure pS19 levels are not altered by the K4Q mutation, we next assayed the phosphorylation of WT MYL9 in NRMT1 KO HCT116 cells (Shields, Tooley et al. 2017). These cells are deficient in No-methylation (Figure 7E), and as such should mirror the results seen with SSQ MYL9. After calcimycin treatment, the pS19 to total WT MYL9-FLAG ratio was significantly higher in NRMT1 KO HCT116 cells, as compared to control cells (Figure 7E,F). This confirms that loss of $\mathrm{N \alpha}$-methylation, and not the K4Q mutation, promotes the activation of MYL9 through serine 19 phosphorylation, a modification that is critical for proper regulation of cytoskeletal dynamics.

\section{No-methylation of MYL9 promotes its nuclear function}

We next looked at the role of $\mathrm{Na}-\mathrm{PTM}$ in regulating the nuclear function of MYL9, where it serves as a transcriptional activator of ICAM1 (Li and Sarna 2009). As NRMT1 is found in the nucleus, and Na-methylation has been shown to facilitate protein-DNA interactions, we proposed that Na-methylation of MYL9 would facilitate its transcriptional activation of ICAM1 (Chen, Muratore et al. 2007, Tooley, Petkowski et al. 
2010, Dai, Otake et al. 2013, Cai, Fu et al. 2014, Sathyan, Fachinetti et al. 2017). To test this, we treated non-transduced as well as WT and mutant MYL9-FLAG transduced HCT116 cells with TNF $\alpha$ in order to induce ICAM1 transcription, and then measured the induction of ICAM1 transcription for each cell line by qPCR. We found that cells expressing the N $\alpha$-methylation enriched SPK MYL9 mutant had significantly greater induction of ICAM1 transcription than all other cell lines (Figure 8A).

To confirm that enrichment of N $\alpha$-methylation was responsible for the heightened transcriptional activity of SPK MYL9, and not loss of Na-acetylation, this mutant was transduced into control and NRMT1 KO HCT116 cells and ICAM1 transcription was again assayed. Loss of $\mathrm{N} \alpha$-methylation reduced the transcriptional activity of SPK MYL9, as seen by a decrease in ICAM1 transcription when expressed in NRMT1 KO cells as compared to control cells (Figure 8B). This confirms a requirement for $\mathrm{N} \alpha$ methylation to promote the optimal transcriptional activity of MYL9 in its specialized nuclear role.

We next sought to clarify the mechanism by which $\mathrm{N} \alpha$-methylation facilitates the transcriptional activity of MYL9. First, we used immunofluorescence to determine if $\mathrm{N} \alpha$ methylation of MYL9 results in increased nuclear localization, which would increase the pool of MYL9 available to participate in transcription. HCT116 cells transduced with WT, SPK, or SSQ MYL9-Dendra2 were imaged before and post-TNF $\alpha$ treatment. A Dendra2-only expressing cell line was included as a control for non-specific changes in localization. Dendra2-only did not show TNFa responsive localization (Figure 8C). However, all variants of MYL9 showed an increase in the nuclear to total ratio of MYL9Dendra after TNF $\alpha$ treatment (Figure $8 \mathrm{C}$ ). In addition, there were no significant 
differences between MYL9 variants with regards to nuclear localization before or after TNF $\alpha$ treatment. This experiment indicates that N $\alpha$-methylated MYL9 does not increase the pool of nuclear MYL9, and that the mechanism by which this PTM facilitates transcriptional function occurs downstream of nuclear localization.

Previous studies have shown N $\alpha$-methylation to be important for the association of chromatin regulating and DNA damage response proteins with DNA (Chen, Muratore et al. 2007, Dai, Otake et al. 2013, Cai, Fu et al. 2014, Sathyan, Fachinetti et al. 2017). To see if Na-methylation similarly facilitates the protein-DNA interaction of MYL9 with the ICAM1 promoter, we performed ChIP in non-transduced and WT, SPK, and SSQ MYL9-FLAG expressing HCT116 cells. Only the Na-methylation enriched SPK mutant of MYL9 resulted in enriched immunoprecipitation of the ICAM1 promoter over input (Figure 8D). This indicates that N $\alpha$-methylation facilitates the protein-DNA interaction of MYL9 with the ICAM1 promoter, and provides a mechanism by which $\mathrm{N} \alpha$-methylation supports the transcriptional function of MYL9.

\section{Discussion}

Wide spread $\mathrm{N} \alpha$-methylation of skeletal muscle myosin light chains was first reported in the 1980s (Henry, Dalgarno et al. 1982, Henry, Trayer et al. 1985). These light chains shared an APK N-terminal sequence, which fit the predicted eukaryotic consensus sequence at that time, cleavage of the initiator methionine followed by an alanine or proline in the first position, proline in the second, and lysine in the third (Stock, Clarke et al. 1987). A hypothetical PK methyltransferase was proposed, based on these amino acid restrictions (Stock, Clarke et al. 1987). As proline in the second position 
of substrates blocks the activity of NATs, N $\alpha$-methylation and $\mathrm{N} \alpha$-acetylation were considered to be mutually exclusive modifications (Stock, Clarke et al. 1987, Polevoda and Sherman 2003). We later identified two eukaryotic methyltransferases, NRMT1 and NRMT2, allowing for more specific studies of substrate recognition and catalysis (Tooley, Petkowski et al. 2010). These studies revealed the NRMTs do not have a strict requirement for proline in the second position, and instead can permit most non-polar and uncharged polar amino acids in this position (Petkowski, Schaner Tooley et al. 2012). In addition, flexibility was found in the first and third amino acids of the consensus sequence (Petkowski, Schaner Tooley et al. 2012). This resulted in the identification of more than 100 proteins that are predicted targets for both $\mathrm{N} \alpha$-methylation and $\mathrm{N} \alpha-$ acetylation (Petkowski, Schaner Tooley et al. 2012). This set of proteins includes the eukaryotic non-muscle myosin light chains, which have an SSK N-terminal sequence (Petkowski, Schaner Tooley et al. 2012). Supporting this finding, mass spectrometry analysis identified both $\mathrm{N} \alpha$-methyl and N $\alpha$-acetyl modification states of MYL9, making it the first confirmed dual substrate (Petkowski, Schaner Tooley et al. 2012). In this study, we verify that N $\alpha$-methylation and $\mathrm{N} \alpha$-acetylation of MYL9 are catalyzed by NRMT1 and NatA, respectively. This allows us to exploit the consensus sequence requirements of NRMT1 and NatA to generate Na-PTM selective mutants of MYL9. We show that SPK MYL9 selects for N $\alpha$-methylation, while SSQ MYL9 selects for N $\alpha$ acetylation.

Regulation of stability has historically been considered the primary role for $\mathrm{N} \alpha-$ methylation and $\mathrm{N} \alpha$-acetylation. Early studies showed that alpha-amino dimethylproline blocked degradation of cytochrome c by aminopeptidases (Pettigrew and Smith 1977, 
Smith and Pettigrew 1980). This function has been proposed as a general function of $\mathrm{N} \alpha$ methylation but has yet to been confirmed with any additional substrates (Stock, Clarke et al. 1987). More recently, a novel protein degradation pathway termed the $\mathrm{Ac} / \mathrm{N}$-end rule was described (Hwang, Shemorry et al. 2010). It was shown that in S. cerevisiae, proteins with an $\mathrm{N} \alpha$-acetylated Met, Ala, Val, Ser, Thr, or Cys are targeted for proteolytic degradation by the E3 ubiquitin ligases Doa10 or Not4 (Hwang, Shemorry et al. 2010, Shemorry, Hwang et al. 2013). This pathway was later demonstrated in human cells for the protein RGS2, with potential impact on blood pressure regulation (Park, Kim et al. 2015). WT MYL9 has an N-terminal Ser that can be Na-acetylated, making it a potential target of the Ac/N-end rule pathway. We employed full-length WT and Na-PTM selective mutants of MYL9 to study the impact of Na-PTMs on MYL9 half-life. In our study, blocking $\mathrm{N} \alpha$-acetylation or N $\alpha$-methylation of MYL9 did not alter stability. This finding aligns with the model that $\mathrm{N} \alpha$-PTMs modify protein stability in a context and substrate specific manner, with factors such as complex formation (i.e. sequestering the $\mathrm{N}$-terminus) and secondary structure of the $\mathrm{N}$-terminus contributing to regulatory outcomes (Shemorry, Hwang et al. 2013, Aksnes, Drazic et al. 2016).

As the NATs and NRMTs show distinct cellular compartmentalization, we tested whether $\mathrm{N} \alpha$-acetylation and $\mathrm{N} \alpha$-methylation regulate the distinct cytoplasmic and nuclear roles of MYL9 (Tooley and Schaner Tooley 2014, Aksnes, Drazic et al. 2016). We first investigated how N $\alpha$-PTMs modulate the cytoplasmic role of MYL9 as a regulator of NMII activity and cytoskeletal dynamics by looking at the downstream cellular processes of cell adhesion and migration (Conti and Adelstein 2008, Vicente-Manzanares, Ma et al. 2009). While PTMs on the N-terminal tail of MYL9 are recognized as key regulators of 
NMII dynamics (Heissler and Sellers 2014), this was the first study to investigate the functional impact of N $\alpha$-PTMs . We found that blocking $\mathrm{N} \alpha$-methylation through expression of an SSQ MYL9 mutant led to both increased cell spreading on fibronectin and increased migration. These results are indicative of increased cytoskeletal dynamics occurring downstream of heightened NMII activation. Importantly, we showed that the SSQ MYL9 mutant did not undergo increased Na-acetylation as compared to WT MYL9, ruling out the possibility that the increased cytoskeletal activity was related to increased $\mathrm{N} \alpha$-acetylation. Corresponding with this result, we did not find blocking $\mathrm{N} \alpha$-acetylation to alter our measures of cytoskeletal function.

Phosphorylation of MYL9 at serine 19 increases NMII association with F-actin as well as ATPase activity (Amano, Ito et al. 1996, Heissler and Sellers 2014). We found that N $\alpha$-methylation of MYL9 decreases the occurrence of $\mathrm{pS} 19$, offering a mechanism for the increased cytoskeletal activity that was observed when $\mathrm{N} \alpha$-methylation was blocked. Further studies are needed to reveal the mechanism by which $\mathrm{N} \alpha$-methylation of MYL9 reduces pS19, but possibilities include altered interactions with kinases or phosphatases. In our study, calcimycin, a calcium ionophore that activates MLCK, was used to induce phosphorylation of MYL9. However, the impact of N $\alpha$-methylation on MYL9 pS19 likely extends beyond MLCK to phosphorylation catalyzed by the Rho GTPase associated kinases, as cell spreading and migration showed sensitivity to $\mathrm{N} \alpha$ methylation and these processes involve multiple kinases. Precedent for the interplay of N $\alpha$-PTMs with internal residue PTMs has been set by studies of Histone H4 (Schiza, Molina-Serrano et al. 2013, Fulton, Zhang et al. 2017). N $\alpha$-acetylation of histone $\mathrm{H} 4$ reduces arginine 3 methylation by yeast histone methyltransferase 1 (Hmt1) and by 
human protein arginine methyltransferase 3 (PRMT3) (Schiza, Molina-Serrano et al. 2013, Fulton, Zhang et al. 2017). Serine 19 phosphorylation of MYL9 is often accompanied by phosphorylation of threonine 18, a PTM that further increases NMII activity (Amano, Ito et al. 1996, Heissler and Sellers 2014). In contrast, phosphorylation of MYL9 at serines 1 and 2 by protein kinase $\mathrm{C}$ has been described to inhibit NMII activity (Nishikawa, Sellers et al. 1984, Ikebe, Hartshorne et al. 1987, Heissler and Sellers 2014). The proximity of these PTMs, taken together with our finding of interplay between $\mathrm{N} \alpha$-methylation and pS19, suggest that the N-terminal PTMs of MYL9 may exert complex, combinatorial control over NMII activity. Future studies will further investigate the interplay between N-terminal and internal side chain PTMs of MYL9.

We next investigated how Na-PTMs regulate the nuclear function of MYL9 as a transcriptional activator of ICAM1. In colon smooth muscle cells, MYL9 binds the ICAM1 core promoter region, interacts with RNA polymerase II and TFIIB, and promotes the transcription of ICAM1 (Li and Sarna 2009). It has separately been shown that TNF $\alpha$ signaling results in a myosin-dependent increase in ICAM1 transcription $(\mathrm{Wu}$, Guo et al. 2009). We found that upon TNF $\alpha$ treatment, expression of the SPK MYL9 mutant results in significantly greater ICAM1 transcription as compared to WT or SSQ MYL9. Our in vitro enzyme assays show that the SPK mutant both blocks NatA activity and is a preferred substrate of NRMT1, likely resulting in increased levels of N $\alpha$ methylated MYL9 in addition to blocking N $\alpha$-acetylation.

Using NRMT1 KO cells, which lack N $\alpha$-trimethylation, we confirmed that $\mathrm{N} \alpha$ methylation facilitates the transcription of ICAM1. When SPK MYL9 was expressed in NRMT1 KO cells it was unable to induce transcription of ICAM1 at levels seen in 
control cells. A number of NRMT substrates require localization to DNA for their function. Na-methylation has been shown to be required for proper protein-DNA interaction and downstream function for RCC1, DDB2, CENP-A, and CENP-B (Chen, Muratore et al. 2007, Dai, Otake et al. 2013, Cai, Fu et al. 2014, Sathyan, Fachinetti et al. 2017). N $\alpha$-trimethylation in particular is proposed to facilitate protein-DNA interactions because it results in a $\mathrm{pH}$-insensitive positive charge at the amino terminus that is favorable for association with the negatively charged DNA phosphate backbone (Stock, Clarke et al. 1987, Tooley, Petkowski et al. 2010, Tooley and Schaner Tooley 2014). Accordingly, we performed ChIP and found that $\mathrm{N} \alpha$-methylation enhances the association of MYL9 with the ICAM1 promoter. MYL9 has also been described to interact with the promoter and activate transcription of xanthine oxidase in cardiomyocytes (Zhang, Liu et al. 2015). As such, it seems likely that transcriptional activation by MYL9, and the promotion of this function by N $\alpha$-methylation, will be identified in more settings in the future.

We have shown that $\mathrm{N} \alpha$-methylation favors the specialized, nuclear function of MYL9 by both reducing participation in cytoskeletal activities and by increasing association with DNA. This provides the first report of how Na-PTMs regulate MYL9 function. However, many questions remain regarding the Na-PTMs of MYL9. In particular, a clear role for $\mathrm{N} \alpha$-acetylation has yet to emerge. One possibility is that levels of MYL9 N $\alpha$-acetylation regulate substrate availability for $\mathrm{N} \alpha$-methylation. NATs occur in the cytoplasm and catalyze both co-translational and post-translational modification of substrates (Aksnes, Drazic et al. 2016). This means that NATs have access to substrates before the NRMTs, which are compartmentalized in the nucleus, and suggests that the 
degree of MYL9 N $\alpha$-acetylation will dictate the degree of MYL9 N $\alpha$-methylation (Tooley, Petkowski et al. 2010, Tooley and Schaner Tooley 2014). In this way, Naacetylation may mark MYL9 molecules designated for cytoplasmic activity. In addition to MYL9, a number of predicted dual NRMT and NAT substrates are known to have both cytoplasmic and nuclear roles, including inversin and NEMO (Nurnberger, Bacallao et al. 2002, Huang, Wuerzberger-Davis et al. 2003). This raises the distinct possibility that regulation of compartmental activity is a conserved role for $\mathrm{N} \alpha$-acetylation and $\mathrm{N} \alpha$ methylation. If there are distinct pools designated for each or a single pool that can be interchangeably $\mathrm{N} \alpha$-acetylated or $\mathrm{N} \alpha$-methylated remains to be determined. Alpha-amino deacetylases and demethylases have been proposed, but have yet to be identified (Tooley and Schaner Tooley 2014). However, whether or not Na-PTMs prove to be interchangeable or static, our study makes clear that one substrate can occur as multiple $\mathrm{N} \alpha$-proteoforms, and these proteoforms serve to increase protein functional diversity.

The importance of uncovering the properties of protein regulation by Na-PTMs is highlighted by developmental defects and disease states associated with dysregulation of $\mathrm{N} \alpha$-methylation and $\mathrm{N} \alpha$-acetylation. NRMT1 KO mice display improper development, premature aging, and premature morbidity (Bonsignore, Tooley et al. 2015).

Additionally, a number of mutations in NRMT1 that decrease catalytic activity have been associated with cancers, and knockdown of this enzyme has been shown to increase mammary tumorigenesis (Bonsignore, Butler et al. 2015, Shields, Tooley et al. 2017). A mutation in NAA10, the catalytic subunit of NatA, results in the lethal X-linked developmental disorder Ogden syndrome (Van Damme, Stove et al. 2014, Myklebust, Van Damme et al. 2015). Dysregulation of $\mathrm{N} \alpha$-acetylation is also observed in multiple 
cancers, and overexpression of NatA has been shown to drive oncogenic transformation in lung cells (Kalvik and Arnesen 2013). Interestingly, aberrant post-translational regulation of MYL9 has also been observed in multiple cancers, including those of the breast and lung (Newell-Litwa, Horwitz et al. 2015). Further studies that reveal the regulatory roles of $\mathrm{N} \alpha$-acetylation and $\mathrm{N} \alpha$-methylation at the protein level are essential to expanding our understanding of basic cell biology and will also reveal novel pathways that contribute to disease related processes.

\section{Experimental procedures}

\section{Recombinant protein expression and in vitro enzyme assays}

Human NRMT1 (rhNRMT1) and NAA10 (rhNAA10) were expressed as His6tagged recombinant proteins and purified as previously described (Chen, Brownawell et al. 2004, Shields, Tooley et al. 2017). Briefly, protein ORFs (GE Dharmacon, Marlborough, MA) were amplified and subcloned into the pet15b vector (EMD Millipore, Billerica, MA), expressed in BL21 Star (DE3) Escherichia coli (Thermo Scientific, Waltham, MA), and purified on $\mathrm{Ni}^{2+}$-NTA beads (Qiagen, Hilden, Germany). In vitro methyltransferase experiments were carried out using the MTase-Glo Methyltransferase Assay (Promega, Madson, WI) following the manufacturers guidelines. $0.2 \mu \mathrm{M}$ rhNRMT1 was incubated at room temperature with synthetic peptide substrates corresponding to the 14 N-terminal amino-acids of WT or mutant MYL9 (Fig 2A) (AnaSpec, Fremont, CA) in the presence of $40 \mu \mathrm{M}$ s-adenosylmethionine (SAM). Peptide substrates were used at concentrations ranging from 0 to $160 \mu \mathrm{M}$. Reactions were stopped at 20 minutes by addition of trifluoroacetic acid. Methyltransferase activity was 
then measured by the accumulation of a luminescent signal, which was generated by reaction of a detection reagent with the methyltransferase reaction product sadenosylhomocysteine (SAH).

In vitro acetyltransferase experiments were performed using the Enzo Acetyltransferase Activity Kit (Enzo Life Sciences, Farmingdale, NY) following manufacturers guidelines. $0.1 \mu \mathrm{M}$ rhNAA10 was incubated with $\mathrm{N}$-terminal peptides of WT or mutant MYL9 at room temperature in the presence of excess acetyl-CoA. The reaction was stopped after 30 minutes by addition of ice cold isopropyl alcohol. Acetyltransferase activity was measured by reading fluorescence (Ex 380 nm/Em 520 $\mathrm{nm}$ ) generated by the reaction of a detection reagent with the acetyltransferase reaction product CoA.

All readings were taken on a Cytation5 cell imaging multi-mode reader (BioTek, Winooski, VT). For both methyltransferase and acetyltransferase assays, background signal was measured by the inclusion of no substrate control reactions and was subtracted from experimental reactions. Background subtracted signal intensities at varying substrate concentrations were then fit to a model of Michaelis-Menten enzyme kinetics and a Km determination was made using GraphPad Prism 7 software (San Diego, CA).

\section{Molecular cloning, mutagenesis, and lentivirus production}

To generate the C-terminally tagged MYL9-Dendra2 fusion protein, the MYL9 protein ORF (GE Dharmacon) was amplified and subcloned into the pDendra2-N vector (Clontech, Mountain View, CA) using XhoI and HindIII restriction sites. Site-directed mutagenesis was performed using the Quikchange system (Agilent Technologies, Santa 
Clara, CA) to generate S3P (SPK) and K4Q (SSQ) mutant MYL9-Dendra2 fusion proteins. WT, SPK, and SSQ MYL9-Dendra2, as well as Dendra2 alone, were then amplified and subcloned into the pCDH-EF1-MCS-IRES-Puro lentiviral expression vector (System Biosciences, Palo Alto, CA) using XbaI and NheI restriction sites. The following forward primers and their reverse compliments were used for mutagenesis: S3P: 5'-GATCTCGAGATGTCCCCCAAGCGGGCCAAAGC-3' and K4Q: 5'CGAGATGTCCAGCCAGCGGGCCAAAGCC-3'. To generate C-terminally tagged MYL9-FLAG proteins, WT, SPK, and SSQ MYL9 were amplified from the MYL9pDendra2 constructs and subcloned into the pWPI lentiviral expression vector (Addgene, Cambridge, MA) using 5' and 3' PmeI restriction sites. The following 3' primer included the FLAG nucleotide sequence followed by a stop codon:

5'-CGGTTTAAACTCATTTATCATCATCATCTTTATAATCGTCGTCTTT

\section{ATCCTTGGCGC-3'}

Lentivirus was generated through co-transfecting HEK293T cells with $50 \mu \mathrm{g}$ of expression plasmid (pCDH or pWPI from above), $37.5 \mu \mathrm{g}$ psPAX2 packaging vector, and $15 \mu \mathrm{g}$ pMD2.G envelope plasmid using calcium phosphate transfection. Viral supernatants were collected forty-eight hours after transfection, concentrated with 100KDa molecular weight cut off filters (Millipore Sigma, Burlington, MA), and tittered in HEK293T cells. GFP expressed by the pWPI vector and Dendra2 expressed by the pCDH vector was used for titering.

\section{Cell culture, transgene expression, and small molecule treatment}


HEK293T human embryonic kidney and NIH 3T3 mouse embryonic fibroblast cell lines were cultured in Dulbecco's Modified Eagle Medium (DMEM; Life Technologies, Grand Island, NY) with 10\% fetal bovine serum (FBS; Atlanta Biologicals, Atlanta, GA) and 1\% penicillin-streptomycin (P/S; Life Technologies). HCT116 human colorectal carcinoma and NRMT1 KO HCT116 cell lines were cultured in McCoy's 5A Modified Medium (Life Technologies) supplemented with 10\% FBS and $1 \% \mathrm{P} / \mathrm{S}$. NRMT1 KO cells were previously generated and verified by sequencing and protein expression (Shields, Tooley et al. 2017). The maintenance of this cell line was verified by Western Blotting for loss of N $\alpha$-methylation (Fig 4E). All cells were grown on tissue-culture treated plastic and maintained at $37^{\circ} \mathrm{C}$ and $5 \% \mathrm{CO}_{2}$. HEK293T, NIH 3T3, and HCT116 cell lines were a generous gift from Dr. Ian Macara, Vanderbilt University.

For experiments involving transgene expression, cells were harvested with Trypsin-EDTA (Life Technologies), plated in fresh media, and transduced with lentivirus at a multiplicity of infection (MOI) of 2. Transgene expression was confirmed and cells were used for experiments 3-4 days after transduction. Cells transduced with the $\mathrm{pCDH}$ vector were selected for by treatment with $2 \mu \mathrm{g} / \mathrm{ml}$ puromyocin 48 hours after transduction, and were used for experiments 48 hours after treatment. For experiments involving small molecule treatment, cells were cultured to $80 \%$ confluence, and media was changed to fresh media containing the desired small compound. Calcium ionophore A23187 (calcimycin; Sigma Aldrich, St. Louis, MO) was resuspended in DMSO and used at a final concentration of $0.1 \mu \mathrm{M}$. Cells were treated with calcimycin for 45 minutes to induce phosphorylation of MYL9 by MLCK. Recombinant human tumor necrosis 
factor alpha (TNF $\alpha$; Life Technologies) was resuspended in sterile, distilled water and used at a final concentration of $20 \mathrm{ng} / \mathrm{ml}$. Cells used in transcriptional studies were treated for 2 hours, while cells used for localization and promoter binding studies were treated for 1 hour.

\section{Half-life measurement and modeling}

25K HEK293 cells expressing Dendra2 or Dendra2-MYL9 fusion proteins were plated in triplicate in black-walled, clear-bottom 96-well tissue culture plates and given 24 hours to adhere. Experiments were then carried out in a Cytation 5 cell imaging multimode reader maintained at $5 \% \mathrm{CO}_{2}$ and $37^{\circ} \mathrm{C}$. Cells were imaged pre-photoconversion at 20x in the GFP and RFP channels, followed by photoconversion through exposure to the DAPI laser line (UV) at maximum intensity for 16 seconds. Following photoconversion, cells were imaged in the RFP channel every 4 hours for 48 hours, imaging settings (LED intensity, integration time, gain) were maintained throughout experiments. Sum RFP fluorescence intensity values were calculated from post-photoconeversion images at each time point, and then were plotted relative to the $0 \mathrm{~h}$ intensity. 3-4 experiments were performed for each group, and MYL9-Dendra decay curves were then generated in GraphPad Prism using a one-phase exponential decay model. Initial y values were set to 1 for all curves and curve plateaus (y-value at infinite time) were set to 0 . Decay curves

for each MYL9-Dendra variant were compared to WT in a pairwise fashion to determine if the data sets could be adequately fit by a single curve or if independent curves were required. An extra sum-of-squares $\mathrm{F}$ test was used to compare the goodness of fit of shared and independent curves, and subsequently determine the probability with which 
the shared curve represents both data sets. MYL9 half-life was calculated as $\ln (2) / k$, with $\mathrm{k}$ being the rate constant $\left(\mathrm{h}^{-1}\right)$ generated by the exponential decay model.

\section{Cell spreading}

2-well chamber slides (Thermo Scientific) were coated with $3 \mu \mathrm{g} / \mathrm{cm}^{2}$ fibronectin (Corning, Corning, NY) in tris-buffered saline for 1 hour at room temperature. The remaining solution was removed and slides were blocked with $5 \mathrm{mg} / \mathrm{ml}$ bovine serum albumin (BSA; Research Products International, Mt. Prospect, IL) in phosphate-buffered saline. Control and NIH 3T3 cells expressing WT, SPK, or SSQ MYL9-FLAG were grown to confluence, trypsinized, counted, and resuspended at 100k cells/ml in fresh media. Cells were then placed on ice for 20 minutes to promote rounding. $70 \mathrm{~K}$ cells were then plated per chamber, and chamber slides were immediately placed in a Cytation 5 cell imaging multi-mode reader with $\mathrm{CO}_{2}$ maintained at $5 \%$ in the sample chamber. The sample chamber was raised from room temperature to $37^{\circ} \mathrm{C}$, with time 0 being defined as when $37^{\circ} \mathrm{C}$ was reached. Cells were then imaged with a 20x phase contrast objective every 15 minutes for 1 hour. The surface area was quantified for the 4 largest cells per image at each time point by tracing cell outlines using the Image $1.47 \mathrm{v}(\mathrm{NIH}$, Bethesda, MD) plug-in NeuronJ version 1.4.3 (Meijering, Jacob et al. 2004). 12 cell areas taken from 3 independent experiments were used to generate the mean cell surface area for each sample at each time point.

\section{Transwell migration}


Cell migration was measured using a 96-well basement membrane extract (BME) cell invasion assay (Trevigen, Gaithersburg, MD) as previously described (Bonsignore, Butler et al. 2015). Briefly, control and WT, SPK, or SSQ MYL9-FLAG expressing HCT116 cells were serum-starved for 24 hours in McCoy's 5A Modified Medium with $0.1 \%$ BSA. 50K cells in serum-free media were then plated on $0.25 \mathrm{x}$ BME in triplicate in the upper chamber of a transwell plate. Media supplemented with 1\% FBS was plated in the lower chamber of transwells to serve as a chemoattractant. Migration was allowed to proceed for 24 hours, non-migrating cells were washed away, and migrating cells were stained using Calcein-AM. Fluorescence at $485 \mathrm{~nm}$ excitation, $520 \mathrm{~nm}$ emission was used to quantify the degree of cell migraton.

\section{Western blots}

Primary antibodies and dilutions used for Western Blotting were: rabbit antiFLAG (1:500; Invitrogen, Carlsbad, CA), HRP-conjugated mouse anti-FLAG (1:1000; Sigma Aldrich), rabbit anti- $\beta$-actin (1:1000; Cell Signaling Technologies, Danvers, MA), rabbit anti-pS19 MYL9 (1:1000; Cell Signaling Technologies), and rabbit anti-Natrimethyl RCC1 (1:10,000) (Chen, Muratore et al. 2007), and rabbit anti-N $\alpha$-acetyl MYL9 (1:1000) (Ubf1). The Ubf1 antibody (Cocalico Biologicals, Inc., Stevens, PA) was provided as custom rabbit antisera containing polyclonal antibodies against a synthetic Na-acetyl MYL9 peptide linked to keyhole limpet hemocyanin. Secondary antibody used was donkey anti-rabbit (1:5,000; Jackson ImmunoResearch, West Grove, PA). Densitometry was performed using ImageJ $1.47 \mathrm{v}$ software (NIH). 


\section{Dot Blots}

The specificity of the Ubf1 antibody for N $\alpha$-acetyl MYL9 was validated by performing dot blots. $2 \mu \mathrm{g}$ of unmodified, N $\alpha$-acetyl, $\mathrm{N} \alpha$-methyl, and $\mathrm{N} \alpha$-trimethyl MYL9 synthetic peptides (AnaSpec) were spotted onto a nitrocellulose membrane and then blotted with Ubf1 (1:1000) followed by donkey anti-rabbit $(1: 5,000)$ secondary antibody.

\section{Immunoprecipitation}

Protein lysates from control, WT, or SSQ MYL9-FLAG expressing NIH3T3 cells were incubated with $20 \mu \mathrm{l}$ of M2 anti-FLAG beads (Sigma Aldrich) overnight at $4{ }^{\circ} \mathrm{C}$. Beads were washed with $0.1 \%$ NP40 (IBI Scientific, Peosta, IA) before eluting precipitated proteins in $40 \mu \mathrm{l}$ of $5 \mathrm{x}$ Laemmli sample buffer at $90{ }^{\circ} \mathrm{C}$ for 5 minutes. Two SDS-PAGE gels were loaded with the eluate and Western blotting was performed for total FLAG and N $\alpha$-acetyl MYL9. $20 \mu \mathrm{l}$ of inout lysate was also resolved by SDS-PAGE and blotted for FLAG and GAPDH.

\section{Real time PCR analysis}

Cells were lysed in TRIzol (Life Technologies) and RNA was then extracted in chloroform, pelleted in isopropanol, and washed with ethanol. The SuperScript FirstStrand Synthesis System (Life Technologies) was used to generate cDNA. SYBR Green PCR Master Mix (BioRad, Herculaes, CA) was used to detect cDNA amplification on a CFX96 Touch Real-Time PCR Detection System (BioRad). Transcript expression levels were compared using the $\Delta \Delta \mathrm{CT}$ quantification method, with GAPDH serving as a 
control. Melt curves were performed to confirm the presence of single reaction products. Primers (Integrated DNA Technologies, Coralville, IA) used were:

ICAM1 forward 5'-GTAGCAGCCGCAGTCATAAT-3'

ICAM1 reverse 5’-GGGCCTGTTGTAGTCTGTATTT-3’

GAPDH forward 5'-ACAGCCTCAAGATCATCAGCAA-3'

GAPDH reverse 5'-CCATCACGCCACAGTTTCC-3'.

\section{Immunofluorescence}

Dendra2 or MYL9-Dendra2 expressing HCT116 cells were analyzed for MYL9 cellular compartmentalization either before or 1 hour post-TNF $\alpha$ treatment. Cells were fixed with $4 \%$ paraformaldehyde, permeabilized with $0.3 \%$ Triton X-100, and blocked with 3\% BSA. Mouse anti-Dendra2 primary antibody (1:150; Origene, Rockville, MD) followed by Alexa Fluor 488 conjugated goat anti-mouse secondary antibody $(1: 2,000$; Invitrogen) was used to detect MYL9-Dendra2 or Dendra2 alone. Cells were counterstained with Hoechst (1:50,000; AnaSpec). Imaging was performed on a Cytation 5 cell imaging multi-mode reader with a 40x objective and image analysis was performed using Gen5 software (BioTek). Total Dendra2 signal was quantified by the sum green fluorescence intensity of images. To quantify nuclear Dendra2, the sum green fluorescence intensity overlapping with Hoechst signal was quantified.

\section{Chromatin immunoprecipitation}

Control and WT, SPK, or SSQ MYL9-FLAG expressing HCT116 cells were treated with TNF $\alpha$ for $1 \mathrm{~h}$. Cells were cross-linked with $1 \%$ formaldehyde, resuspended in 
lysis buffer, and sonicated to fragment DNA. $10 \%$ of total sheared lysate was saved as an input sample. MYL9-FLAG was then immunoprecipitated from lysates using M2 antiFLAG beads (Sigma Aldrich) that were pre-blocked in herring sperm DNA. After immunoprecipitation, beads were washed and bound material was eluted. De-crosslinking was performed by incubating with $5 \mathrm{M} \mathrm{NaCl}$. Eluates were then treated with RNase A and

proteinase K. The remaining immunoprecipitated DNA was isolated using a Qiagen PCR purification kit (Qiagen) and resuspended in TE buffer. Input samples were processed alongside ChIP samples after elution. Equal amounts of purified DNA were amplified by PCR and analyzed by running on $2 \%$ agarose gels. PLK-1 served as a control for nonspecific DNA binding. Primers for the PLK-1 (Integrated DNA Technologies) and ICAM1 (Invitrogen) promoters were as follows: ICAM1 forward 5'-

CGCCCGATTGCTTTAGCTTG-3', ICAM1 reverse 5'GGCTGAGGTTGCAACTCTGA-3', PLK-1 forward 5'GGTTTGGTTTCCCAGGCTAT-3', and PLK-1 reverse 5'GCTGGGAACGTTACAAAAGC-3'.

\section{Statistical Analyses}

Statistics were performed with GraphPad Prism 7 software. For experiments involving the comparison of only two groups, a two-tailed Student's t-test was performed. For experiments involving the comparison of three or more groups, one-way ANOVA was performed with Tukey's test for multiple comparisons between all groups. For experiments involving comparison of three or more groups at multiple time points, two-way random measures ANOVA with Tukey's multiple comparisons test between all 
groups was performed. For experiments involving comparison of three or more groups

under two conditions, regular two-way ANOVA with Bonferroni's multiple comparisons test between all groups was performed. All error bars shown represent standard deviation. 
A)

\begin{tabular}{|c|c|c|}
\hline MYL9 variant & N-terminal sequence & N $\alpha$-PTM status \\
\hline WT & SSKRAKAKTTKKRPK & Me3-MYL9 and Ac-MYL9 \\
\hline S3P & SPKRAKAKTTKKRPK & Me3-MYL9 \\
\hline K4Q & SSQRAKAKTTKKRPK & Ac-MYL9 \\
\hline
\end{tabular}

NRMT1

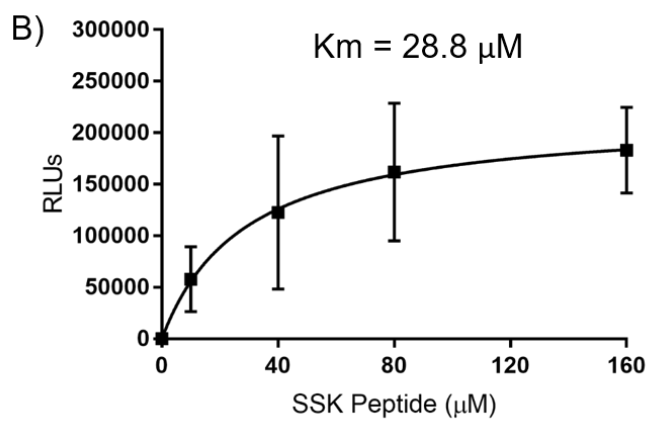

D)
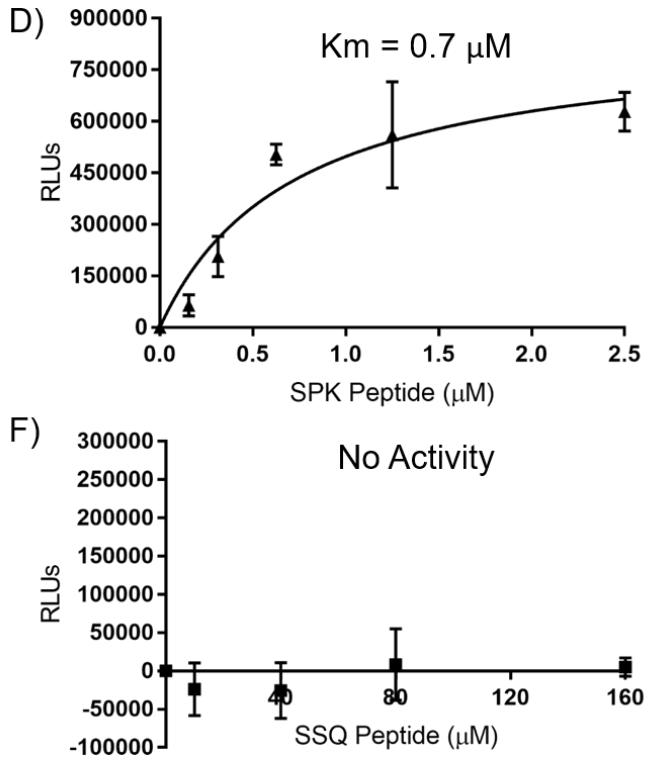

NAA10
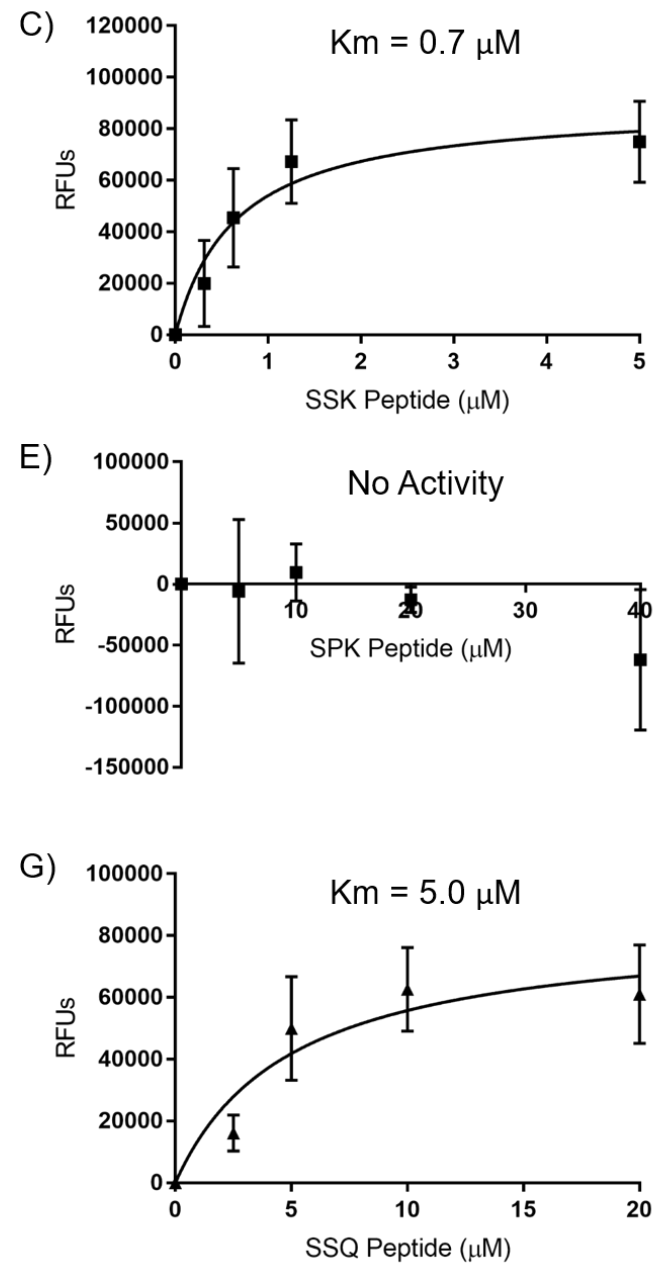
Figure 3 WT MYL9 is a substrate of both NRMT1 and NatA, while MYL9 mutants can be either N $\alpha$-acetylated or N $\alpha$-methylated. A) WT MYL9 (SSK) has been found in N $\alpha$-methylated and N $\alpha$-acetylated forms. The S3P (SPK) MYL9 mutant is N $\alpha$ methylated, and the K4Q (SSQ) MYL9 mutant is Na-acetylated. In vivo, the initiator methionine of WT MYL9 is cleaved to reveal the N-terminal sequence shown. B-G) In vitro methyltransferase and acetyltransferase assays were performed to determine the $\mathrm{Km}$ of NRMT1 or NAA10 (the catalytic subunit of NatA) when using peptides corresponding to the $14 \mathrm{~N}$-terminal amino acids (after Met cleavage) of WT and mutant MYL9 as substrates. B) The Km of NRMT1 with WT (SSK) MYL9 was determined to be $28.8 \mu \mathrm{M}$. C) NAA10 with WT (SSK) MYL9 had a Km of $0.7 \mu$ M. D) SPK MYL9 was confirmed to be a preferred substrate of NRMT1 with a Km of $0.7 \mu \mathrm{M}$. E) NAA10 showed no activity with SPK MYL9 up to $40 \mu \mathrm{M}$. F) SSQ MYL9 was not a substrate of NRMT1, showing no activity up to $160 \mu \mathrm{M}$. G) The Km of NAA10 with SSQ MYL9 was $5.0 \mu \mathrm{M}$. n=3 for all experiments. All error bars represent standard deviation. 


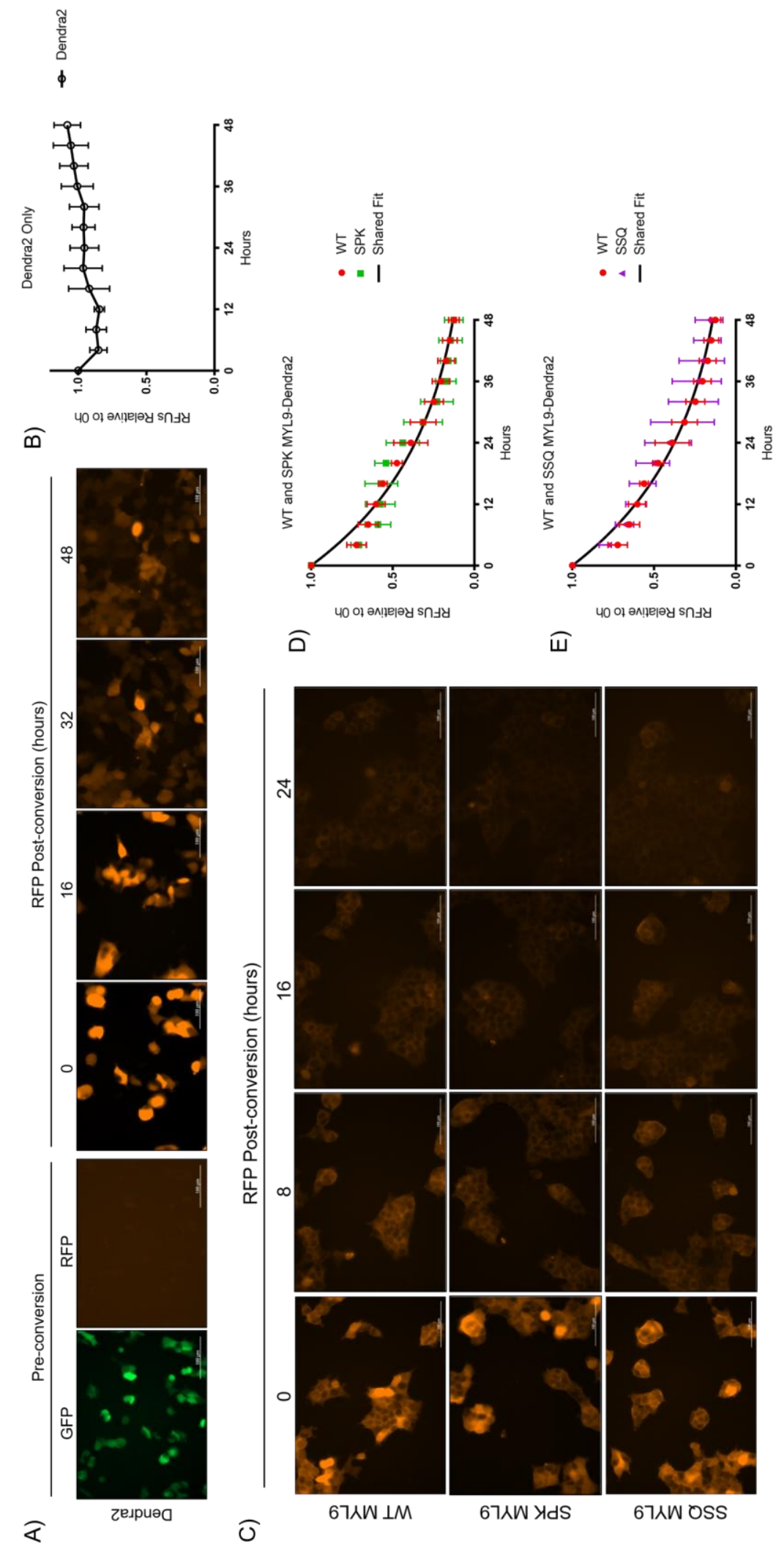


Figure 4 The half-life of MYL9 is not altered by No-PTMs. A-E) HEK293T cells were transduced with MYL9-Dendra2 or Dendra2 fluorescent protein alone. Dendra2 was photoconverted from green to red by exposure to UV light. Protein half-life was tracked by measuring RFP signal every 4 hours for 48 hours. A) Fluorescence images of cells expressing Dendra2 alone. B) The sum fluorescence intensity of Dendra2 only expressing cells is plotted over 48 hours. Individual cells show decreased RFP intensity as cell division occurs, but the sum intensity over the field of view remains constant. C) Fluorescent images of cells expressing WT or mutant MYL9-Dendra2 out to 24 hours. D,E) Fluorescent decay for WT, SPK, and SSQ MYL9 was plotted and fit to a model of one-phase exponential decay. SPK and SSQ MYL9 were each fit to an individual model of decay and a model of decay shared with WT MYL9. Individual and shared fit models were then evaluated by an extra sum-of-squares F test. For both SPK and SSQ MYL9 it was determined that a shared model of decay with WT MYL9 was as effective as an individual model, indicating no effect on stability. The half-life of MYL9 was determined to be 16.4 hours. Scale bars are $100 \mu \mathrm{m} . \mathrm{n}=3-4$ for all experiments. All error bars represent standard deviation. 


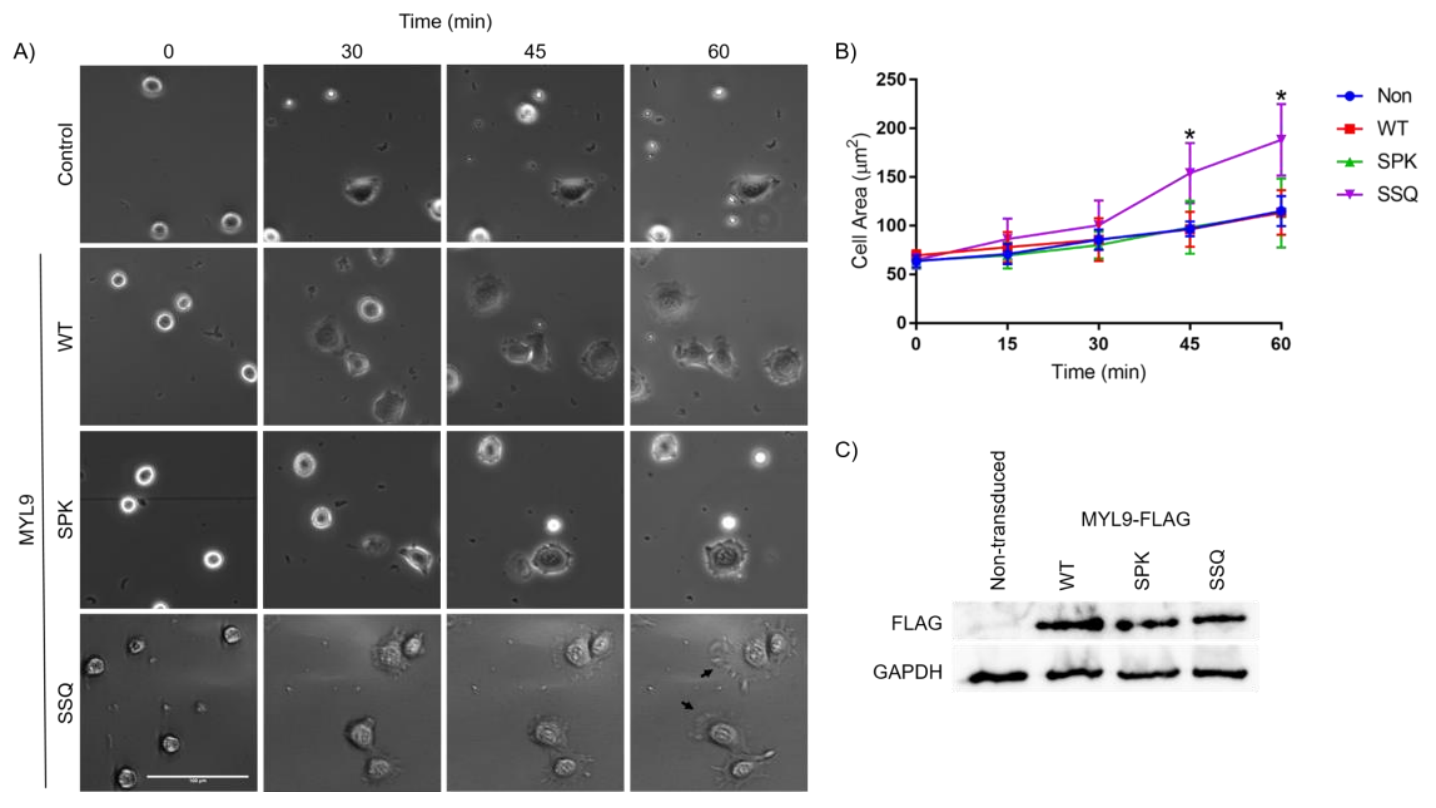


Figure 5 Loss of MYL9 Na-methylation increases cell spreading on fibronectin. A)

NIH 3 T3 mouse fibroblasts were plated in chamber slides coated with $3 \mu \mathrm{g} / \mathrm{cm}^{2}$

fibronectin and cell spreading was monitored as a measure of cytoskeletal rearrangement.

Cells were imaged every 15 minutes for 1 hour. Non-transduced control cells and cells

expressing WT or SPK MYL9 all showed comparable, modest cell spreading over 1

hour. Cells expressing the N $\alpha$-methylation deficient SSQ mutant of MYL9 showed

considerable cell spreading, with lamellipodia and filopodia (black arrows) readily

observable. Scale bar is $100 \mu \mathrm{m}$. B) Cell spreading was quantified by measuring the cell

surface area of the four largest cells per image at each time point. Each data point

represents 12 cells measured over three independent experiments $(n=3)$. Cells expressing SSQ MYL9 covered significantly greater area than all other cell lines at $45(\mathrm{p}<.01)$ and $60(\mathrm{p}<.001)$ minutes as determined by two-way random measures ANOVA with Tukey's

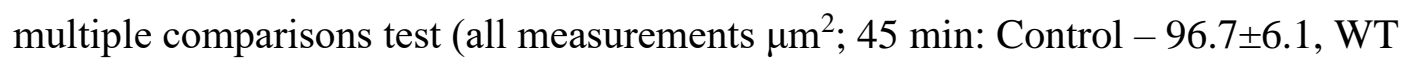

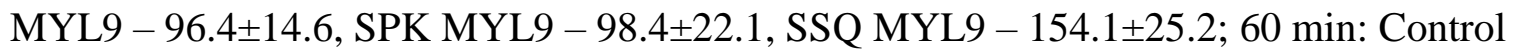

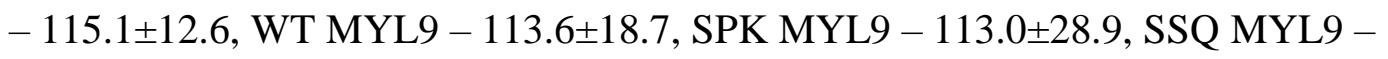
188.3 \pm 30.0 ). C) Equal expression of MYL9 variants was confirmed through Western Blotting. FLAG was used as a measure of MYL9-FLAG expression. GAPDH was used as a loading control. All error bars represent standard deviation. 
A)
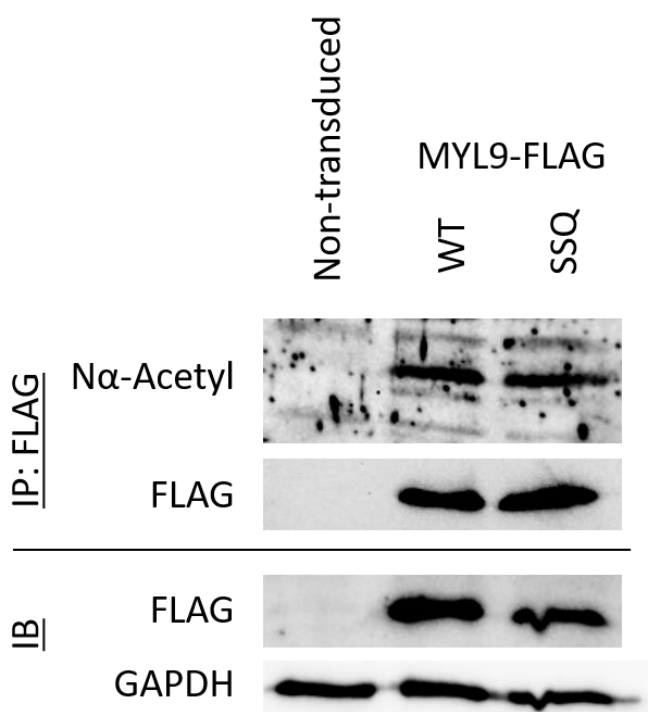

B)

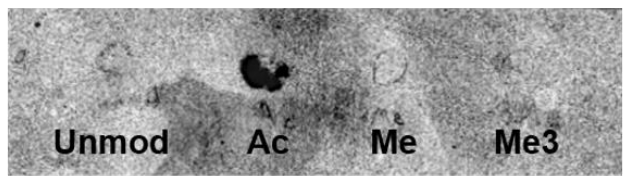


Figure 6 The SSQ mutant of MYL9 does not show increased Na-acetylation. A) To confirm that alterations in MYL9 function with the SSQ mutant are due to loss of N $\alpha$ methylation and not an increase in $\mathrm{N} \alpha$-acetylation, the degree of $\mathrm{N} \alpha$-acetylation of WT and SSQ MYL9-FLAG was probed in NIH3T3 cells. Immunoblots (IB) from input lysate of GAPDH and FLAG are shown as a loading control and as a measure of MYL9-FLAG expression, respectively. MYL9-FLAG was immunoprecipitated (IP) with anti-FLAG beads and then the levels of total MYL9-FLAG and Na-acetyl MYL9-FLAG were evaluated by Western blotting. N $\alpha$-acetylation was blotted for using a newly generated antibody raised against a synthetic $\mathrm{N} \alpha$-acetyl MYL9 peptide. N $\alpha$-acetylation of MYL9 did not increase with the SSQ mutant as compared to WT. B) A dot blot shows the specificity of the newly generated Na-acetyl MYL9 antibody (Ubf1). Synthetic N-

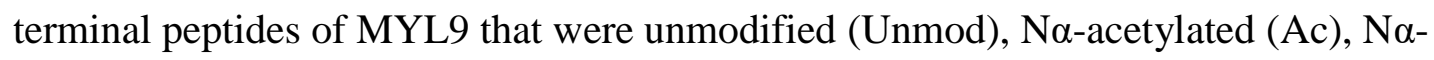
methylated (Me), or Na-trimethylated (Me3) were spotted onto a nitrocellulose membrane and then probed with Ubf1. Only the N $\alpha$-acetyl MYL9 peptide spot is detected by the Ubf1 antibody. 
A)

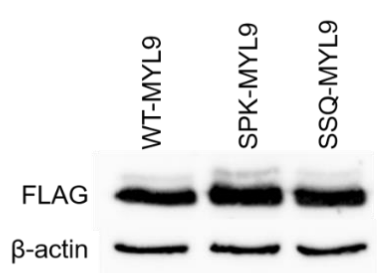

C)

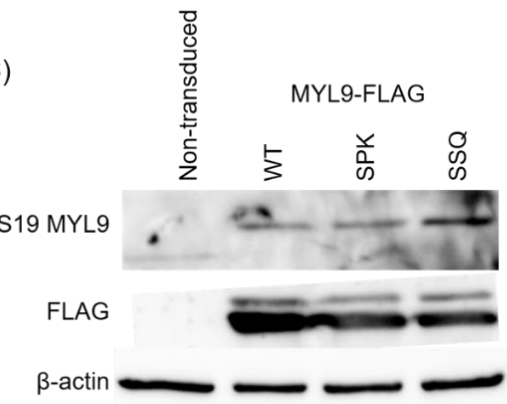

E) Non-transduced WT MYL9-FLAG

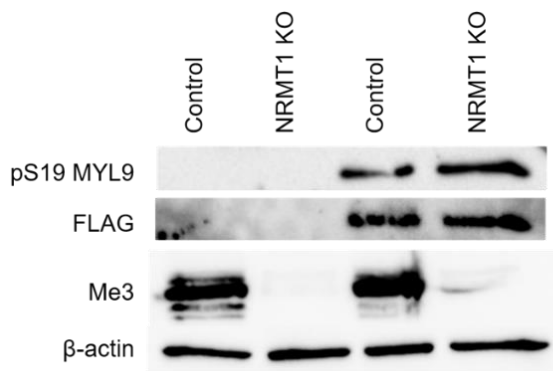

B)

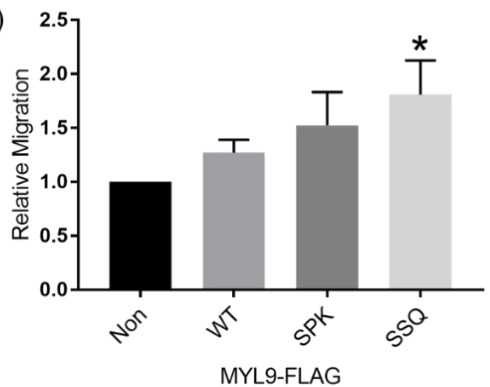

D)

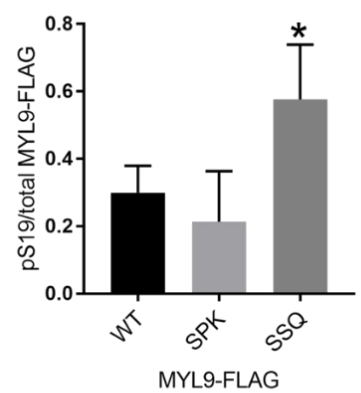

F)

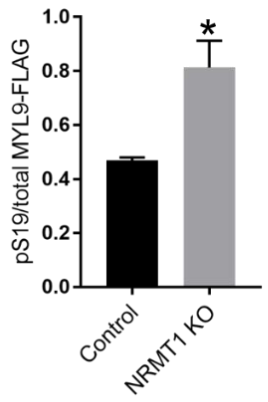


Figure 7 No-methylation limits the cytoskeletal activity of MYL9. A,B) HCT116 cells were transduced with WT or mutant MYL9-FLAG and transwell migration assays were performed. A) Western Blotting confirms that MYL9 variants were expressed at equal levels. $\beta$-actin was used as a loading control. B) Only cells expressing the nonmethylatable SSQ MYL9 mutant showed significantly greater migration than nontransduced control cells $(\mathrm{p}=.01)$, indicating enhanced cytoskeletal activity (Control 1.00, WT $-1.27 \pm 0.10, \mathrm{SPK}-1.52 \pm 0.25, \mathrm{SSQ}-1.81 \pm 0.26) . \mathrm{C}, \mathrm{D})$ To determine if phosphorylation of MYL9 is altered by Na-PTM state, HCT116 cells transduced with WT or mutant MYL9-FLAG were treated with $0.1 \mathrm{uM}$ calcimycin for 45 min to induce pS19, which promotes NMII cytoskeletal activity. C) Representative blot showing increased pS19 of the non-methylatable SSQ MYL9 mutant. FLAG blot used to determine total MYL9 protein levels. D) SSQ MYL9 had a significantly greater ratio of pS19 to total protein than SPK MYL9 (p<.05; WT - 0.30 \pm 0.06, SPK $-0.21 \pm 0.12$, SSQ $0.58 \pm 0.13)$. E,F) To further test the role of $\mathrm{N} \alpha$-methylation in the phosphorylation of MYL9, control and NRMT1 KO HCT116 cells were transduced with WT MYL9-FLAG and treated with calcimycin. E) Representative blot showing increased pS19 WT MYL9 in cells that lack Na-methylation (Me3). F) WT MYL9 in NRMT1 KO cells had a significantly greater ratio of pS19 to total protein than WT MYL9 in control cells ( $\mathrm{p}<.005$; Control $-0.47 \pm 0.01, \mathrm{NRMT} 1 \mathrm{KO}-0.81 \pm 0.08)$. One-way ANOVA with Tukey's multiple comparisons test was used for analysis of results in B and D. Results in F were analyzed by a Student's two-tailed t-test. $n=3$ for all experiments. All error bars represent standard deviation. 

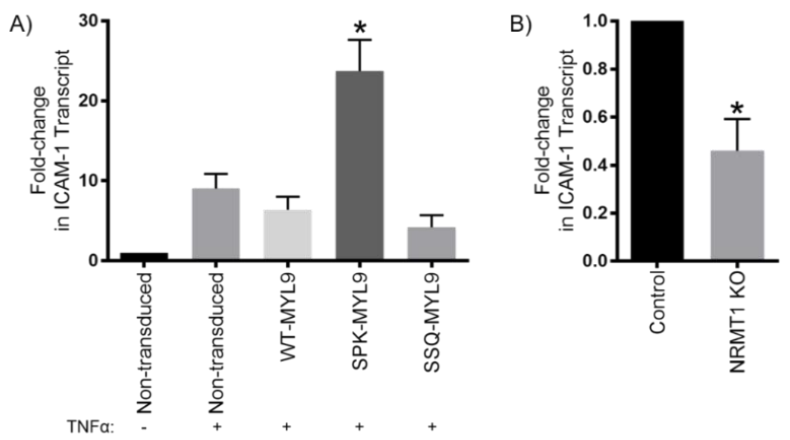

D)

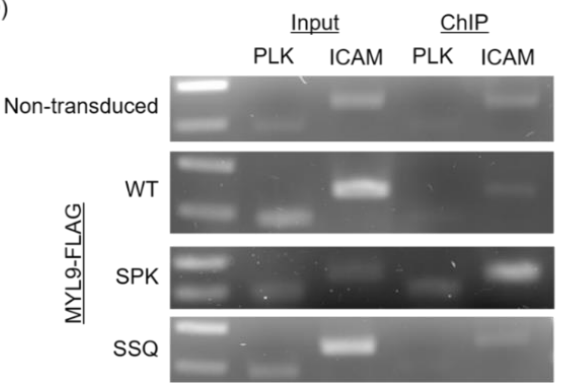

C)
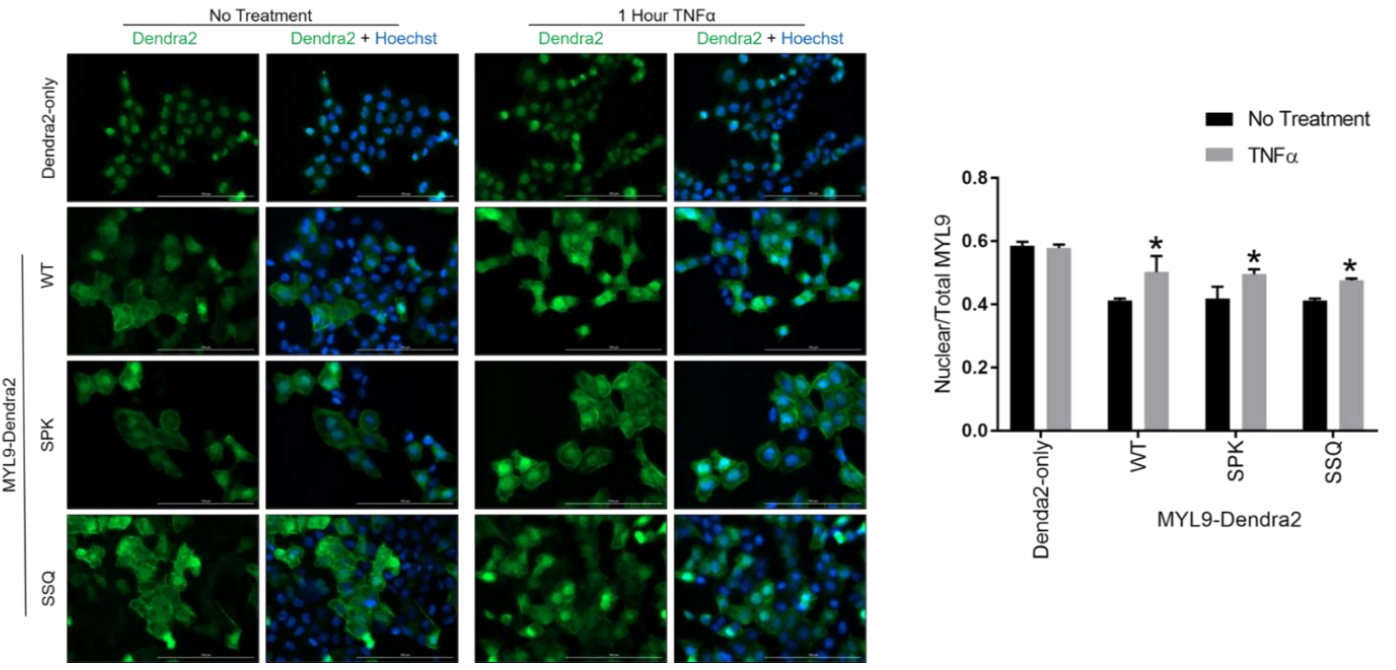
Figure 8 No-methylation promotes the transcriptional activity of MYL9. A) HCT116 cells transduced with WT or mutant MYL9-FLAG were treated with 20ng/ml TNF $\alpha$ for 2 hours before ICAM1 transcript levels were measured by qPCR. Cells expressing the N $\alpha$ methylation enriched SPK mutant of MYL9 show significantly greater transcription of ICAM1 than all other TNF $\alpha$ stimulated cell lines. Results are shown as fold-change compared to untreated, non-transduced cells, and one-way ANOVA with Tukey's multiple comparisons test was performed for statistical analysis $(\mathrm{p}<.001$; Control 9.03 $\pm 1.50, \mathrm{WT}-6.35 \pm 1.36, \mathrm{SPK}-23.71 \pm 3.21, \mathrm{SSQ}-4.18 \pm 1.23)$. B) Control and NRMT1 KO HCT116 cells were transduced with SPK MYL9-FLAG, treated with TNF $\alpha$, and ICAM1 transcript levels were measured. The induction of ICAM1 transcription by SPK MYL9 was significantly decreased in methylation-deficient NRMT1 KO cells. Results are shown as fold-change compared to treated control cells, and a Student's twotailed t-test was performed for statistical analysis $(\mathrm{p}<.005$; Control -1.00 , NRMT1 KO $0.46 \pm 0.11)$. C) To test if $\mathrm{N} \alpha$-methylation promotes nuclear localization, WT and mutant MYL9-Dendra2 proteins were transduced into HCT116 cells and treated with TNFa. Cells were fixed at $0 \mathrm{~h}$ and $1 \mathrm{~h}$ post-TNF $\alpha$ treatment, and the nuclear/total MYL9-Dendra2 ratio was calculated. All MYL9-Dendra2 protein variants showed equal increases in nuclear localization after TNF $\alpha$ treatment $(\mathrm{p}<.05)$. Control Dendra2 protein showed no change in localization upon treatment. Two-way ANOVA with Bonferroni's multiple comparisons test was used for analysis of results (Dendra2-only No Tx $-0.59 \pm 0.01$, TNF $\alpha-0.58 \pm 0.01$; WT No Tx $-0.41 \pm 0.005$, TNF $\alpha-0.50 \pm 0.04$; SPK No Tx $0.42 \pm 0.03, \mathrm{TNF} \alpha-0.50 \pm 0.01$; SSQ No Tx $-0.41 \pm 0.005, \mathrm{TNF} \alpha-0.48 \pm 0.005)$. Scale bars are $100 \mu \mathrm{m}$. D) To test if N $\alpha$-methylation promotes MYL9 binding to the ICAM1 
promoter, HCT116 cells were transduced with WT or mutant MYL9-FLAG, treated with $\mathrm{TNF} \alpha$ for $1 \mathrm{~h}$, and promoter binding was analyzed by ChIP. The PLK promoter served as an off-target control sequence. Immunoprecipitated DNA was analyzed by PCR amplification and analysis on an agarose gel. The N $\alpha$-methylation enriched SPK MYL9FLAG mutant was the only protein to result in detectable enrichment of the ICAM1 promoter sequence over input. $\mathrm{n}=3$ for all experiments. All error bars represent standard deviation. 


\title{
CHAPTER III \\ WORKING MODEL, SUPPLEMENTARY EXPERIMENTS, AND FUTURE DIRECTIONS
}

\author{
$\underline{\text { Working Model }}$ \\ Chapter II described the first study of the coordinated biological regulation of a \\ protein, MYL9, by N $\alpha$-methylation and $\mathrm{N} \alpha$-acetylation. The literature described in \\ chapter I served as a starting point from which to form hypotheses and ask questions \\ about the biochemical and functional impact of these modifications on MYL9. This \\ literature indicated that MYL9 has distinct cytoplasmic (Heissler and Sellers 2014) and \\ nuclear (Li and Sarna 2009, Zhang, Liu et al. 2015) roles, the regulation of which is \\ poorly understood. We found that, matching the nuclear compartmentalization of NRMTs \\ (Tooley and Schaner Tooley 2014), Na-methylation both promotes the nuclear function \\ of MYL9 and blocks its cytoplasmic activation (Figure 9). N $\alpha$-methylation led to \\ increased binding at the core promoter of ICAM1 and upregulated transcription of this \\ gene in response to TNF $\alpha$. This fits with previous studies of $\mathrm{N} \alpha$-methylation, which have \\ shown that this modification promotes protein-DNA interactions (Chen, Muratore et al. \\ 2007, Tooley, Petkowski et al. 2010, Cai, Fu et al. 2014). The literature also described \\ abundant instances of interaction between internal residue methylation with \\ phosphorylation (Biggar and Li 2015). We found such an interaction between Na- \\ methylation of MYL9 and serine 19 phosphorylation. Na-methylation decreased
}


phosphorylation at S19, presumably simultaneously reducing NMII activation, as this corresponded with decreased rates of cell spreading and migration, processes that require NMII driven actin filament rearrangement (Vicente-Manzanares, Ma et al. 2009).

In our studies, $\mathrm{N} \alpha$-acetylation was not required to promote MYL9 cytoplasmic functions. As indicated by our current working model (Figure 9), this has led to a new hypothesis that $\mathrm{N} \alpha$-acetylation may function to regulate the availability of MYL9 for N $\alpha$ methylation. This hypothesis is based on the cytoplasmic localization of NATs and their ability to associate with the ribosome and catalyze co-translational modification of substrates (Starheim, Gevaert et al. 2012). Dual substrates of NATs and NRMTs, such as MYL9, are available for N $\alpha$-acetylation before they localize to the nucleus and are available for $\mathrm{N} \alpha$-methylation (Aksnes, Drazic et al. 2016). As such, N $\alpha$-acetylation of MYL9 may serve to limit the pool of MYL9 that is available to be recruited for specialized nuclear function by N $\alpha$-methylation. Regulation of MYL9 by N $\alpha$-acetylation in this way would help to ensure that adequate pools of MYL9 are always available for its primary role as a regulator of NMII activity.

\section{Supplementary Experiments}

The above studies addressed the roles of $\mathrm{N} \alpha$-acetylation and $\mathrm{N} \alpha$-methylation on MYL9 stability and interaction with DNA. The literature reviewed in chapter I, however, also describes/predicts roles for $\mathrm{N} \alpha$-acetylation and $\mathrm{N} \alpha$-methylation in regulating proteinprotein interactions. We sought to address how these interactions may fit into our working model of MYL9 regulation by Na-PTMs and have begun several preliminary experiments to answer this question. 
Protein-protein interactions occur at sites of internal residue acetylation and methylation on both histone and non-histone proteins (Zhang, Wen et al. 2012, Zhang, Cooper et al. 2015). 'Reader' proteins contain conserved domains that recognize and bind these modified residues (Taverna, Li et al. 2007). To date, no conserved domains that recognize $\mathrm{N} \alpha$-methylation or $\mathrm{N} \alpha$-acetylation have been described. Several instances of protein-protein interactions have been described that directly involve acetylated Ntermini, but such interactions have yet to be experimentally demonstrated for methylated $\mathrm{N}$-termini. One pressing question is if known reader domains of internal methylation and acetylation can also recognize alpha-amino modifications.

To address whether any known reader domains recognize and bind the methylated or acetylated alpha-amino group of MYL9, an in vitro binding screen was performed. Experiments were carried out at the MD Anderson Protein Array and Analysis Core under the direction of Dr. Mark Bedford. Arrays of recombinant methyl or acetyl reader domains were immobilized on chips using an Aushon 2470 Arrayer. The methyl reader array consisted of 104 unique domain constructs (Figure 10A) and the acetyl reader array consisted of 30 unique domain constructs (Figure 10B). Biotinylated N-terminal peptides of MYL9 were synthesized and flowed over the reader chips. Unmodified, mono, and tri methylated MYL9 peptides were tested for binding on the methyl reader array. Unmodified and acetylated MYL9 peptides were tested for binding on the acetyl reader array. Peptides that bound reader domains were then detected using streptavidinAlexaFluor488 and visualized using a Molecular Probes GenePix 4400A MicroArray Scanner. 
No known methyl or acetyl reader domains (except two "sticky" domains that commonly show non-specific hydrophobic interactions with peptides; unpublished data, Dr. Mark Bedford) showed affinity for modified MYL9 peptides (Figure 10C, D). Domain families tested with the methyl reader array included Tudor, PHD, chromo, PWWP, MBT, AGENET, and BAH. The acetyl reader array tested the bromo and YEATS domain families. Together, these represent a thorough screen of known methylation and acetylation binding modules (Gardner, Allis et al. 2011). Similar in vitro reader domain and peptide arrays have helped to decipher the histone code and have also been utilized to find novel non-histone protein-protein interactions (Espejo, Cote et al. 2002, Shanle, Shinsky et al. 2017), showing the validity of this method. For that reason, it is likely that N $\alpha$-methylated and No-acetylated MYL9 are not being read by previously described domains. While this result is specific to MYL9, it seems possible that it may hold true for $\mathrm{N} \alpha-\mathrm{PTM}$ in general, as the $\mathrm{N}$-terminal $\alpha$-amine presents a considerably different steric environment than is found at the $\varepsilon$-amine of lysine or at the guanidino group of arginine. In addition, the affinity of reader domains for internal modifications can be influenced by neighboring residue identity (Taverna, Li et al. 2007), highlighting the importance of protein sequence context in these interactions. N $\alpha$-PTMs present a unique sequence context as compared to all internal PTMs, and this may play a role in the lack of binding observed in our study.

It is quite possible that unique protein domains specifically recognize and bind $\mathrm{N} \alpha$-methylation and $\mathrm{N} \alpha$-acetylation. To test this hypothesis for MYL9, I performed an unbiased pull-down screen for modification-specific interactors in HEK293 cells using stable isotope labeling of amino acids in cell culture (SILAC) LC-MS/MS. Briefly, cells 
were grown in normal media (light) or media supplemented with ${ }^{13} \mathrm{C}$ labeled lysine (heavy) for 8 passages. This resulted in $98.9 \%$ incorporation of isotopically labeled lysine into proteins of cells grown in heavy media as determined by LC-MS/MS. For pulldowns, synthetic 14 amino acid N-terminal peptides of MYL9 were synthesized in an unmodified, $\mathrm{N} \alpha$-acetylated, $\mathrm{N} \alpha$-monomethylated, and $\mathrm{N} \alpha$-trimethylated state. All peptides were synthesized with a C-terminal biotin moiety, allowing them to be linked to M280 streptavidin Dynabeads. Pulldowns with unmodified MYL9 peptide were performed using protein lysate harvested from cells grown in light media. Separate pulldowns were performed with acetylated, monomethylated, or trimethylated MYL9 peptides using heavy isotope labeled protein lysate. Each pull-down was performed with $20 \mu \mathrm{g}$ of peptide and $300 \mu \mathrm{g}$ of protein lysate. After pull-downs, beads were washed and then bound protein was eluted in Laemilli buffer. For analysis, elutions from each modified peptide pull-down were mixed with an elution from an unmodified peptide pulldown. This generated three samples that each contained light proteins that interacted with unmodified MYL9 and heavy proteins that interacted with one of the forms of modified MYL9, allowing for a quantitative comparison of interactors based on modification state. Samples were then resolved by SDS-PAGE, in-gel trypsin digested, and subjected to LC-MS/MS using a NanoAcquity HPLC system interfaced to a ThermoFisher Q Exactive mass spectrometer. LC-MS/MS and subsequent data analysis were performed by MS Bioworks.

Each sample yielded approximately 1,300 protein identifications, with 1,611 total proteins identified across all three sample pairs. Only proteins that had a SILAC ratio (peptides identified in both light and heavy states) were included for further analysis, 
resulting in approximately 650 proteins per sample pair. Interactions of interest were further selected by setting a cut-off of a three-fold change in the SILAC ratio (0.33>heavy/light>3). Interestingly, all modification states of MYL9 predominantly reduced protein-protein interactions and this was particularly evident for monomethylated and trimethylated MYL9 (Figure 11A). Because we were interested in identifying readers of $\mathrm{N} \alpha$-PTMs, I selected 3 of the 8 candidate interactors that showed increased binding to modified MYL9 (increased heavy/light ratio) for further validation by peptide pull-downs followed by Western blot. These included the proteasomal subunit PSMD7, the 7SK snRNP subunit HEXIM2, and the adapter protein 14-3-3 $\sigma$ (Figure 11B). Contrary to the SILAC results, PSMD7 and HEXIM2 each showed equal binding to all forms of the MYL9 peptide by Western blotting, while 14-3-3 $\sigma$ failed to show detectable binding to any of the MYL9 peptides (Figure 11C). These results indicate that the small number of enhanced binding interactions seen with modified MYL9 as compared to unmodified MYL9 may have been artefactual.

Mono and trimethylated MYL9 peptides each showed approximately 300 downregulated interactions in the SILAC pulldown screen as compared to unmodified MYL9 peptide (Figure 11A). Meanwhile, acetylated MYL9 peptide only showed 22 downregulated protein interactions as compared to unmodified MYL9 peptide (Figure 11A). This suggests that the blocking of protein-protein interactions, as opposed to promoting of protein-protein interactions, may be an important regulatory feature of MYL9 Na-methylation. To initially confirm the SILAC screen findings concerning downregulated interactions, the interaction of Cofilin-1, a regulator of actin polymerization, with MYL9 peptides was evaluated by peptide pull-down and Western 
blot. Cofilin-1 showed just over 2-fold reduction in binding to mono and trimethylated MYL9 peptides as compared to unmodified MYL9 (Figure 11C), supporting the SILAC screen result (Figure 11D).

The large number of interactions downregulated by Na-methylation of MYL9 was initially perplexing. However, functional studies of MYL9 Na-PTMs showed that methylation blocked the cytoplasmic functions of MYL9, specifically those of migration and cell spreading, while favoring its nuclear function as a transcriptional activator

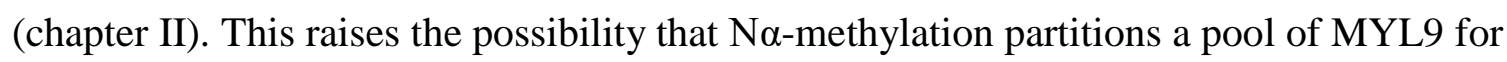
nuclear rather than cytoplasmic activity in part by blocking protein interactions necessary for cytoplasmic function. This is an intriguing possibility, as compartmental-specific functional roles were observed for N $\alpha$-methylated MYL9 but no corresponding alteration in cellular localization was seen. An increase in protein-DNA interactions was shown to facilitate the nuclear function of N $\alpha$-methylated MYL9. As such, regulation of molecular interactions, including protein-protein interactions, may explain how compartmental specific roles are regulated by Na-PTMs despite the lack of strict compartmental localization. It will be interesting to see if further downregulated interactions are confirmed and if these are functionally related to the blocking of MYL9's cytoplasmic activity.

\section{$\underline{\text { Future Directions }}$}

Blocking of MYL9 protein-protein interactions by Na-methylation could potentially elucidate the mechanism behind the decrease in S19 phosphorylation associated with this modification. Decreased affinity of S19 kinases for N $\alpha$-methylated 
MYL9 would lead to decreased S19 phosphorylation. However, these particular interactions would not be identified by the above SILAC screen, as the pulldown peptides only corresponded to the first 14 amino acids of MYL9. Additionally, kinase-substrate interactions are difficult to capture by pulldown and co-immunoprecipitation techniques because of the transient nature of these interactions. For this reason, in vitro enzyme assays that evaluate the ability of kinases, such as MLCK or ROCK, to modify an $\mathrm{N} \alpha$ methylated MYL9 peptide would provide a viable first step to follow-up on this mechanism. If kinase activity was seen to be decreased by MYL9 N $\alpha$-methylation, the role of protein-protein interactions in this could be further investigated through the use of biophysical methods, such as isothermal titration calorimetry. An alternative mechanism could be the altered interaction of MYL9 with serine/threonine phosphatases. Namethylation favoring an interaction of MYL9 with the phosphatase MLCP at serine 19 would explain the effect on phosphorylation observed, but this does not fit with the SILAC screen findings that show $\mathrm{N} \alpha$-methylation as predominantly blocking proteinprotein interactions.

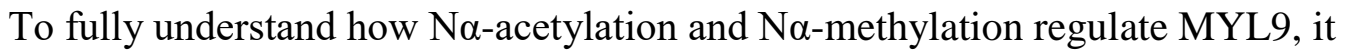
will be important to gain a better understanding of the occurrence of these modifications. It would be of great interest to know if the relative ratio of unmodified, N $\alpha$-acetyl, and Na-methyl MYL9 is constant or shows variation by cell type, tissue, or through development. The functional diversity of NMII in humans is increased by the expression of three distinct isoforms, each of which have small but important differences in functionality (Betapudi 2014). This is highlighted by the fact that NMIIA KO in mice is lethal at embryonic day 6.5 (E6.5) (Conti, Even-Ram et al. 2004), while NMIIB KO is 
lethal at E14.5 (Tullio, Accili et al. 1997, Tullio, Bridgman et al. 2001), and mice with NMIIC KO can live into adulthood (Ma, Jana et al. 2010). Additionally, NMII isoform expression varies by cell type, and isoforms have been shown to participate in distinct cellular functions (Newell-Litwa, Horwitz et al. 2015). The Na-PTMs of MYL9 may similarly function to increase NMII functional diversity in subtle but significant ways. Characterizing the Na-PTM state of MYL9 in numerous settings would be an invaluable tool for generating hypotheses related to the function of these modifications.

We attempted to quantify the relative ratio of unmodified, N $\alpha$-methylated, and Na-acetylated MYL9 in HEK293 cells through mass spectrometry. However, the ability to quantify the abundance of MYL9 Na-PTMs proved to be technically limited by the ability to detect the N-terminal peptide with enough abundance to generate reliable comparisons between $\mathrm{N} \alpha$-PTM states. Immunoaffinity enrichment for a particular N $\alpha$ PTM state, such as by using the Ubf1 Na-acetyl MYL9 antibody, could be used to increase the detection of the N-terminal peptide, but this methodology would not facilitate the quantitative comparison of multiple N $\alpha$-PTM states. This method could, however, be employed to track how the abundance of a single N $\alpha$-PTM varies across conditions, such as through development or in a disease setting.

A key question regarding protein regulation by Na-PTMs is if these modifications are dynamic and reversible. To date, no erasers of $\mathrm{N} \alpha$-methylation or $\mathrm{N} \alpha$-acetylation have been identified. This is surprising given that protein methylation and acetylation occurring on internal residues are subject to removal by a number of eraser enzymes (Gardner, Allis et al. 2011, Choudhary, Weinert et al. 2014, Biggar and Li 2015). The presence of erasers allows the regulatory impact of these internal modifications to be 
reversed, creating a tunable system for protein regulation that involves a balance between the activity of writers and erasers (Torres and Fujimori 2015). It is quite possible that erasers of $\mathrm{N} \alpha$-methylation and $\mathrm{N} \alpha$-acetylation exist but have yet to be identified. The occurrence of Na-methylation was first recognized in the 1970s (Pettigrew and Smith 1977), but the responsible enzymes were not identified until 2010 (Tooley, Petkowski et al. 2010).

The presence of a N $\alpha$-PTM erasers could be assayed for by testing for activity in cell lysate fractions. Such a method was employed in the identification of NRMT1 (Tooley, Petkowski et al. 2010). The eraser identification assay would involve producing pre-modified recombinant proteins and then incubating them with cell fractions separated by chromatography. Pre-modified proteins could be generated using a yeast protein expression system that also overexpresses an Na-PTM modifying enzyme (Johnson, Geeves et al. 2013). Enzymatic removal of Na-PTMs could be assayed for after incubation with cell fractions through the use of subtiligase. Subtiligase is an engineered enzyme that can be employed to ligate biotin to free protein alpha-amino groups (Wiita, Seaman et al. 2014), and it has previously been used to detect changes in the abundance of $\mathrm{N \alpha}$-acetylation (Yi, Pan et al. 2011). A cell fraction that has eraser activity would result in an increase in free alpha-amino termini and subsequent biotinylation by subtiligase. Western blotting and detecting of biotin with streptavidin-HRP could be used to analyze changes in the abundance of free alpha amino termini and thus cell fractions that show eraser activity. To avoid an increase in signal from contaminants in the cell fraction, the pre-modified recombinant protein could be C-terminally tagged, allowing for this test protein to be immunopurified before analysis. This methodology has the 
advantage of being applicable to the search for erasers of any $\mathrm{N} \alpha-\mathrm{PTM}$, with the selectivity of the assay being determined by the modification placed on the recombinant test protein. It is also independent from the need of modification-specific antibodies for each substrate/PTM pair tested.

The possibility that erasers of $\mathrm{N} \alpha$-methylation and $\mathrm{N} \alpha$-acetylation are not present must also be considered. In this scenario, proteins would be stably N $\alpha$-modified until degradation. As such, one possibility is that the regulatory nature of Na-PTMs is to stably increase protein functional diversity, creating pools of biochemically distinct proteins from a single gene product. In this model, non-reversible PTMs can be conceptually likened to alternative splicing, which is capable of producing distinct protein isoforms from a single gene. Whether $\mathrm{N} \alpha$-methylation and $\mathrm{N} \alpha$-acetylation prove to be stable or reversible modifications remains to be seen.

As was described in the current working model, it is likely that the degree to which MYL9 is N $\alpha$-acetylated is a determinant of the abundance of its $\mathrm{N} \alpha$-methylation. This would be especially true if the modifications are static and there are no $\mathrm{N} \alpha$-erasers. Interplay between the occurrence of these modifications, in which one N $\alpha$-PTM blocks the availability of the alpha-amino group for the opposing modification, has implications for the regulation of MYL9 and other dual modified substrates in a number of scenarios. Metabolic state is linked to the global occurrence of protein acetylation through fluctuation of acetyl-CoA levels (Choudhary, Weinert et al. 2014). Acetyl-CoA is an essential cofactor employed by acetyltransferases and is also a key metabolic intermediate in glycolysis and fatty acid $\beta$-oxidation (Lin, Su et al. 2012). Glucose availability has been shown to impact histone acetylation in a manner that requires ATP- 
citrate lyase, which converts glucose derived citrate into acetyl-CoA, establishing a link between carbon source utilization and the enzymatic deposition of protein acetylation (Wellen, Hatzivassiliou et al. 2009). A link between acetyl-CoA levels and Naacetylation of apoptotic proteins was shown in several mammalian cell lines, establishing that NAT activity is also sensitive to metabolic state (Yi, Pan et al. 2011). The link between acetyl-CoA availability and $\mathrm{N} \alpha$-acetylation has been suggested to alter cell biology in both normal development and cancer transformation as metabolic profiles shift during these processes (Silva and Martinho 2015). The occurrence of substrates that are dual targets of NATs and NRMTs suggests that metabolic alterations that impact acetylation levels will have an inverse effect on methylation levels. How metabolism impacts the interplay of $\mathrm{N} \alpha$-acetylation and $\mathrm{N} \alpha$-methylation and ultimately protein regulation will be an important area of continued research.

The relevance of interplay between $\mathrm{N} \alpha$-acetylation and $\mathrm{N} \alpha$-methylation extends beyond metabolite availability. Several disorders are associated with mutations in NatA. Children with the X-linked lethal disorder Ogden syndrome harbor a causal S37P mutation in NAA10, the catalytic subunit of NatA (Rope, Wang et al. 2011). This mutation results in a reduction in the degree of $\mathrm{N} \alpha$-acetylation of NatA substrates, leading to severe global developmental delays (Van Damme, Stove et al. 2014, Myklebust, Van Damme et al. 2015). Additional mutations in NAA10, including R116W, $\mathrm{R} 83 \mathrm{C}$, and F128L cause disorders that are characterized by intellectual disabilities and developmental delays (Rauch, Wieczorek et al. 2012, Saunier, Stove et al. 2016). The pathology of these disorders is associated with $\mathrm{N} \alpha$-acetylation deficiency, but the mechanistic consequences of this deficiency are not understood at the substrate level. It 
would be of great interest to know if disease-associated NatA mutations that lead to a loss of $\mathrm{N} \alpha$-acetylation also result in a subsequent increase in $\mathrm{N} \alpha$-methylation. Studies that address this question would contribute to a mechanistic understanding of protein dysregulation in NAT disorders.

Numerous cancers are associated with dysregulated expression of MYL9 or its upstream kinases (Newell-Litwa, Horwitz et al. 2015), showing that precise regulation of MYL9 is crucial to proper cell function. Additionally, altered expression of both NRMTs and NATs are found in cancers, but their mechanistic contribution to disease progression is not yet understood. NRMT expression is low in testicular and breast cancers, but high in colorectal cancers and lymphoma (Tooley and Schaner Tooley 2014). Supporting a mechanistic role for NRMT in cancer progression, tumorigenesis was greatly favored by NRMT1 KD in a breast cancer xenograft study using MCF-7 cells (Bonsignore, Butler et al. 2015). NatA has been found overexpressed in both colorectal and breast cancer (Kalvik and Arnesen 2013), and NatA overexpression has been shown to be sufficient to drive transformation in lung and colorectal cells (Ren, Jiang et al. 2008, Lee, Ou et al. 2010). Clearly, precise regulation of MYL9, N $\alpha$-methylation, and $\mathrm{N} \alpha$-acetylation are all required for proper cell function. As such, understanding the specific regulation of MYL9 by $\mathrm{N} \alpha$-methylation and $\mathrm{N} \alpha$-acetylation, and how this regulation is altered in disease, is likely to provide novel insights into disease related mechanisms.

In this dissertation, I first demonstrated that, contrary to current models, neither $\mathrm{N} \alpha$-acetylation nor $\mathrm{N} \alpha$-methylation affect the half-life of MYL9. I then went on to show that $\mathrm{N} \alpha$-PTMs regulate the distinct functions of MYL9 in the cytoplasm and nucleus. N $\alpha-$ methylation favors the specialized function of MYL9 as a transcription factor in the 
nucleus by promoting its interaction with the ICAM1 promotor. Simultaneously, $\mathrm{N} \alpha-$ methylation limited MYL9 phosphorylation at serine 19, leading to decreased cytoskeletal activity. Preliminary data also indicates that $\mathrm{N} \alpha$-methylation may block protein-protein interactions of MYL9 to regulate this functional switch. Though $\mathrm{N} \alpha$ methylated and N $\alpha$-acetylated forms of MYL9 were seen to be functionally distinct, the role of $\mathrm{N} \alpha$-acetylation remains unclear. I propose a model in which $\mathrm{N} \alpha$-acetylation governs the degree to which MYL9 is available for N $\alpha$-methylation. Such an interplay between $\mathrm{N} \alpha$-acetylation and $\mathrm{N} \alpha$-methylation would have large ramifications for both normal cell biology and in multiple disease settings. In all, I have shown that $\mathrm{N} \alpha$ methylation and $\mathrm{N} \alpha$-acetylation are distinct and important regulators of MYL9 function. In addition to further studying the role of these modifications for MYL9, the regulatory paradigms I have described should guide future studies of other dual NRMT and Nat substrates. Conducting further substrate level studies of protein regulation by $\mathrm{N} \alpha-\mathrm{PTMs}$ will be key to understanding how these modifications contribute to cellular function and disease. 


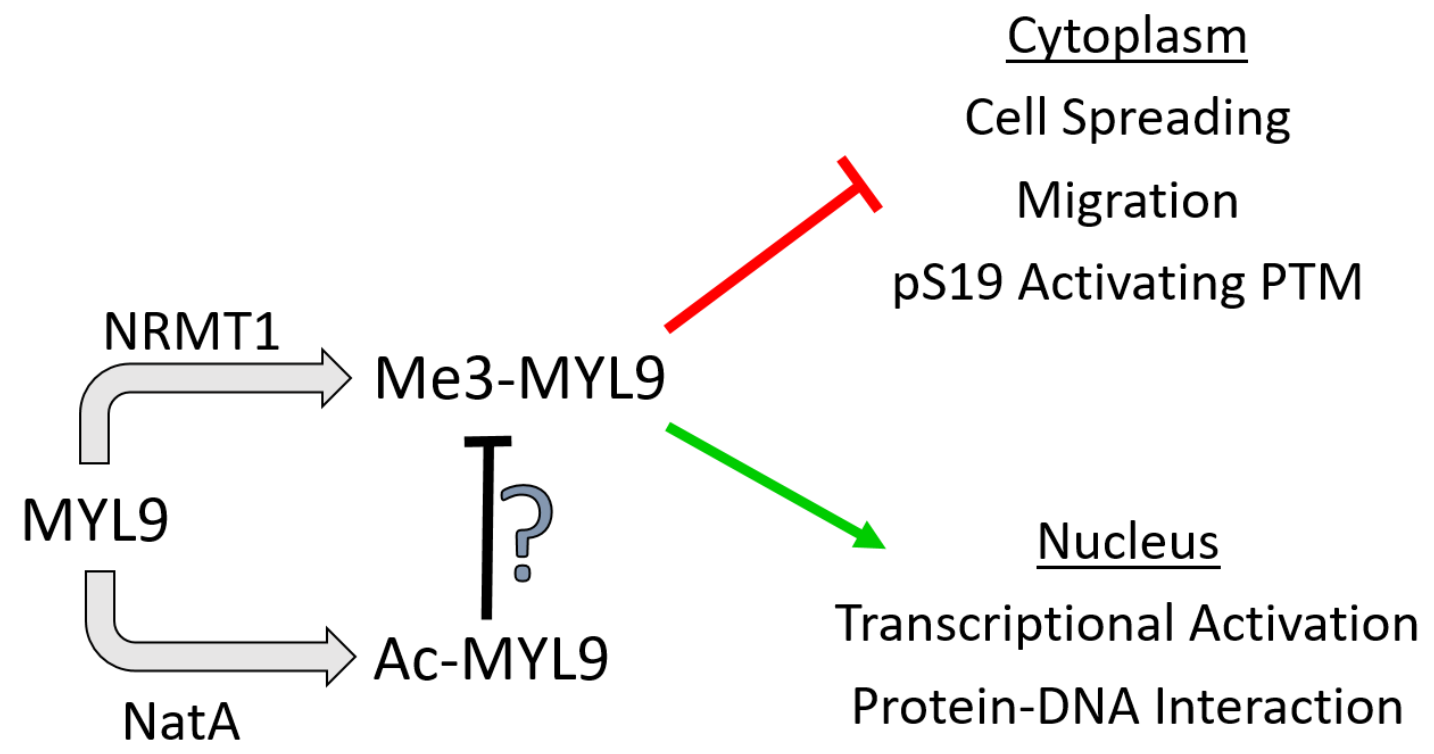


Figure 9 No-methylation facilitates the nuclear function of MYL9 by both blocking its cytoplasmic activation and favoring its interaction with DNA. MYL9

predominantly functions in the cytoplasm as a regulator of cytoskeletal dynamics through its association with non-muscle myosin II. N $\alpha$-methylation of MYL9 was found to decrease its phosphorylation at serine 19, a crucial activating PTM, while simultaneously leading to a decrease in cell spreading and migration, functions that require active cytoskeletal rearrangement. In the nucleus, Na-methylation of MYL9 led to increased binding to the ICAM1 promoter and transcription of the ICAM1 gene. Taken together, these results show that N $\alpha$-methylation favors a specialized nuclear activity of MYL9 by both blocking its canonical functions and promoting its interaction with DNA. N $\alpha$ acetylation of MYL9 was not required for the functions examined. Because N $\alpha$ acetylation can occur co-translationally, this modification may serve to block the $\mathrm{N} \alpha$ methylation of MYL9 and as such limit the pool of MYL9 that is available for recruitment to nuclear function. 

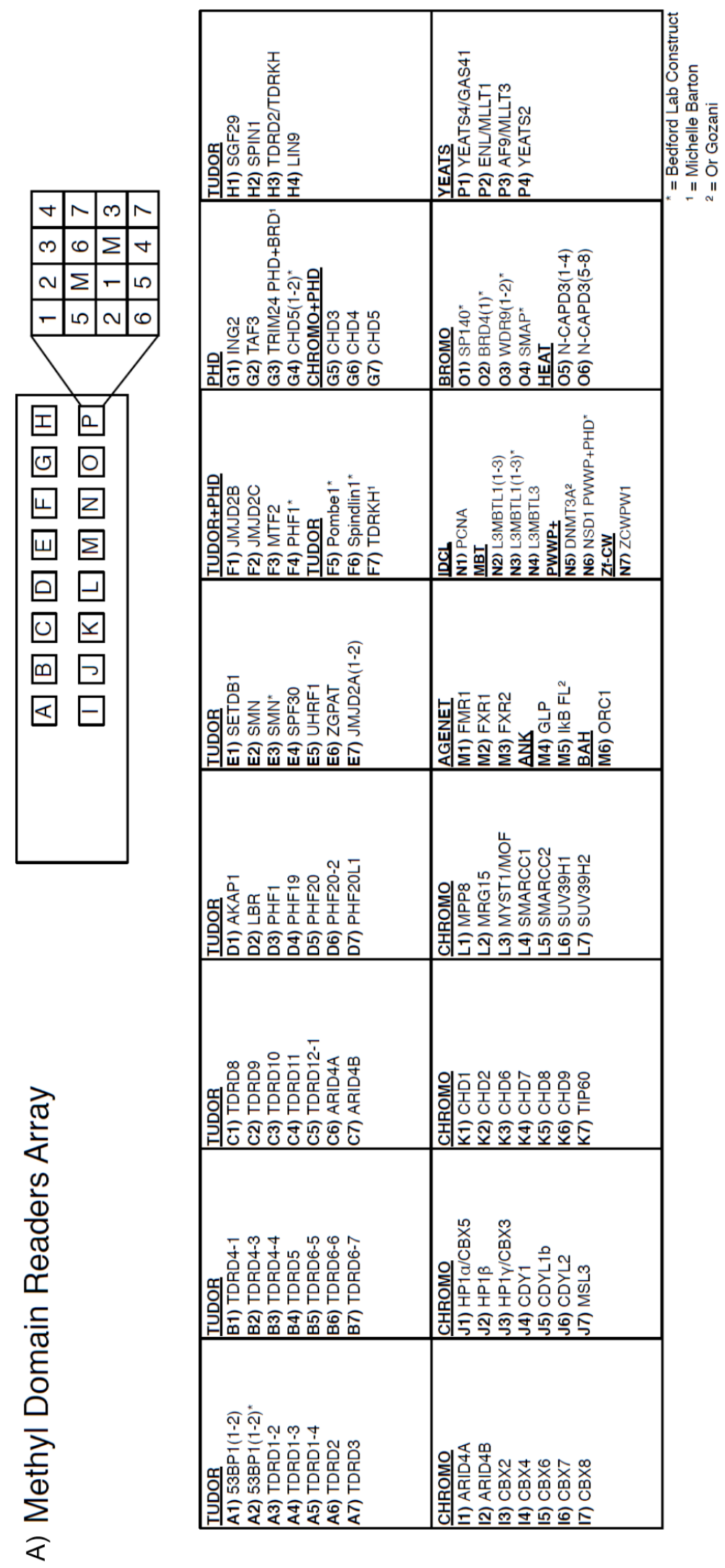


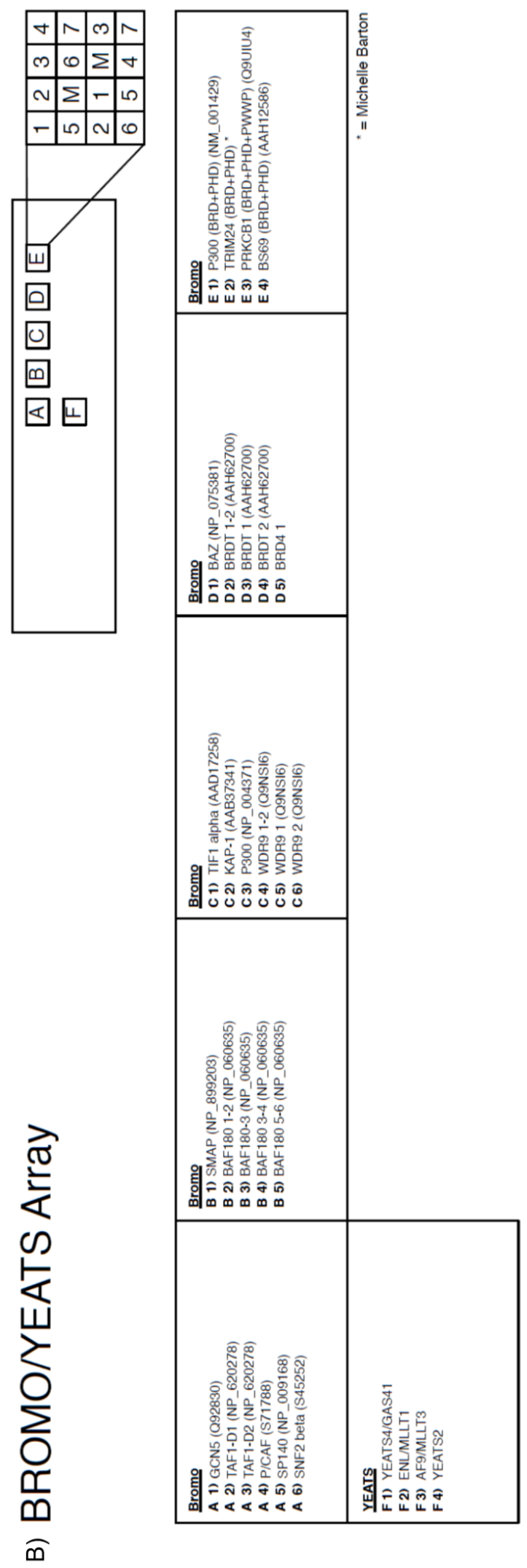




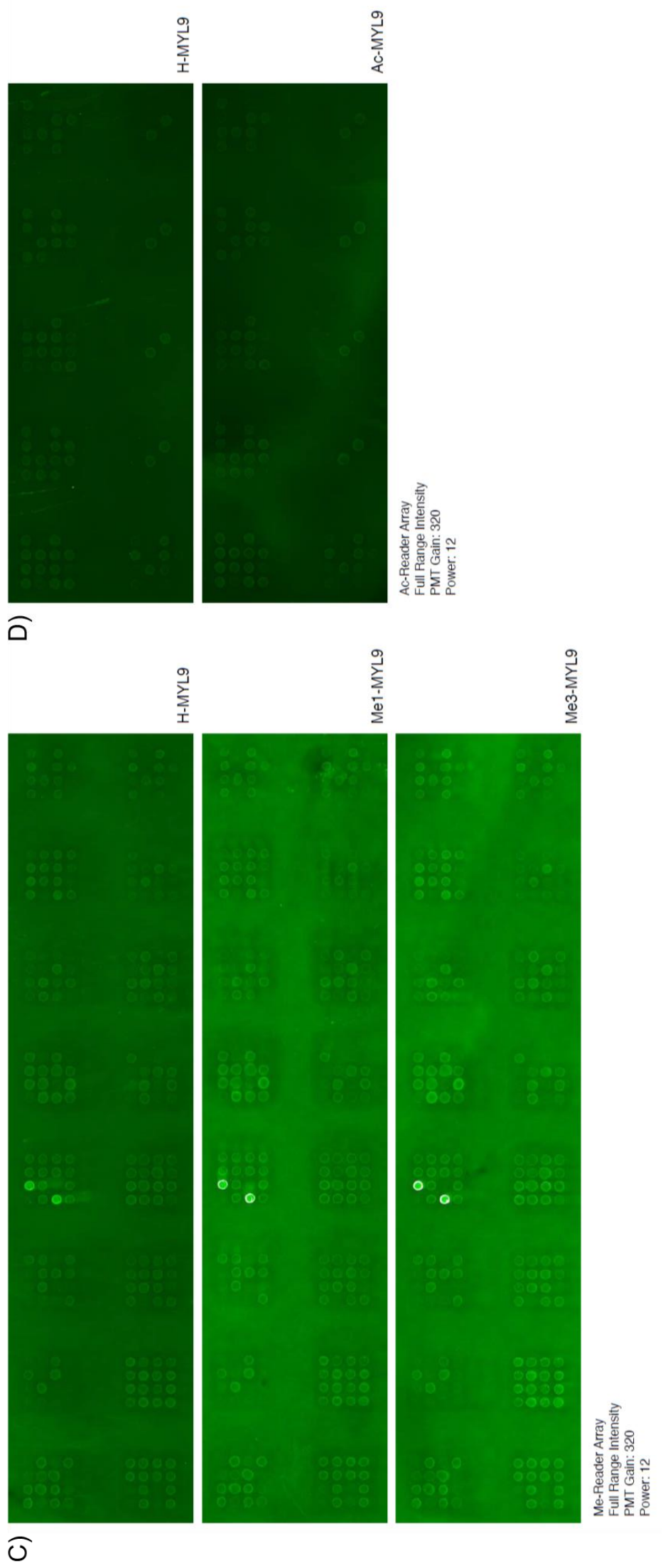


Figure 10 Known methyl and acetyl reader domains do not bind Na-PTMs.

Recombinant methyl (A) and acetyl (B) reader domains were immobilized on a microarray chip. C,D) Biotinylated unmodified and modified peptides of MYL9 were flowed over the microarray. Bound peptide was detected with streptavidin-AF488. N $\alpha$ PTMs of MYL9 were not specifically bound by any of the tested reader domains. C) Non-specific binding was observed for all forms of MYL9 peptide to the Tudor domain from the LBR protein (chip 4, positions 2 and 9). This protein module is recognized as consistently undergoing non-specific interactions (unpublished data, Dr. Mark Bedford). 

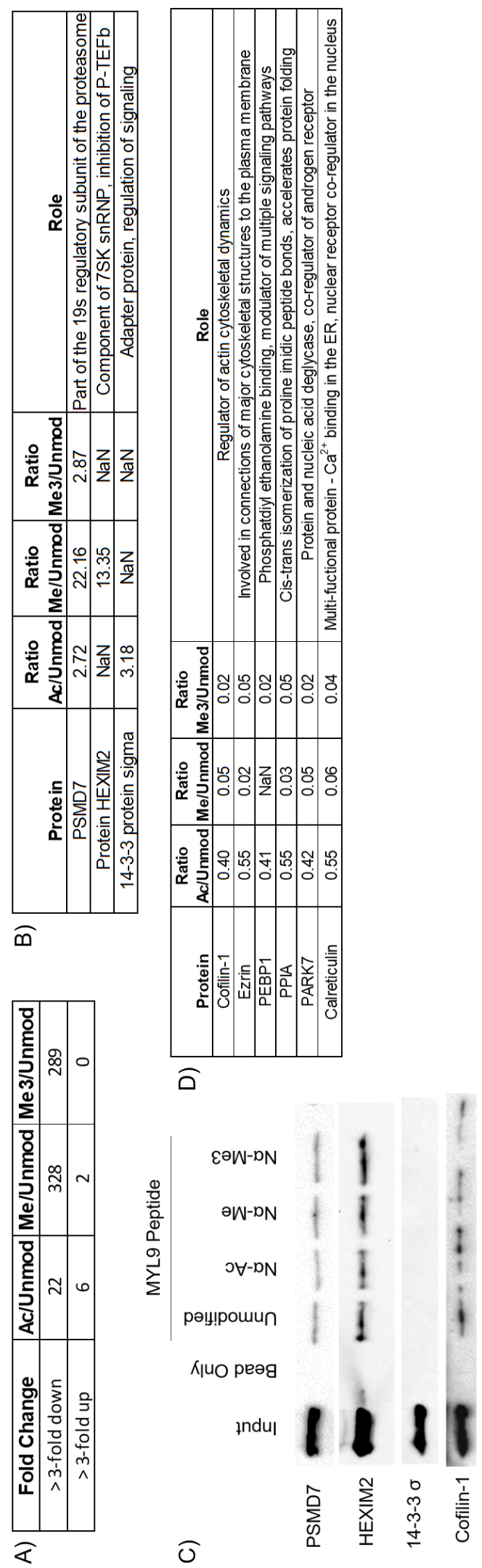


\section{Figure 11 SILAC screen identifies Na-methylation as an inhibitor of MYL9 protein-}

protein interactions. Synthetic peptides of MYL9 that were unmodified, or alpha-amino acetylated, monomethylated, or trimethylated were used to pulldown interactors from light or heavy isotope labeled HEK293 protein lysates. Each modified MYL9 pulldown was combined with an unmodified MYL9 pulldown and changes in interactions were quantified by SILAC LC-MS/MS. A) Few increases in interactions were seen with any modification of MYL9. Notably, both mono and trimethylation led to widespread blocking of interactions. B) Several proteins of interest that showed upregulated interaction with MYL9 modifications were selected for verification by Western blot. C) Western blots of pulldowns failed to confirm the increased interactions reported by the SILAC screen for PSMD7, HEXIM2, and 14-3-3 $\sigma$, indicating that the small number of increased interactions reported may be artefacts. D) Several proteins of interest that showed downregulated interaction with Na-methylated MYL9 are highlighted. Both mono and trimethylation led to a large decrease in interactions with diverse proteins, including those associated with cytoskeletal and transcriptional regulation. A decrease in Cofilin-1 interaction with methylated MYL9 was confirmed by Western blotting (C). 


\section{REFERENCES}

Accili, D. and K. C. Arden (2004). "FoxOs at the crossroads of cellular metabolism, differentiation, and transformation." Cell 117(4): 421-426.

Adam, V., K. Nienhaus, D. Bourgeois and G. U. Nienhaus (2009). "Structural basis of enhanced photoconversion yield in green fluorescent protein-like protein Dendra2." Biochemistry 48(22): 4905-4915.

Adelstein, R. S. and M. A. Conti (1975). "Phosphorylation of platelet myosin increases actin-activated myosin ATPase activity." Nature 256(5518): 597-598.

Aksnes, H., A. Drazic, M. Marie and T. Arnesen (2016). "First Things First: Vital Protein Marks by N-Terminal Acetyltransferases." Trends Biochem Sci 41(9): 746-760.

Aksnes, H., P. Van Damme, M. Goris, K. K. Starheim, M. Marie, S. I. Stove, C. Hoel, T. V. Kalvik, K. Hole, N. Glomnes, C. Furnes, S. Ljostveit, M. Ziegler, M. Niere, K. Gevaert and T. Arnesen (2015). "An organellar nalpha-acetyltransferase, naa60, acetylates cytosolic $\mathrm{N}$ termini of transmembrane proteins and maintains Golgi integrity." Cell Rep 10(8): 1362-1374.

Amano, M., M. Ito, K. Kimura, Y. Fukata, K. Chihara, T. Nakano, Y. Matsuura and K. Kaibuchi (1996). "Phosphorylation and activation of myosin by Rho-associated kinase (Rho-kinase)." J Biol Chem 271(34): 20246-20249. 
Aoki, M., H. Jiang and P. K. Vogt (2004). "Proteasomal degradation of the FoxO1 transcriptional regulator in cells transformed by the P3k and Akt oncoproteins." Proc Natl Acad Sci U S A 101(37): 13613-13617.

Arnesen, T., K. K. Starheim, P. Van Damme, R. Evjenth, H. Dinh, M. J. Betts, A. Ryningen, J. Vandekerckhove, K. Gevaert and D. Anderson (2010). "The chaperone-like protein HYPK acts together with NatA in cotranslational N-terminal acetylation and prevention of Huntingtin aggregation." Mol Cell Biol 30(8): 1898-1909.

Arnesen, T., P. Van Damme, B. Polevoda, K. Helsens, R. Evjenth, N. Colaert, J. E. Varhaug, J. Vandekerckhove, J. R. Lillehaug, F. Sherman and K. Gevaert (2009). "Proteomics analyses reveal the evolutionary conservation and divergence of $\mathrm{N}$-terminal acetyltransferases from yeast and humans." Proc Natl Acad Sci U S A 106(20): 81578162.

Barlev, N. A., L. Liu, N. H. Chehab, K. Mansfield, K. G. Harris, T. D. Halazonetis and S. L. Berger (2001). "Acetylation of p53 activates transcription through recruitment of coactivators/histone acetyltransferases."

Barski, A., S. Cuddapah, K. Cui, T. Y. Roh, D. E. Schones, Z. Wang, G. Wei, I. Chepelev and K. Zhao (2007). "High-resolution profiling of histone methylations in the human genome." Cell 129(4): 823-837.

Beach, J. R., L. S. Licate, J. F. Crish and T. T. Egelhoff (2011). "Analysis of the role of Ser1/Ser2/Thr9 phosphorylation on myosin II assembly and function in live cells." $\underline{\text { BMC }}$ Cell Biol 12: 52 . 
Behnia, R., B. Panic, J. R. Whyte and S. Munro (2004). "Targeting of the Arf-like GTPase Arl3p to the Golgi requires N-terminal acetylation and the membrane protein Sys1p." Nat Cell Biol 6(5): 405-413.

Betapudi, V. (2014). "Life without double-headed non-muscle myosin II motor proteins." Front Chem 2: 45.

Biggar, K. K. and S. S. Li (2015). "Non-histone protein methylation as a regulator of cellular signalling and function." Nat Rev Mol Cell Biol 16(1): 5-17.

Bilodeau, S., M. H. Kagey, G. M. Frampton, P. B. Rahl and R. A. Young (2009). "SetDB1 contributes to repression of genes encoding developmental regulators and maintenance of ES cell state." Genes Dev 23(21): 2484-2489.

Boisvert, F. M., U. Dery, J. Y. Masson and S. Richard (2005). "Arginine methylation of MRE11 by PRMT1 is required for DNA damage checkpoint control." Genes Dev 19(6): 671-676.

Boisvert, F. M., A. Rhie, S. Richard and A. J. Doherty (2005). "The GAR motif of 53BP1 is arginine methylated by PRMT1 and is necessary for 53BP1 DNA binding activity." Cell Cycle 4(12): 1834-1841.

Bonsignore, L. A., J. S. Butler, C. M. Klinge and C. E. Schaner Tooley (2015). "Loss of the N-terminal methyltransferase NRMT1 increases sensitivity to DNA damage and promotes mammary oncogenesis." Oncotarget 6(14): 12248-12263. 
Bonsignore, L. A., J. G. Tooley, P. M. Van Hoose, E. Wang, A. Cheng, M. P. Cole and C. E. Schaner Tooley (2015). "NRMT1 knockout mice exhibit phenotypes associated with impaired DNA repair and premature aging." Mech Ageing Dev 146-148: 42-52.

Brown, J. L. and W. K. Roberts (1976). "Evidence that approximately eighty per cent of the soluble proteins from Ehrlich ascites cells are Nalpha-acetylated." J Biol Chem 251(4): 1009-1014.

Brune, V., E. Tiacci, I. Pfeil, C. Doring, S. Eckerle, C. J. van Noesel, W. Klapper, B. Falini, A. von Heydebreck, D. Metzler, A. Brauninger, M. L. Hansmann and R. Kuppers (2008). "Origin and pathogenesis of nodular lymphocyte-predominant Hodgkin lymphoma as revealed by global gene expression analysis." J Exp Med 205(10): 22512268.

Cai, Q., L. Fu, Z. Wang, N. Gan, X. Dai and Y. Wang (2014). "alpha-N-methylation of damaged DNA-binding protein 2 (DDB2) and its function in nucleotide excision repair." J Biol Chem 289(23): 16046-16056.

Carr, S. M., S. Munro, B. Kessler, U. Oppermann and N. B. La Thangue (2011).

"Interplay between lysine methylation and Cdk phosphorylation in growth control by the retinoblastoma protein." EMBO J 30(2): 317-327.

Carrozza, M. J., B. Li, L. Florens, T. Suganuma, S. K. Swanson, K. K. Lee, W. J. Shia, S. Anderson, J. Yates, M. P. Washburn and J. L. Workman (2005). "Histone H3 methylation by Set 2 directs deacetylation of coding regions by Rpd3S to suppress spurious intragenic transcription." Cell 123(4): 581-592. 
Chen, T., A. M. Brownawell and I. G. Macara (2004). "Nucleocytoplasmic shuttling of JAZ, a new cargo protein for exportin-5." Mol Cell Biol 24(15): 6608-6619.

Chen, T., T. L. Muratore, C. E. Schaner-Tooley, J. Shabanowitz, D. F. Hunt and I. G. Macara (2007). "N-terminal alpha-methylation of RCC1 is necessary for stable chromatin association and normal mitosis." Nat Cell Biol 9(5): 596-603.

Choudhary, C., C. Kumar, F. Gnad, M. L. Nielsen, M. Rehman, T. C. Walther, J. V. Olsen and M. Mann (2009). "Lysine acetylation targets protein complexes and coregulates major cellular functions." Science 325(5942): 834-840.

Choudhary, C., B. T. Weinert, Y. Nishida, E. Verdin and M. Mann (2014). "The growing landscape of lysine acetylation links metabolism and cell signalling." Nat Rev Mol Cell Biol 15(8): 536-550.

Chrzanowska-Wodnicka, M. and K. Burridge (1996). "Rho-stimulated contractility drives the formation of stress fibers and focal adhesions." J Cell Biol 133(6): 1403-1415.

Collins, R. E., J. P. Northrop, J. R. Horton, D. Y. Lee, X. Zhang, M. R. Stallcup and X. Cheng (2008). "The ankyrin repeats of G9a and GLP histone methyltransferases are mono- and dimethyllysine binding modules." Nat Struct Mol Biol 15(3): 245-250.

Conti, M. A. and R. S. Adelstein (2008). "Nonmuscle myosin II moves in new directions." J Cell Sci 121(Pt 1): 11-18.

Conti, M. A., S. Even-Ram, C. Liu, K. M. Yamada and R. S. Adelstein (2004). "Defects in cell adhesion and the visceral endoderm following ablation of nonmuscle myosin heavy chain II-A in mice." J Biol Chem 279(40): 41263-41266. 
Creyghton, M. P., A. W. Cheng, G. G. Welstead, T. Kooistra, B. W. Carey, E. J. Steine, J. Hanna, M. A. Lodato, G. M. Frampton, P. A. Sharp, L. A. Boyer, R. A. Young and R. Jaenisch (2010). "Histone H3K27ac separates active from poised enhancers and predicts developmental state." Proc Natl Acad Sci U S A 107(50): 21931-21936.

Cross, R. A., A. P. Jackson, S. Citi, J. Kendrick-Jones and C. R. Bagshaw (1988).

"Active site trapping of nucleotide by smooth and non-muscle myosins." $\underline{\mathrm{J} \text { Mol Biol }}$ 203(1): 173-181.

Dai, X., K. Otake, C. You, Q. Cai, Z. Wang, H. Masumoto and Y. Wang (2013).

"Identification of novel alpha-n-methylation of CENP-B that regulates its binding to the centromeric DNA." J Proteome Res 12(9): 4167-4175.

de Lanerolle, P. (2012). "Nuclear actin and myosins at a glance." J Cell Sci 125(Pt 21): 4945-4949.

de Lanerolle, P. and L. Serebryannyy (2011). "Nuclear actin and myosins: life without filaments." Nat Cell Biol 13(11): 1282-1288.

Di Cerbo, V., F. Mohn, D. P. Ryan, E. Montellier, S. Kacem, P. Tropberger, E. Kallis, M. Holzner, L. Hoerner, A. Feldmann, F. M. Richter, A. J. Bannister, G. Mittler, J. Michaelis, S. Khochbin, R. Feil, D. Schuebeler, T. Owen-Hughes, S. Daujat and R. Schneider (2014). "Acetylation of histone H3 at lysine 64 regulates nucleosome dynamics and facilitates transcription." Elife 3: e01632.

Dikiy, I. and D. Eliezer (2014). "N-terminal acetylation stabilizes N-terminal helicity in lipid- and micelle-bound alpha-synuclein and increases its affinity for physiological membranes." J Biol Chem 289(6): 3652-3665. 
Dorr, A., V. Kiermer, A. Pedal, H. R. Rackwitz, P. Henklein, U. Schubert, M. M. Zhou, E. Verdin and M. Ott (2002). "Transcriptional synergy between Tat and PCAF is dependent on the binding of acetylated Tat to the PCAF bromodomain." EMBO J 21(11): 2715-2723.

Dupont, S., L. Morsut, M. Aragona, E. Enzo, S. Giulitti, M. Cordenonsi, F. Zanconato, J. Le Digabel, M. Forcato, S. Bicciato, N. Elvassore and S. Piccolo (2011). "Role of YAP/TAZ in mechanotransduction." Nature 474(7350): 179-183.

Edwards, A. V., V. Schwammle and M. R. Larsen (2014). "Neuronal process structure and growth proteins are targets of heavy PTM regulation during brain development." $\underline{\mathbf{J}}$ Proteomics 101: 77-87.

Espejo, A., J. Cote, A. Bednarek, S. Richard and M. T. Bedford (2002). "A proteindomain microarray identifies novel protein-protein interactions." Biochem J 367(Pt 3): 697-702.

Esteve, P. O., Y. Chang, M. Samaranayake, A. K. Upadhyay, J. R. Horton, G. R. Feehery, X. Cheng and S. Pradhan (2011). "A methylation and phosphorylation switch between an adjacent lysine and serine determines human DNMT1 stability." Nat Struct Mol Biol 18(1): 42-48.

Esteve, P. O., H. G. Chin, J. Benner, G. R. Feehery, M. Samaranayake, G. A. Horwitz, S. E. Jacobsen and S. Pradhan (2009). "Regulation of DNMT1 stability through SET7mediated lysine methylation in mammalian cells." Proc Natl Acad Sci U S A 106(13): 5076-5081. 
Ferrari, K. J., A. Scelfo, S. Jammula, A. Cuomo, I. Barozzi, A. Stutzer, W. Fischle, T. Bonaldi and D. Pasini (2014). "Polycomb-dependent H3K27me1 and H3K27me2 regulate active transcription and enhancer fidelity." Mol Cell 53(1): 49-62.

Filippakopoulos, P. and S. Knapp (2012). "The bromodomain interaction module." FEBS Lett 586(17): 2692-2704.

Finak, G., N. Bertos, F. Pepin, S. Sadekova, M. Souleimanova, H. Zhao, H. Chen, G. Omeroglu, S. Meterissian, A. Omeroglu, M. Hallett and M. Park (2008). "Stromal gene expression predicts clinical outcome in breast cancer." Nat Med 14(5): 518-527.

Fischle, W., B. S. Tseng, H. L. Dormann, B. M. Ueberheide, B. A. Garcia, J. Shabanowitz, D. F. Hunt, H. Funabiki and C. D. Allis (2005). "Regulation of HP1chromatin binding by histone H3 methylation and phosphorylation." Nature 438(7071): 1116-1122.

Forte, G. M., M. R. Pool and C. J. Stirling (2011). "N-terminal acetylation inhibits protein targeting to the endoplasmic reticulum." PLoS Biol 9(5): e1001073.

Fulton, M. D., J. Zhang, M. He, M. C. Ho and Y. G. Zheng (2017). "Intricate Effects of alpha-Amino and Lysine Modifications on Arginine Methylation of the N-Terminal Tail of Histone H4." Biochemistry 56(28): 3539-3548.

Gardner, K. E., C. D. Allis and B. D. Strahl (2011). "Operating on chromatin, a colorful language where context matters." J Mol Biol 409(1): 36-46.

Gautschi, M., S. Just, A. Mun, S. Ross, P. Rucknagel, Y. Dubaquie, A. EhrenhoferMurray and S. Rospert (2003). "The yeast N(alpha)-acetyltransferase NatA is 
quantitatively anchored to the ribosome and interacts with nascent polypeptides." Mol Cell Biol 23(20): 7403-7414.

Gehani, S. S., S. Agrawal-Singh, N. Dietrich, N. S. Christophersen, K. Helin and K. Hansen (2010). "Polycomb group protein displacement and gene activation through MSK-dependent H3K27me3S28 phosphorylation." Mol Cell 39(6): 886-900.

Goetze, S., E. Qeli, C. Mosimann, A. Staes, B. Gerrits, B. Roschitzki, S. Mohanty, E. M. Niederer, E. Laczko, E. Timmerman, V. Lange, E. Hafen, R. Aebersold, J. Vandekerckhove, K. Basler, C. H. Ahrens, K. Gevaert and E. Brunner (2009). "Identification and functional characterization of N-terminally acetylated proteins in Drosophila melanogaster." PLoS Biol 7(11): e1000236.

Golomb, E., X. Ma, S. S. Jana, Y. A. Preston, S. Kawamoto, N. G. Shoham, E. Goldin, M. A. Conti, J. R. Sellers and R. S. Adelstein (2004). "Identification and characterization of nonmuscle myosin II-C, a new member of the myosin II family." J Biol Chem 279(4): 2800-2808.

Gronroos, E., U. Hellman, C. H. Heldin and J. Ericsson (2002). "Control of Smad7 stability by competition between acetylation and ubiquitination." Mol Cell 10(3): 483493.

Guo, A., H. Gu, J. Zhou, D. Mulhern, Y. Wang, K. A. Lee, V. Yang, M. Aguiar, J. Kornhauser, X. Jia, J. Ren, S. A. Beausoleil, J. C. Silva, V. Vemulapalli, M. T. Bedford and M. J. Comb (2014). "Immunoaffinity enrichment and mass spectrometry analysis of protein methylation." Mol Cell Proteomics 13(1): 372-387. 
Gurskaya, N. G., V. V. Verkhusha, A. S. Shcheglov, D. B. Staroverov, T. V.

Chepurnykh, A. F. Fradkov, S. Lukyanov and K. A. Lukyanov (2006). "Engineering of a monomeric green-to-red photoactivatable fluorescent protein induced by blue light." Nat Biotechnol 24(4): 461-465.

Hartsough, E. J., R. D. Meyer, V. Chitalia, Y. Jiang, V. E. Marquez, I. V. Zhdanova, J. Weinberg, C. E. Costello and N. Rahimi (2013). "Lysine methylation promotes VEGFR2 activation and angiogenesis." Sci Signal 6(304): ra104.

Heissler, S. M. and J. R. Sellers (2014). "Myosin light chains: Teaching old dogs new tricks." Bioarchitecture 4(6): 169-188.

Helbig, A. O., S. Gauci, R. Raijmakers, B. van Breukelen, M. Slijper, S. Mohammed and A. J. Heck (2010). "Profiling of N-acetylated protein termini provides in-depth insights

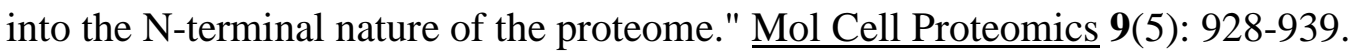

Helsens, K., P. Van Damme, S. Degroeve, L. Martens, T. Arnesen, J. Vandekerckhove and K. Gevaert (2011). "Bioinformatics analysis of a Saccharomyces cerevisiae Nterminal proteome provides evidence of alternative translation initiation and posttranslational N-terminal acetylation." J Proteome Res 10(8): 3578-3589.

Henry, G. D., D. C. Dalgarno, G. Marcus, M. Scott, B. A. Levine and I. P. Trayer (1982). "The occurrence of alpha-N-trimethylalanine as the $\mathrm{N}$-terminal amino acid of some myosin light chains." FEBS Lett 144(1): 11-15.

Henry, G. D., I. P. Trayer, S. Brewer and B. A. Levine (1985). "The widespread distribution of alpha-N-trimethylalanine as the $\mathrm{N}$-terminal amino acid of light chains from vertebrate striated muscle myosins." Eur J Biochem 148(1): 75-82. 
Hoelzle, M. K. and T. Svitkina (2012). "The cytoskeletal mechanisms of cell-cell junction formation in endothelial cells." Mol Biol Cell 23(2): 310-323.

Hofmann, W. A., G. M. Vargas, R. Ramchandran, L. Stojiljkovic, J. A. Goodrich and P. de Lanerolle (2006). "Nuclear myosin I is necessary for the formation of the first phosphodiester bond during transcription initiation by RNA polymerase II." $\underline{\mathrm{J} \text { Cell }}$ Biochem 99(4): 1001-1009.

Hsu, J. M., C. T. Chen, C. K. Chou, H. P. Kuo, L. Y. Li, C. Y. Lin, H. J. Lee, Y. N. Wang, M. Liu, H. W. Liao, B. Shi, C. C. Lai, M. T. Bedford, C. H. Tsai and M. C. Hung (2011). "Crosstalk between Arg 1175 methylation and Tyr 1173 phosphorylation negatively modulates EGFR-mediated ERK activation." Nat Cell Biol 13(2): 174-181.

Huang, T. T., S. M. Wuerzberger-Davis, Z. H. Wu and S. Miyamoto (2003). "Sequential modification of NEMO/IKKgamma by SUMO-1 and ubiquitin mediates NF-kappaB activation by genotoxic stress." Cell 115(5): 565-576.

Humphrey, J. D., E. R. Dufresne and M. A. Schwartz (2014). "Mechanotransduction and extracellular matrix homeostasis." Nat Rev Mol Cell Biol 15(12): 802-812.

Huveneers, S., H. Truong, R. Fassler, A. Sonnenberg and E. H. Danen (2008). "Binding of soluble fibronectin to integrin alpha5 beta1 - link to focal adhesion redistribution and contractile shape." J Cell Sci 121(Pt 15): 2452-2462.

Hwang, C. S., A. Shemorry and A. Varshavsky (2010). "N-terminal acetylation of cellular proteins creates specific degradation signals." Science 327(5968): 973-977. 
Ikebe, M., D. J. Hartshorne and M. Elzinga (1987). "Phosphorylation of the 20,000dalton light chain of smooth muscle myosin by the calcium-activated, phospholipiddependent protein kinase. Phosphorylation sites and effects of phosphorylation." J Biol Chem 262(20): 9569-9573.

Ikebe, M., J. Koretz and D. J. Hartshorne (1988). "Effects of phosphorylation of light chain residues threonine 18 and serine 19 on the properties and conformation of smooth muscle myosin." J Biol Chem 263(13): 6432-6437.

Ito, A., Y. Kawaguchi, C. H. Lai, J. J. Kovacs, Y. Higashimoto, E. Appella and T. P. Yao (2002). "MDM2-HDAC1-mediated deacetylation of p53 is required for its degradation." EMBO J 21(22): 6236-6245.

Ivanov, G. S., T. Ivanova, J. Kurash, A. Ivanov, S. Chuikov, F. Gizatullin, E. M. HerreraMedina, F. Rauscher, 3rd, D. Reinberg and N. A. Barlev (2007). "Methylationacetylation interplay activates p53 in response to DNA damage." Mol Cell Biol 27(19): 6756-6769.

Jacobson, R. H., A. G. Ladurner, D. S. King and R. Tjian (2000). "Structure and function of a human TAFII250 double bromodomain module." Science 288(5470): 1422-1425.

Jing, E., S. Gesta and C. R. Kahn (2007). "SIRT2 regulates adipocyte differentiation through FoxO1 acetylation/deacetylation." Cell Metab 6(2): 105-114.

Johnson, M., M. A. Geeves and D. P. Mulvihill (2013). "Production of amino-terminally acetylated recombinant proteins in E. coli." Methods Mol Biol 981: 193-200. 
Joshi, A. A. and K. Struhl (2005). "Eaf3 chromodomain interaction with methylated H3K36 links histone deacetylation to Pol II elongation." Mol Cell 20(6): 971-978.

Jung, H. R., D. Pasini, K. Helin and O. N. Jensen (2010). "Quantitative mass spectrometry of histones H3.2 and H3.3 in Suz12-deficient mouse embryonic stem cells reveals distinct, dynamic post-translational modifications at Lys-27 and Lys-36." $\underline{\text { Mol }}$ Cell Proteomics 9(5): 838-850.

Kachirskaia, I., X. Shi, H. Yamaguchi, K. Tanoue, H. Wen, E. W. Wang, E. Appella and O. Gozani (2008). "Role for 53BP1 Tudor domain recognition of p53 dimethylated at lysine 382 in DNA damage signaling." J Biol Chem 283(50): 34660-34666.

Kalvik, T. V. and T. Arnesen (2013). "Protein N-terminal acetyltransferases in cancer." Oncogene 32(3): 269-276.

Katoh, K., Y. Kano, M. Amano, H. Onishi, K. Kaibuchi and K. Fujiwara (2001). "Rhokinase--mediated contraction of isolated stress fibers." J Cell Biol 153(3): 569-584.

Kawamoto, S. and R. S. Adelstein (1991). "Chicken nonmuscle myosin heavy chains: differential expression of two mRNAs and evidence for two different polypeptides." $\underline{\mathrm{J}}$ Cell Biol 112(5): 915-924.

Kim, A., C. M. Kiefer and A. Dean (2007). "Distinctive signatures of histone methylation in transcribed coding and noncoding human beta-globin sequences." Mol Cell Biol 27(4): 1271-1279.

Kim, T. W., B. H. Kang, H. Jang, S. Kwak, J. Shin, H. Kim, S. E. Lee, S. M. Lee, J. H. Lee, J. H. Kim, S. Y. Kim, E. J. Cho, J. H. Kim, K. S. Park, J. H. Che, D. W. Han, M. J. 
Kang, E. C. Yi and H. D. Youn (2015). "Ctbp2 Modulates NuRD-Mediated

Deacetylation of H3K27 and Facilitates PRC2-Mediated H3K27me3 in Active

Embryonic Stem Cell Genes During Exit from Pluripotency." Stem Cells 33(8): 24422455.

Kimura, K., M. Ito, M. Amano, K. Chihara, Y. Fukata, M. Nakafuku, B. Yamamori, J.

Feng, T. Nakano, K. Okawa, A. Iwamatsu and K. Kaibuchi (1996). "Regulation of myosin phosphatase by Rho and Rho-associated kinase (Rho-kinase)." Science 273(5272): 245-248.

Kizer, K. O., H. P. Phatnani, Y. Shibata, H. Hall, A. L. Greenleaf and B. D. Strahl (2005). "A novel domain in Set2 mediates RNA polymerase II interaction and couples histone H3 K36 methylation with transcript elongation." Mol Cell Biol 25(8): 3305-3316.

Kontaki, H. and I. Talianidis (2010). "Lysine methylation regulates E2F1-induced cell death." Mol Cell 39(1): 152-160.

Kornberg, R. D. and Y. Lorch (1999). "Chromatin-modifying and -remodeling complexes." Curr Opin Genet Dev 9(2): 148-151.

Kornberg, R. D. and Y. Lorch (1999). "Twenty-five years of the nucleosome, fundamental particle of the eukaryote chromosome." Cell 98(3): 285-294.

Krause, C. D., Z. H. Yang, Y. S. Kim, J. H. Lee, J. R. Cook and S. Pestka (2007). "Protein arginine methyltransferases: evolution and assessment of their pharmacological and therapeutic potential." Pharmacol Ther 113(1): 50-87. 
Lan, F., R. E. Collins, R. De Cegli, R. Alpatov, J. R. Horton, X. Shi, O. Gozani, X. Cheng and Y. Shi (2007). "Recognition of unmethylated histone H3 lysine 4 links BHC80 to LSD1-mediated gene repression." Nature 448(7154): 718-722.

Lau, P. N. and P. Cheung (2011). "Histone code pathway involving H3 S28 phosphorylation and K27 acetylation activates transcription and antagonizes polycomb silencing." Proc Natl Acad Sci U S A 108(7): 2801-2806.

Lee, C. F., D. S. Ou, S. B. Lee, L. H. Chang, R. K. Lin, Y. S. Li, A. K. Upadhyay, X. Cheng, Y. C. Wang, H. S. Hsu, M. Hsiao, C. W. Wu and L. J. Juan (2010). "hNaa10p contributes to tumorigenesis by facilitating DNMT1-mediated tumor suppressor gene silencing." J Clin Invest 120(8): 2920-2930.

Lee, J., A. Andreeva, C. W. Sipe, L. Liu, A. Cheng and X. Lu (2012). "PTK7 regulates myosin II activity to orient planar polarity in the mammalian auditory epithelium." $\underline{\text { Curr }}$ Biol 22(11): 956-966.

Li, Q. and S. K. Sarna (2009). "Nuclear myosin II regulates the assembly of preinitiation complex for ICAM-1 gene transcription." Gastroenterology 137(3): 1051-1060, 1060 e1051-1053.

Li, Y., H. Wen, Y. Xi, K. Tanaka, H. Wang, D. Peng, Y. Ren, Q. Jin, S. Y. Dent, W. Li, H. Li and X. Shi (2014). "AF9 YEATS domain links histone acetylation to DOT1Lmediated H3K79 methylation." Cell 159(3): 558-571.

Lin, H., X. Su and B. He (2012). "Protein lysine acylation and cysteine succination by intermediates of energy metabolism." ACS Chem Biol 7(6): 947-960. 
Lorch, Y. and R. D. Kornberg (2017). "Chromatin-remodeling for transcription." Q Rev Biophys 50: e5.

Ma, X., S. S. Jana, M. A. Conti, S. Kawamoto, W. C. Claycomb and R. S. Adelstein (2010). "Ablation of nonmuscle myosin II-B and II-C reveals a role for nonmuscle myosin II in cardiac myocyte karyokinesis." Mol Biol Cell 21(22): 3952-3962.

Matsuzaki, H., H. Daitoku, M. Hatta, H. Aoyama, K. Yoshimochi and A. Fukamizu (2005). "Acetylation of Foxo1 alters its DNA-binding ability and sensitivity to phosphorylation." Proc Natl Acad Sci U S A 102(32): 11278-11283.

Meijering, E., M. Jacob, J. C. Sarria, P. Steiner, H. Hirling and M. Unser (2004). "Design and validation of a tool for neurite tracing and analysis in fluorescence microscopy images." Cytometry A 58(2): 167-176.

Monda, J. K., D. C. Scott, D. J. Miller, J. Lydeard, D. King, J. W. Harper, E. J. Bennett and B. A. Schulman (2013). "Structural conservation of distinctive N-terminal acetylation-dependent interactions across a family of mammalian NEDD8 ligation enzymes." Structure 21(1): 42-53.

Mujtaba, S., Y. He, L. Zeng, A. Farooq, J. E. Carlson, M. Ott, E. Verdin and M. M. Zhou (2002). "Structural basis of lysine-acetylated HIV-1 Tat recognition by PCAF bromodomain." Mol Cell 9(3): 575-586.

Mullen, J. R., P. S. Kayne, R. P. Moerschell, S. Tsunasawa, M. Gribskov, M. ColavitoShepanski, M. Grunstein, F. Sherman and R. Sternglanz (1989). "Identification and characterization of genes and mutants for an N-terminal acetyltransferase from yeast." EMBO J 8(7): 2067-2075. 
Munro, S., N. Khaire, A. Inche, S. Carr and N. B. La Thangue (2010). "Lysine methylation regulates the pRb tumour suppressor protein." Oncogene 29(16): 2357-2367.

Myers, F. A., D. R. Evans, A. L. Clayton, A. W. Thorne and C. Crane-Robinson (2001). "Targeted and extended acetylation of histones $\mathrm{H} 4$ and $\mathrm{H} 3$ at active and inactive genes in chicken embryo erythrocytes." J Biol Chem 276(23): 20197-20205.

Myklebust, L. M., S. I. Stove and T. Arnesen (2015). "Naa10 in development and disease." Oncotarget 6(33): 34041-34042.

Myklebust, L. M., P. Van Damme, S. I. Stove, M. J. Dorfel, A. Abboud, T. V. Kalvik, C. Grauffel, V. Jonckheere, Y. Wu, J. Swensen, H. Kaasa, G. Liszczak, R. Marmorstein, N. Reuter, G. J. Lyon, K. Gevaert and T. Arnesen (2015). "Biochemical and cellular analysis of Ogden syndrome reveals downstream Nt-acetylation defects." Hum Mol Genet 24(7): 1956-1976.

Newell-Litwa, K. A., M. Badoual, H. Asmussen, H. Patel, L. Whitmore and A. R. Horwitz (2015). "ROCK1 and 2 differentially regulate actomyosin organization to drive cell and synaptic polarity." J Cell Biol 210(2): 225-242.

Newell-Litwa, K. A., R. Horwitz and M. L. Lamers (2015). "Non-muscle myosin II in disease: mechanisms and therapeutic opportunities." Dis Model Mech 8(12): 1495-1515.

Nigro, E., P. Schettino, R. Polito, O. Scudiero, M. L. Monaco, G. D. De Palma and A. Daniele (2018). "Adiponectin and colon cancer: evidence for inhibitory effects on viability and migration of human colorectal cell lines." Mol Cell Biochem. 
Nishikawa, M., J. R. Sellers, R. S. Adelstein and H. Hidaka (1984). "Protein kinase C modulates in vitro phosphorylation of the smooth muscle heavy meromyosin by myosin light chain kinase." J Biol Chem 259(14): 8808-8814.

Nurnberger, J., R. L. Bacallao and C. L. Phillips (2002). "Inversin forms a complex with catenins and N-cadherin in polarized epithelial cells." Mol Biol Cell 13(9): 3096-3106.

Park, I., C. Han, S. Jin, B. Lee, H. Choi, J. T. Kwon, D. Kim, J. Kim, E. Lifirsu, W. J.

Park, Z. Y. Park, D. H. Kim and C. Cho (2011). "Myosin regulatory light chains are

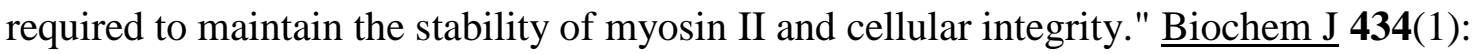
171-180.

Park, S. E., J. M. Kim, O. H. Seok, H. Cho, B. Wadas, S. Y. Kim, A. Varshavsky and C. S. Hwang (2015). "Control of mammalian G protein signaling by N-terminal acetylation and the N-end rule pathway." Science 347(6227): 1249-1252.

Pasini, D., M. Malatesta, H. R. Jung, J. Walfridsson, A. Willer, L. Olsson, J. Skotte, A. Wutz, B. Porse, O. N. Jensen and K. Helin (2010). "Characterization of an antagonistic switch between histone $\mathrm{H} 3$ lysine 27 methylation and acetylation in the transcriptional regulation of Polycomb group target genes." Nucleic Acids Res 38(15): 4958-4969.

Pauler, F. M., M. A. Sloane, R. Huang, K. Regha, M. V. Koerner, I. Tamir, A. Sommer, A. Aszodi, T. Jenuwein and D. P. Barlow (2009). "H3K27me3 forms BLOCs over silent genes and intergenic regions and specifies a histone banding pattern on a mouse autosomal chromosome." Genome Res 19(2): 221-233. 
Petkowski, J. J., L. A. Bonsignore, J. G. Tooley, D. W. Wilkey, M. L. Merchant, I. G. Macara and C. E. Schaner Tooley (2013). "NRMT2 is an N-terminal monomethylase that primes for its homologue NRMT1." Biochem J 456(3): 453-462.

Petkowski, J. J., C. E. Schaner Tooley, L. C. Anderson, I. A. Shumilin, J. L. Balsbaugh, J. Shabanowitz, D. F. Hunt, W. Minor and I. G. Macara (2012). "Substrate specificity of mammalian N-terminal alpha-amino methyltransferase NRMT." Biochemistry 51(30): 5942-5950.

Pettigrew, G. W. and G. M. Smith (1977). "Novel N-terminal protein blocking group identified as dimethylproline." Nature 265(5595): 661-662.

Phillips, H. M., J. N. Murdoch, B. Chaudhry, A. J. Copp and D. J. Henderson (2005). "Vang12 acts via RhoA signaling to regulate polarized cell movements during development of the proximal outflow tract." Circ Res 96(3): 292-299.

Polevoda, B., J. Norbeck, H. Takakura, A. Blomberg and F. Sherman (1999). "Identification and specificities of N-terminal acetyltransferases from Saccharomyces cerevisiae." EMBO J 18(21): 6155-6168.

Polevoda, B. and F. Sherman (2003). "N-terminal acetyltransferases and sequence requirements for N-terminal acetylation of eukaryotic proteins." J Mol Biol 325(4): 595622.

Potter, D. A., J. S. Tirnauer, R. Janssen, D. E. Croall, C. N. Hughes, K. A. Fiacco, J. W. Mier, M. Maki and I. M. Herman (1998). "Calpain regulates actin remodeling during cell spreading." J Cell Biol 141(3): 647-662. 
Rauch, A., D. Wieczorek, E. Graf, T. Wieland, S. Endele, T. Schwarzmayr, B. Albrecht, D. Bartholdi, J. Beygo, N. Di Donato, A. Dufke, K. Cremer, M. Hempel, D. Horn, J. Hoyer, P. Joset, A. Ropke, U. Moog, A. Riess, C. T. Thiel, A. Tzschach, A. Wiesener, E. Wohlleber, C. Zweier, A. B. Ekici, A. M. Zink, A. Rump, C. Meisinger, H. Grallert, H. Sticht, A. Schenck, H. Engels, G. Rappold, E. Schrock, P. Wieacker, O. Riess, T. Meitinger, A. Reis and T. M. Strom (2012). "Range of genetic mutations associated with severe non-syndromic sporadic intellectual disability: an exome sequencing study." Lancet 380(9854): 1674-1682.

Reeder, J. E., Y. T. Kwak, R. P. McNamara, C. V. Forst and I. D'Orso (2015). "HIV Tat controls RNA Polymerase II and the epigenetic landscape to transcriptionally reprogram target immune cells." Elife 4.

Ren, T., B. Jiang, G. Jin, J. Li, B. Dong, J. Zhang, L. Meng, J. Wu and C. Shou (2008). "Generation of novel monoclonal antibodies and their application for detecting ARD1 expression in colorectal cancer." Cancer Lett 264(1): 83-92.

Reynolds, N., M. Salmon-Divon, H. Dvinge, A. Hynes-Allen, G. Balasooriya, D. Leaford, A. Behrens, P. Bertone and B. Hendrich (2012). "NuRD-mediated deacetylation of H3K27 facilitates recruitment of Polycomb Repressive Complex 2 to direct gene repression." EMBO J 31(3): 593-605.

Richards, T. A. and T. Cavalier-Smith (2005). "Myosin domain evolution and the primary divergence of eukaryotes." Nature 436(7054): 1113-1118. 
Richardson, S. L., Y. Mao, G. Zhang, P. Hanjra, D. L. Peterson and R. Huang (2015).

"Kinetic mechanism of protein N-terminal methyltransferase 1." J Biol Chem 290(18): 11601-11610.

Rope, A. F., K. Wang, R. Evjenth, J. Xing, J. J. Johnston, J. J. Swensen, W. E. Johnson, B. Moore, C. D. Huff, L. M. Bird, J. C. Carey, J. M. Opitz, C. A. Stevens, T. Jiang, C. Schank, H. D. Fain, R. Robison, B. Dalley, S. Chin, S. T. South, T. J. Pysher, L. B. Jorde, H. Hakonarson, J. R. Lillehaug, L. G. Biesecker, M. Yandell, T. Arnesen and G. J. Lyon (2011). "Using VAAST to identify an X-linked disorder resulting in lethality in male infants due to N-terminal acetyltransferase deficiency." Am J Hum Genet 89(1): 28-43.

Rothbart, S. B. and B. D. Strahl (2014). "Interpreting the language of histone and DNA modifications." Biochim Biophys Acta 1839(8): 627-643.

Sabates-Bellver, J., L. G. Van der Flier, M. de Palo, E. Cattaneo, C. Maake, H. Rehrauer, E. Laczko, M. A. Kurowski, J. M. Bujnicki, M. Menigatti, J. Luz, T. V. Ranalli, V. Gomes, A. Pastorelli, R. Faggiani, M. Anti, J. Jiricny, H. Clevers and G. Marra (2007). "Transcriptome profile of human colorectal adenomas." Mol Cancer Res 5(12): 12631275.

Sabbattini, P., M. Sjoberg, S. Nikic, A. Frangini, P. H. Holmqvist, N. Kunowska, T. Carroll, E. Brookes, S. J. Arthur, A. Pombo and N. Dillon (2014). "An H3K9/S10 methyl-phospho switch modulates Polycomb and Pol II binding at repressed genes during

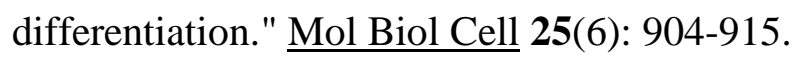

Santos, A. L. and A. B. Lindner (2017). "Protein Posttranslational Modifications: Roles in Aging and Age-Related Disease." Oxid Med Cell Longev 2017: 5716409. 
Sathyan, K. M., D. Fachinetti and D. R. Foltz (2017). "alpha-amino trimethylation of CENP-A by NRMT is required for full recruitment of the centromere." Nat Commun 8: 14678.

Saunier, C., S. I. Stove, B. Popp, B. Gerard, M. Blenski, N. AhMew, C. de Bie, P. Goldenberg, B. Isidor, B. Keren, B. Leheup, L. Lampert, C. Mignot, K. Tezcan, G. M. Mancini, C. Nava, M. Wasserstein, A. L. Bruel, J. Thevenon, A. Masurel, Y. Duffourd, P. Kuentz, F. Huet, J. B. Riviere, M. van Slegtenhorst, L. Faivre, A. Piton, A. Reis, T. Arnesen, C. Thauvin-Robinet and C. Zweier (2016). "Expanding the Phenotype Associated with NAA10-Related N-Terminal Acetylation Deficiency." Hum Mutat 37(8): $755-764$.

Schiza, V., D. Molina-Serrano, D. Kyriakou, A. Hadjiantoniou and A. Kirmizis (2013). "N-alpha-terminal acetylation of histone $\mathrm{H} 4$ regulates arginine methylation and ribosomal DNA silencing." PLoS Genet 9(9): e1003805.

Schneider, T. D., J. M. Arteaga-Salas, E. Mentele, R. David, D. Nicetto, A. Imhof and R. A. Rupp (2011). "Stage-specific histone modification profiles reveal global transitions in the Xenopus embryonic epigenome." PLoS One 6(7): e22548.

Scott, D. C., J. K. Monda, E. J. Bennett, J. W. Harper and B. A. Schulman (2011). "Nterminal acetylation acts as an avidity enhancer within an interconnected multiprotein complex." Science 334(6056): 674-678.

Setty, S. R., T. I. Strochlic, A. H. Tong, C. Boone and C. G. Burd (2004). "Golgi targeting of ARF-like GTPase Arl3p requires its Nalpha-acetylation and the integral membrane protein Sys1p." Nat Cell Biol 6(5): 414-419. 
Shanle, E. K., S. A. Shinsky, J. B. Bridgers, N. Bae, C. Sagum, K. Krajewski, S. B. Rothbart, M. T. Bedford and B. D. Strahl (2017). "Histone peptide microarray screen of chromo and Tudor domains defines new histone lysine methylation interactions."

\section{Epigenetics Chromatin 10: 12.}

Shemorry, A., C. S. Hwang and A. Varshavsky (2013). "Control of protein quality and stoichiometries by N-terminal acetylation and the N-end rule pathway." Mol Cell 50(4): $540-551$

Shields, K. M., J. G. Tooley, J. J. Petkowski, D. W. Wilkey, N. C. Garbett, M. L. Merchant, A. Cheng and C. E. Schaner Tooley (2017). "Select human cancer mutants of NRMT1 alter its catalytic activity and decrease N-terminal trimethylation." Protein Sci 26(8): 1639-1652.

Silva, R. D. and R. G. Martinho (2015). "Developmental roles of protein N-terminal acetylation." Proteomics 15(14): 2402-2409.

Simithy, J., S. Sidoli and B. A. Garcia (2018). "Integrating Proteomics and Targeted Metabolomics to Understand Global Changes in Histone Modifications." Proteomics. Simons, M., M. Wang, O. W. McBride, S. Kawamoto, K. Yamakawa, D. Gdula, R. S. Adelstein and L. Weir (1991). "Human nonmuscle myosin heavy chains are encoded by two genes located on different chromosomes." Circ Res 69(2): 530-539.

Simonsson, M., C. H. Heldin, J. Ericsson and E. Gronroos (2005). "The balance between acetylation and deacetylation controls Smad7 stability." J Biol Chem 280(23): 2179721803. 
Smith, G. M. and G. W. Pettigrew (1980). "Identification of N,N-dimethylproline as the $\mathrm{N}$-terminal blocking group of Crithidia oncopelti cytochrome c557." Eur J Biochem 110(1): 123-130.

Somlyo, A. P. and A. V. Somlyo (2003). "Ca2+ sensitivity of smooth muscle and nonmuscle myosin II: modulated by G proteins, kinases, and myosin phosphatase." Physiol Rev 83(4): 1325-1358.

Starheim, K. K., K. Gevaert and T. Arnesen (2012). "Protein N-terminal acetyltransferases: when the start matters." Trends Biochem Sci 37(4): 152-161.

Stock, A., S. Clarke, C. Clarke and J. Stock (1987). "N-terminal methylation of proteins: structure, function and specificity." FEBS Lett 220(1): 8-14.

Strahl, B. D. and C. D. Allis (2000). "The language of covalent histone modifications." Nature 403(6765): 41-45.

Swygert, S. G. and C. L. Peterson (2014). "Chromatin dynamics: interplay between remodeling enzymes and histone modifications." Biochim Biophys Acta 1839(8): 728736.

Tachibana, M., J. Ueda, M. Fukuda, N. Takeda, T. Ohta, H. Iwanari, T. Sakihama, T. Kodama, T. Hamakubo and Y. Shinkai (2005). "Histone methyltransferases G9a and GLP form heteromeric complexes and are both crucial for methylation of euchromatin at H3-K9." Genes Dev 19(7): 815-826. 
Taverna, S. D., H. Li, A. J. Ruthenburg, C. D. Allis and D. J. Patel (2007). "How chromatin-binding modules interpret histone modifications: lessons from professional pocket pickers." Nat Struct Mol Biol 14(11): 1025-1040.

Tooley, C. E., J. J. Petkowski, T. L. Muratore-Schroeder, J. L. Balsbaugh, J.

Shabanowitz, M. Sabat, W. Minor, D. F. Hunt and I. G. Macara (2010). "NRMT is an alpha-N-methyltransferase that methylates $\mathrm{RCC} 1$ and retinoblastoma protein." Nature 466(7310): 1125-1128.

Tooley, J. G. and C. E. Schaner Tooley (2014). "New roles for old modifications: emerging roles of $\mathrm{N}$-terminal post-translational modifications in development and disease." Protein Sci 23(12): 1641-1649.

Torres, I. O. and D. G. Fujimori (2015). "Functional coupling between writers, erasers and readers of histone and DNA methylation." Curr Opin Struct Biol 35: 68-75.

Totsukawa, G., Y. Yamakita, S. Yamashiro, D. J. Hartshorne, Y. Sasaki and F. Matsumura (2000). "Distinct roles of ROCK (Rho-kinase) and MLCK in spatial regulation of MLC phosphorylation for assembly of stress fibers and focal adhesions in 3T3 fibroblasts." J Cell Biol 150(4): 797-806.

Tropberger, P., S. Pott, C. Keller, K. Kamieniarz-Gdula, M. Caron, F. Richter, G. Li, G. Mittler, E. T. Liu, M. Buhler, R. Margueron and R. Schneider (2013). "Regulation of transcription through acetylation of H3K122 on the lateral surface of the histone octamer." Cell 152(4): 859-872.

Trybus, K. M. (1989). "Filamentous smooth muscle myosin is regulated by phosphorylation." J Cell Biol 109(6 Pt 1): 2887-2894. 
Trybus, K. M. (1991). "Assembly of cytoplasmic and smooth muscle myosins." Curr Opin Cell Biol 3(1): 105-111.

Trybus, K. M., T. W. Huiatt and S. Lowey (1982). "A bent monomeric conformation of myosin from smooth muscle." Proc Natl Acad Sci U S A 79(20): 6151-6155.

Tsai, W. W., Z. Wang, T. T. Yiu, K. C. Akdemir, W. Xia, S. Winter, C. Y. Tsai, X. Shi, D. Schwarzer, W. Plunkett, B. Aronow, O. Gozani, W. Fischle, M. C. Hung, D. J. Patel and M. C. Barton (2010). "TRIM24 links a non-canonical histone signature to breast cancer." Nature 468(7326): 927-932.

Tullio, A. N., D. Accili, V. J. Ferrans, Z. X. Yu, K. Takeda, A. Grinberg, H. Westphal, Y. A. Preston and R. S. Adelstein (1997). "Nonmuscle myosin II-B is required for normal development of the mouse heart." Proc Natl Acad Sci U S A 94(23): 12407-12412.

Tullio, A. N., P. C. Bridgman, N. J. Tresser, C. C. Chan, M. A. Conti, R. S. Adelstein and Y. Hara (2001). "Structural abnormalities develop in the brain after ablation of the gene encoding nonmuscle myosin II-B heavy chain." J Comp Neurol 433(1): 62-74.

Uyeda, T. Q., P. D. Abramson and J. A. Spudich (1996). "The neck region of the myosin motor domain acts as a lever arm to generate movement." Proc Natl Acad Sci U S A 93(9): 4459-4464.

Van Damme, P., R. Evjenth, H. Foyn, K. Demeyer, P. J. De Bock, J. R. Lillehaug, J. Vandekerckhove, T. Arnesen and K. Gevaert (2011). "Proteome-derived peptide libraries allow detailed analysis of the substrate specificities of N(alpha)-acetyltransferases and point to hNaa10p as the post-translational actin N(alpha)-acetyltransferase." $\underline{\text { Mol Cell }}$ Proteomics 10(5): M110 004580. 
Van Damme, P., S. I. Stove, N. Glomnes, K. Gevaert and T. Arnesen (2014). "A

Saccharomyces cerevisiae model reveals in vivo functional impairment of the Ogden syndrome N-terminal acetyltransferase NAA10 Ser37Pro mutant." $\underline{\text { Mol Cell Proteomics }}$ 13(8): 2031-2041.

Varlamova, O., A. Spektor and A. R. Bresnick (2001). "Protein kinase C mediates phosphorylation of the regulatory light chain of myosin-II during mitosis." J Muscle Res Cell Motil 22(3): 243-250.

Vermeulen, M., K. W. Mulder, S. Denissov, W. W. Pijnappel, F. M. van Schaik, R. A. Varier, M. P. Baltissen, H. G. Stunnenberg, M. Mann and H. T. Timmers (2007). "Selective anchoring of TFIID to nucleosomes by trimethylation of histone H3 lysine 4." Cell 131(1): 58-69.

Vezzoli, A., N. Bonadies, M. D. Allen, S. M. Freund, C. M. Santiveri, B. T. Kvinlaug, B. J. Huntly, B. Gottgens and M. Bycroft (2010). "Molecular basis of histone H3K36me3 recognition by the PWWP domain of Brpf1." Nat Struct Mol Biol 17(5): 617-619.

Vicente-Manzanares, M., J. Hodges and A. R. Horwitz (2009). "Dendritic Spines: Similarities with Protrusions and Adhesions in Migrating Cells." Open Neurosci J 3: 8796.

Vicente-Manzanares, M., M. A. Koach, L. Whitmore, M. L. Lamers and A. F. Horwitz (2008). "Segregation and activation of myosin IIB creates a rear in migrating cells." $\underline{\mathbf{J}}$ Cell Biol 183(3): 543-554. 
Vicente-Manzanares, M., X. Ma, R. S. Adelstein and A. R. Horwitz (2009). "Non-muscle myosin II takes centre stage in cell adhesion and migration." Nat Rev Mol Cell Biol 10(11): 778-790.

Vicente-Manzanares, M., J. Zareno, L. Whitmore, C. K. Choi and A. F. Horwitz (2007). "Regulation of protrusion, adhesion dynamics, and polarity by myosins IIA and IIB in migrating cells." J Cell Biol 176(5): 573-580.

Wagner, E. J. and P. B. Carpenter (2012). "Understanding the language of Lys36 methylation at histone H3." Nat Rev Mol Cell Biol 13(2): 115-126.

Wagner, S. A., P. Beli, B. T. Weinert, M. L. Nielsen, J. Cox, M. Mann and C. Choudhary (2011). "A proteome-wide, quantitative survey of in vivo ubiquitylation sites reveals widespread regulatory roles." Mol Cell Proteomics 10(10): M111 013284.

Wang, H., W. An, R. Cao, L. Xia, H. Erdjument-Bromage, B. Chatton, P. Tempst, R. G. Roeder and Y. Zhang (2003). "mAM facilitates conversion by ESET of dimethyl to trimethyl lysine 9 of histone H3 to cause transcriptional repression." Mol Cell 12(2): 475487.

Wei, H., B. Wang, M. Miyagi, Y. She, B. Gopalan, D. B. Huang, G. Ghosh, G. R. Stark and T. Lu (2013). "PRMT5 dimethylates R30 of the p65 subunit to activate NF-kappaB." Proc Natl Acad Sci U S A 110(33): 13516-13521.

Wellen, K. E., G. Hatzivassiliou, U. M. Sachdeva, T. V. Bui, J. R. Cross and C. B. Thompson (2009). "ATP-citrate lyase links cellular metabolism to histone acetylation." Science 324(5930): 1076-1080. 
West, L. E., S. Roy, K. Lachmi-Weiner, R. Hayashi, X. Shi, E. Appella, T. G.

Kutateladze and O. Gozani (2010). "The MBT repeats of L3MBTL1 link SET8-mediated p53 methylation at lysine 382 to target gene repression." J Biol Chem 285(48): 37725 37732.

Wiita, A. P., J. E. Seaman and J. A. Wells (2014). "Global analysis of cellular proteolysis by selective enzymatic labeling of protein N-termini." Methods Enzymol 544: 327-358.

Wolffe, A. P. and J. J. Hayes (1999). "Chromatin disruption and modification." Nucleic Acids Res 27(3): 711-720.

Wu, Q., R. M. Sahasrabudhe, L. Z. Luo, D. W. Lewis, S. M. Gollin and W. S. Saunders (2010). "Deficiency in myosin light-chain phosphorylation causes cytokinesis failure and multipolarity in cancer cells." Oncogene 29(29): 4183-4193.

Wu, X., R. Guo, P. Chen, Q. Wang and P. N. Cunningham (2009). "TNF induces caspase-dependent inflammation in renal endothelial cells through a Rho- and myosin light chain kinase-dependent mechanism." Am J Physiol Renal Physiol 297(2): F316326.

Yamagata, K., H. Daitoku, Y. Takahashi, K. Namiki, K. Hisatake, K. Kako, H. Mukai, Y. Kasuya and A. Fukamizu (2008). "Arginine methylation of FOXO transcription factors inhibits their phosphorylation by Akt." Mol Cell 32(2): 221-231.

Yang, F., Q. Wei, R. S. Adelstein and P. J. Wang (2012). "Non-muscle myosin IIB is essential for cytokinesis during male meiotic cell divisions." Dev Biol 369(2): 356-361. 
Yang, X. D., B. Huang, M. Li, A. Lamb, N. L. Kelleher and L. F. Chen (2009). "Negative regulation of NF-kappaB action by Set9-mediated lysine methylation of the RelA subunit." EMBO J 28(8): 1055-1066.

Ye, J., J. Zhao, U. Hoffmann-Rohrer and I. Grummt (2008). "Nuclear myosin I acts in concert with polymeric actin to drive RNA polymerase I transcription." Genes Dev 22(3): $322-330$.

Yi, C. H., H. Pan, J. Seebacher, I. H. Jang, S. G. Hyberts, G. J. Heffron, M. G. Vander Heiden, R. Yang, F. Li, J. W. Locasale, H. Sharfi, B. Zhai, R. Rodriguez-Mias, H. Luithardt, L. C. Cantley, G. Q. Daley, J. M. Asara, S. P. Gygi, G. Wagner, C. F. Liu and J. Yuan (2011). "Metabolic regulation of protein N-alpha-acetylation by Bcl-xL promotes cell survival." Cell 146(4): 607-620.

Yuan, J., M. Pu, Z. Zhang and Z. Lou (2009). "Histone H3-K56 acetylation is important for genomic stability in mammals." Cell Cycle 8(11): 1747-1753.

Yuen, S. L., O. Ogut and F. V. Brozovich (2009). "Nonmuscle myosin is regulated during smooth muscle contraction." Am J Physiol Heart Circ Physiol 297(1): H191-199.

Zhang, J., R. Sprung, J. Pei, X. Tan, S. Kim, H. Zhu, C. F. Liu, N. V. Grishin and Y. Zhao (2009). "Lysine acetylation is a highly abundant and evolutionarily conserved

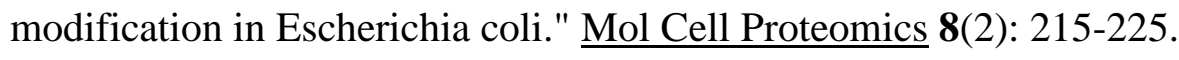

Zhang, L., N. G. Gurskaya, E. M. Merzlyak, D. B. Staroverov, N. N. Mudrik, O. N. Samarkina, L. M. Vinokurov, S. Lukyanov and K. A. Lukyanov (2007). "Method for real-time monitoring of protein degradation at the single cell level." Biotechniques 42(4): $446,448,450$. 
Zhang, T., S. Cooper and N. Brockdorff (2015). "The interplay of histone modifications writers that read." EMBO Rep 16(11): 1467-1481.

Zhang, X., H. Wen and X. Shi (2012). "Lysine methylation: beyond histones." Acta Biochim Biophys Sin (Shanghai) 44(1): 14-27.

Zhang, Y. S., B. Liu, X. J. Luo, T. B. Li, J. J. Zhang, J. J. Peng, X. J. Zhang, Q. L. Ma, C. P. Hu, Y. J. Li, J. Peng and Q. Li (2015). "Nuclear cardiac myosin light chain 2 modulates NADPH oxidase 2 expression in myocardium: a novel function beyond muscle contraction." Basic Res Cardiol 110(4): 38.

Zhang, Y. S., B. Liu, X. J. Luo, J. J. Zhang, N. S. Li, Q. L. Ma, J. L. Jiang, Y. J. Li, Q. Li and J. Peng (2015). "A novel function of nuclear nonmuscle myosin regulatory light chain in promotion of xanthine oxidase transcription after myocardial ischemia/reperfusion." Free Radic Biol Med 83: 115-128.

Zhang, Z., K. Kulkarni, S. J. Hanrahan, A. J. Thompson and D. Barford (2010). "The APC/C subunit Cdc16/Cut9 is a contiguous tetratricopeptide repeat superhelix with a homo-dimer interface similar to Cdc27." EMBO J 29(21): 3733-3744.

Zhong, C., M. Chrzanowska-Wodnicka, J. Brown, A. Shaub, A. M. Belkin and K. Burridge (1998). "Rho-mediated contractility exposes a cryptic site in fibronectin and induces fibronectin matrix assembly." J Cell Biol 141(2): 539-551.

Zippo, A., R. Serafini, M. Rocchigiani, S. Pennacchini, A. Krepelova and S. Oliviero (2009). "Histone crosstalk between H3S10ph and H4K16ac generates a histone code that mediates transcription elongation." Cell 138(6): 1122-1136. 
APPENDIX

\section{LIST OF ABBREVIATIONS}

53BP1 - P53-Binding Protein 1

AKT - AKT Serine/Threonine Kinase 1

APC/C - Anaphase Promoting Complex/Cyclosome

CBP - CREB Binding Protein

Cdc42 - Cell Division Cycle 42

CENP-A - Centromere Protein A

CENP-I - Centromere Protein I

CENP-T - Centromere Protein T

CoA - Coenzyme A

CTBP2 - C-Terminal Binding Protein 2

Cul1 - Cullin 1

Cut9 - Cell Division Cycle 16 Homolog

Dcn1 - Defective In Cullin Neddylation 1

DDB2 - Damage Specific DNA Binding Protein 2

DNMT1 - DNA Methyltransferase 1

Doa10 - ERAD-Associated E3 Ubiquitin-protein Ligase DOA10

E2F1 - E2F Transcription Factor 1 
EGF - Epidermal Growth Factor

ELC - Essential Light Chain

ER - Endoplasmic Reticulum

FOXO1 - Forkhead Box O1

HAT - Histone Acetyltransferase

Hen1 - Anaphase-Promoting Complex Subunit Hcn1

HDAC1 - Histone Deacetylase 1

HEXIM2 - Hexamethylene Bisacetamide Inducible 2

Hyx - Cell Division Cycle 73 Homolog

ICAM1 - Intercellular Adhesion Molecule 1

KD - Knockdown

$\mathrm{KO}-$ Knockout

L3MBTL1 - Lethal (3) Malignant Brain Tumor-like Protein 1

MDM2 - E3 Ubiquitin-protein Ligase Mdm2

MHC - Myosin Heavy Chain

MLCK - Myosin Light Chain Kinase

MLCP - Myosin Light Chain Phosphatase

MRE11 - Double-strand Break Repair Protein MRE11

MYL9 - Myosin Regulatory Light Chain 9

Na-PTM - Alpha-amino Post-translational Modification

NAA10 - N(Alpha)-Acetyltransferase 10, NatA Catalytic Subunit NAA15 - N(Alpha)-Acetyltransferase 15, NatA Auxiliary Subunit NAT - N-terminal Acetyltransferase 
NatA - N-terminal Acetyltransferase A

NRMT1 - N-terminal RCC1 Methyltransferase 1

NRMT2 - N-terminal RCC1 Methyltransferase 2

NF- $\mathrm{B}$ - Nuclear Factor Kappa-B

NMI - Non-muscle Myosin I

NMII - Non-muscle Myosin II

NURD - Nucleosome Remodeling and Deacetylase Complex

p53 - Tumor Protein P53

p65 - NF-Kappa-B Transcription Factor P65

PCAF - p300/CBP Associated Factor

PCP - Planar Cell Polarity

PKC - Protein Kinase C

PRC2 - Polycomb Repressive Complex 2

PRMT - Protein Arginine Methyltransferase Family

PSMD7 - Proteasome 26S Subunit, Non-ATPase 7

Rac - Rac Family Small GTPase

$\mathrm{Rb}$ - Retinoblastoma Protein

RhoA - Ras Homolog Family Member A

RLC - Regulatory Light Chain

RNAPI - RNA Polymerase I

RNAPII - RNA Polymerase II

ROCK - Rho Associated Coiled-Coil Containing Protein Kinase

RTK - Receptor Tyrosine Kinase 
SAM - S-Adenosyl Methionine

SETD2 - SET Domain Containing 2

SMAD7 - SMAD Family Member 7

SMURF1 - SMAD Specific E3 Ubiquitin Protein Ligase 1

SMYD2 - SET And MYND Domain Containing 2

TAF1 - TATA-Box Binding Protein Associated Factor 1

TAR - Transactivation Response Element

Tat - Transactivator of Transcription

$\mathrm{TEFb}$ - Transcription Elongation Factor B

TFIIB - Transcription Factor II B

TFIID - Transcription Factor II D

TGF $\beta$ - Transforming Growth Factor Beta

THOC7 - THO Complex 7

TNF $\alpha$ - Tumor Necrosis Factor Alpha

TRIM24 - Tripartite Motif Containing 24

Ubc12 - NEDD8-conjugating Enzyme UBC12

VEGFR2 - Vascular Endothelial Growth Factor Receptor 2

$\mathrm{XDH}$ - Xanthine Oxidase

YAP - Yes Associated Protein

ZIPK - Zipper Interacting Protein Kinase 


\section{CURRICULUM VITAE}

Chris Nevitt

University of Louisville $\square$ Louisville, KY $40202 \square$ (502) 291-3990 $\square$ cdnevi01@louisville.edu

\section{EDUCATION}

UNIVERSITY OF LOUISVILLE - College of Arts and Sciences, Department of Chemistry, Louisville, KY

Awarded 2013 - B.S. Chemistry, Biochemistry Concentration

UNIVERSITY OF LOUISVILLE - School of Medicine, Department of Biochemistry and Molecular Genetics, Louisville, KY

2014-present - Ph.D. Biochemistry

Awarded 2016 - M.S. Biochemistry

\section{SPECIAL COURSES}

August 1 - 14, 2017 - Proteomics Course, Cold Spring Harbor Laboratories

\section{RESEARCH EXPERIENCE}

Nov 2015-present - Graduate Student, Dept. of Biochemistry and Molecular Genetics, University of Louisville, Mentor: Dr. Christine Schaner Tooley, Project: Biochemical and Functional Characterization of N-terminal PostTranslational Modifications on Myosin Regulatory Light Chain 9

Sept 2013-Oct 2015 - Research Technologist (Sept 2013-Aug 2014) and Graduate Student (Aug 2014-Oct 2015), Dept. of Biochemistry and Molecular Genetics, Cardiovascular Innovation Institute, University of Louisville, Mentor: Dr. Amanda LeBlanc, Project: Etiology and Treatment of Age-Related Coronary Microvascular Dysfunction 
Fall 2011 - Research Assistant, Dept. of Biochemistry and Molecular Genetics, University of Louisville, PI: Dr. Yong Li, Project: MicroRNA Expression in Cancer

Summer 2011 - Summer Fellow, Cancer Biology Graduate Program, Wayne State University, Mentor: Dr. Malathy Shekhar, Project: Evaluation of Small Molecule Inhibitors of Rad6B in Breast Cancer

Fall 2010-Spring 2011 - Research Assistant, Dept. of Biochemistry and Molecular Genetics, University of Louisville, PI: Dr. Chuan Hu, Project: Integrin Recycling and Cell Migration

\section{PUBLICATIONS}

Nevitt, C., McKenzie, G., Christian, K., Austin, J., Hencke, S., Hoying, J., and LeBlanc, A. (2016) Physiological levels of thrombospondin-1 decrease NO-dependent vasodilation in coronary microvessels from aged rats. American journal of physiology Heart and circulatory physiology 310, H1842-1850 PMID: 27199114

LeBlanc, A. J., and Nevitt, C. D. (2015) Targeting the Vessel Underdogs: Therapeutic Approaches for Microvessel Dysfunction in the Heart. Crit Rev Biomed Eng 43, 473-489 PMID: 27480587

Hunter, R. K., 2nd, Nevitt, C. D., Gaskins, J. T., Keller, B. B., Bohler, H. C., Jr., and LeBlanc, A. J. (2015) AdiposeDerived Stromal Vascular Fraction Cell Effects on a Rodent Model of Thin Endometrium. PloS one 10, e0144823 PMCID: PMC4684382 Aird, A. L.*, Nevitt, C. D.*, Christian, K., Williams, S. K., Hoying, J. B., and LeBlanc, A. J. (2015) Adipose-derived stromal vascular fraction cells isolated from old animals exhibit reduced capacity to support the formation of microvascular networks. Exp Gerontol 63, 18-26 PMCID: PMC4346434 *authors contributed equally

Riggs K. A.; Hasan N.; Humphrey D.; Raleigh C.; Nevitt C.; Corbin D.; Hu C. Regulation of integrin endocytic recycling and chemotactic cell migration by syntaxin 6 and VAMP3 interaction. J. Cell Sci. 2012, 125 (Pt 16), 3827-39. PMCID: 
PMC3462080

\section{PRESENTATIONS}

December 2017 - N-terminal protein modifications regulate the activity of Myosin Regulatory Light Chain 9 in colorectal carcinoma cells. Poster Presentation, ASCB/EMBO Annual Meeting

November 2017 - Take It From the Top: Na-PTMs Differentially Modulate the Activity of a Myosin Light Chain. Research Conference, Department of Biochemistry and Molecular Genetics, University of Louisville

July 2016 - Regulation of Gene Expression through N6-Adenosine Methylation of mRNA. Seminar, Department of Biochemistry and Molecular Genetics, University of Louisville

October 2015 - Engineered Chromatin Looping for the Therapeutic Control of Gene Expression. Seminar, Department of Biochemistry and Molecular Genetics, University of Louisville

March 2015 - Advanced Age Impairs the Neovascular Potential of Adipose-Derived Stromal Vascular Fraction Cells. Poster Presentation, $3^{\text {rd }}$ Annual KY-APS Meeting Fall 2015 - Physiological Levels of Thrombospondin-1 Decrease NO-Dependent Vasodilation in Coronary Microvessels from Aged Rats. Poster Presentation, Sixth Biochemistry \& Molecular Genetics Colloquium, Research! Louisville 2015 August 2011 - Evaluation of Small Molecule Inhibitors of Rad6B in Breast Cancer. Poster Presentation, Wayne State University and Karmanos Cancer Institute Undergraduate Summer Fellowship

\section{AWARDS}

September 2017 - American Society for Cell Biology Travel Award to attend the 2017 ASCB/EMBO Annual Meeting

May 2017 - National Institute of Child Health and Human Development Tuition Award to attend the 2017 Proteomics Course at Cold Spring Harbor Laboratories 
August 2015 - Michael Gordon Travel Award for First Place Poster, Sixth Biochemistry \& Molecular Genetics Colloquium, University of Louisville

March 2015 - Top Graduate Student Poster Award, $3^{\text {rd }}$ annual Meeting of the Kentucky Chapter of the American Physiological Society

\section{TEACHING AND MENTORSHIP}

Fall 2016 - Tooley Lab, Student Mentorship: Michael Miller, SUNY Buffalo Undergraduate

Spring 2016 - University of Louisville, Teaching Assistant: Biochemistry II (BIOC647)

Summer 2015 - LeBlanc Lab, Student Mentorship: Katelyn Christian, Georgetown College Undergraduate, Sarah Hencke, Georgetown College Undergraduate, Jeff Austin, University of Louisville Medical Student

Summer 2014 - LeBlanc Lab, Student Mentorship: Grant McKenzie, University of Louisville Undergraduate, Katelyn Christian, Georgetown College Undergraduate

\section{PROFESSIONAL MEMBERSHIPS AND INVOLVEMENT}

2017 - Member of The American Society for Cell Biology

Spring 2015 - Summer 2016 - University of Louisville, Science Policy and Outreach Group 